THERMAL VACUUM CHAMBER REFURBISHMENT AND ANALYSIS

\author{
A Thesis \\ presented to \\ the Faculty of California Polytechnic State University, \\ San Luis Obispo
}

\author{
In Partial Fulfillment \\ of the Requirements for the Degree \\ Master of Science in Aerospace Engineering
}

by

Adrian Williams

June 2018 
(C) 2018

Adrian Williams

ALL RIGHTS RESERVED 


\section{COMMITTEE MEMBERSHIP}

TITLE:

Thermal Vacuum Chamber Refurbishment and Analysis

AUTHOR:

Adrian Williams

DATE SUBMITTED: June 2018

COMMITTEE CHAIR: Kira Abercromby, Ph.D.

Associate Professor of Aerospace Engineering

COMMITTEE MEMBER: Amelia Greig, Ph.D.

Assistant Professor of Aerospace Engineering

COMMITTEE MEMBER: Jordi Puig-Suari, Ph.D.

Professor of Aerospace Engineering

COMMITTEE MEMBER: Roland Coelho

VP Launch Services, Tyvak NanoSatellite Systems 


\title{
ABSTRACT \\ Thermal Vacuum Chamber Refurbishment and Analysis
}

\author{
Adrian Williams
}

Spacecraft are subject to different environments while on orbit around the Earth and beyond. One of the most critical of these environments that must be counteracted is the thermal environment. Each spacecraft has an operating temperature that is specified in the mission requirements. The requirement stems from internal component operating temperatures that are critical to mission success. Prior to placing the spacecraft in orbit, engineers must be sure that the spacecraft will survive or risk losing the mission entirely.

The primary way to mitigate this risk is to use a thermal vacuum chamber (TVAC). The chamber is designed to resemble a space environment by reducing the pressure within the chamber to 1e-6 Torr. The differentiating factor between a vacuum chamber and a thermal vacuum chamber is the ability for the TVAC to complete a process known as thermal cycling using a temperature controller. Thermal cycling begins at a set temperature and increases within the chamber to a designated hot temperature expected to be seen on orbit. After the maximum temperature is reached, it remains there for a specified amount of time in what is called a soak. The controller then reduces the temperature to a specified cold temperature where a second soak takes place. Finally, the temperature is returned to the initial temperature and the process is repeated for a number of cycles until testing is complete.

For the purpose of this thesis, only the initial temperature increase and the first soak are being investigated. The chamber being used to run these experiments was graciously donated by MDA US Systems, however, no additional documentation was provided with the chamber. The Two identical black coated aluminum and brass cylinders have been chosen to be run with three different temperature profiles. The 
profiles are manually designed in the temperature controller on the chamber and vary by final soak temperature. To supplement the testing, simulations have been created for each test case in order to verify the computer model of the chamber. The simulations utilize AutoCad and Thermal Desktop to provide the results for comparison.

Each of the tests were completed successfully and produced good results that corresponded well to the simulation. The largest difference between the simulation cylinder temperature and the experimental cylinder temperature was $1.9{ }^{\circ} \mathrm{C}$. The effectiveness and efficiency of the blue chamber was compared to the other thermal vacuum chamber in the Space Environments lab. Overall, the Blue Chamber proved to be more robust and much easier to operate than the HVEC thermal vacuum chamber. 


\section{ACKNOWLEDGMENTS}

I would like to start off by thanking my parents, Barb and Rick. Without their unconditional support, I would not have been able to accomplish many of my goals including the completion of this thesis. Thank you both for everything, I consider myself very lucky to have you both in my life. I would also like to thank my sister, Rachel, who has been an excellent role model for me even as we have moved on to new chapters of our lives.

To Dr. Kira Abercromby, I cannot thank you enough for all the help you have given me over the course of this thesis and my undergraduate career. You have always provided me with helpful and knowledgeable advice for both school and life.

Thank you to Cody Thompson for helping me get the chamber plugged in and running smoothly. You always made sure I had everything I needed for my project, and I am very appreciative of that.

Finally, thank you to my committee members who answered any questions I had and helped me along the way. 


\section{TABLE OF CONTENTS}

Page

LIST OF TABLES . . . . . . . . . . . . . . . . . . .

LIST OF FIGURES . . . . . . . . . . . . . . . . . . xi CHAPTER

1 Introduction . . . . . . . . . . . . . . . . . . 1

1.1 Thesis Statement . . . . . . . . . . . . . . . . 1

1.2 Space Environment . . . . . . . . . . . . . . . . . 1

1.3 Thermal Vacuum Chambers . . . . . . . . . . . . . . 3

1.4 NASA General Environmental Verification Standard . . . . . . . . . 3

1.5 Motivation .......................... 4

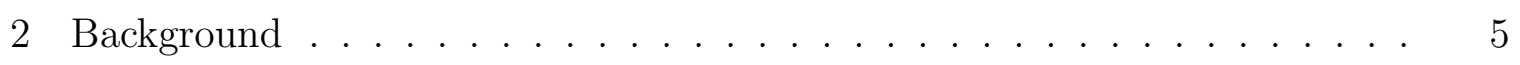

2.1 Vacuum Heat Transfer . . . . . . . . . . . . . . . . 5

2.2 Previous TVAC Work at Cal Poly . . . . . . . . . . . . . 8

2.3 Thermal Desktop . . . . . . . . . . . . . . . . . . . 10

3 Experimental Apparatus . . . . . . . . . . . . . . . . . . . . 12

3.1 Overview . . . . . . . . . . . . . . . . . . 12

3.2 Thermal Vacuum Chamber . . . . . . . . . . . . . . . . . . . 12

3.2.1 Mechanical Pump . . . . . . . . . . . . . 13

3.2.2 Turbo Pump ...................... 14

3.2.3 Platen ........................... 16

3.2.4 Shroud ............................ 18

3.2.5 Control Panel . . . . . . . . . . . . . . . . . . . . 19

3.2.6 Heating System . . . . . . . . . . . . . . . 20

3.2.7 Cooling System . . . . . . . . . . . . . . . 20

3.3 Convectron and Ion Gauge Controller . . . . . . . . . . . . . . . . . . 22

3.3.1 Convectron Gauges . . . . . . . . . . . . . . . 23

3.3 .2 Ion Gauge . . . . . . . . . . . . . . . . . . . 24

3.4 Thermocouple Controller . . . . . . . . . . . . . . 25

3.5 Blue Chamber Refurbishment . . . . . . . . . . . . . . . 28 
4 Testing. . . . . . . . . . . . . . . . . . . . . . 31

4.1 Experimental Testing . . . . . . . . . . . . . . . . . . 31

4.1 .1 Test $\operatorname{Setup~\ldots ...~.~.~.~.~.~.~.~.~.~.~.~.~.~.~.~} 32$

4.2 Validation of Testing . . . . . . . . . . . . . . 35

5 Results . . . . . . . . . . . . . . . . . . . . . 40

$5.140{ }^{\circ} \mathrm{C}$ Aluminum Test $\ldots \ldots \ldots \ldots \ldots \ldots$

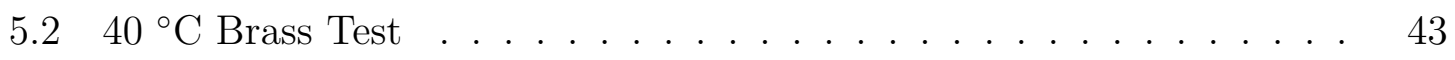

$5.360{ }^{\circ} \mathrm{C}$ Aluminum Test $\ldots \ldots \ldots \ldots \ldots \ldots . \ldots \ldots$

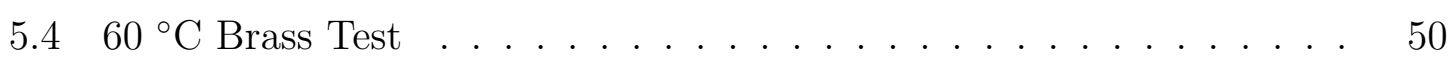

$5.580^{\circ} \mathrm{C}$ Aluminum Test $\ldots \ldots \ldots \ldots \ldots \ldots \ldots$

$5.680^{\circ} \mathrm{C}$ Brass Test $\ldots \ldots \ldots \ldots \ldots \ldots \ldots \ldots$

5.7 Chamber Pressure-Temperature Correlation . . . . . . . . . 59

5.8 Plexigals Thermal Isolation _ . . . . . . . . . . . . . . . 59

5.9 Platen-Chamber Temperature Relationship . . . . . . . . . . . 60

6 Conclusion . . . . . . . . . . . . . . . . . . . . . . . . 61

7 Future Work . . . . . . . . . . . . . . . . . . . . 63

7.1 Cooling System . . . . . . . . . . . . . . . . 63

7.2 Switch Controlled Venting System . . . . . . . . . . . . . 64

7.3 DAQ System . . . . . . . . . . . . . . . . . . . . 64

7.4 Refine Thermal Desktop Model . . . . . . . . . . . . . . . 65

7.5 Platen Temperature Gradient . . . . . . . . . . . . . . 65

7.6 Turbo Pump . . . . . . . . . . . . . . . . . 66

7.7 Thermocouples . . . . . . . . . . . . . . 66

7.8 Chamber Shroud . . . . . . . . . . . . . . . . . 67

7.9 Test Setup . . . . . . . . . . . . . . . . . . . . . . 67

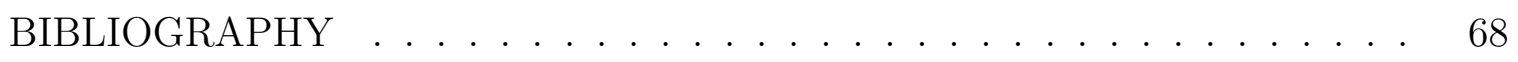
APPENDICES

A Chamber Operating Procedure . . . . . . . . . . 70

B Chamber Profiles . . . . . . . . . . . . . . . . 72

C Chamber Pressures During Testing . . . . . . . . . . 76

C.1 Aluminum $40{ }^{\circ} \mathrm{C}$ Test . . . . . . . . . . . . . . . 76

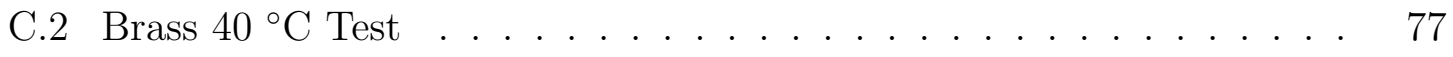


C.3 Aluminum $60{ }^{\circ} \mathrm{C}$ Test . . . . . . . . . . . . . . . . . . 77

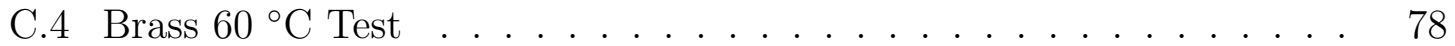

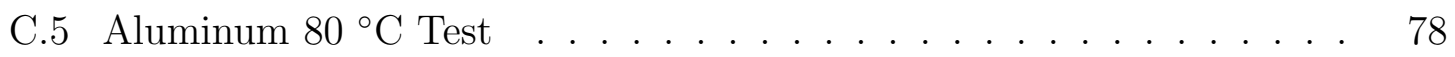

C.6 Brass $80{ }^{\circ} \mathrm{C}$ Test . . . . . . . . . . . . . . . . . . . 79

C.7 Chamber Pump Down . . . . . . . . . . . . . . . . . . . 79

D Chamber Troubleshooting . . . . . . . . . . . . . 81

E Chamber Shroud Temperature Profiles ... . . . . . . . . . 82

F Experimental Data . . . . . . . . . . . . . . . 86 


\section{LIST OF TABLES}

Table

Page

4.1 Simulation Material Properties . . . . . . . . . . . . 37

$5.140{ }^{\circ} \mathrm{C}$ Aluminum Cylinder Test . . . . . . . . . . . . . 43

$5.240^{\circ} \mathrm{C}$ Brass Cylinder Test . . . . . . . . . . . . . . . . 47

$5.360{ }^{\circ} \mathrm{C}$ Aluminum Cylinder Test . . . . . . . . . . . . . 50

$5.460{ }^{\circ} \mathrm{C}$ Brass Cylinder Test . . . . . . . . . . . . . . . 53

$5.580^{\circ} \mathrm{C}$ Aluminum Cylinder Test . . . . . . . . . . . 56

$5.6 \quad 80{ }^{\circ} \mathrm{C}$ Brass Cylinder Test . . . . . . . . . . . . . . . . 59

C.1 Chamber Pump Down Pressure vs. Time . . . . . . . . . . . . 80 


\section{LIST OF FIGURES}

Figure

Page

2.1 Thermal Radiation Wavelength[3] . . . . . . . . . . . 6

2.2 HVEC Thermal Vacuum Chamber . . . . . . . . . . . 8

$3.1 \quad$ Chamber Schematic . . . . . . . . . . . . . . . 13

$3.2 \quad$ Mechanical Pump . . . . . . . . . . . . . . . . 14

3.3 Turbo Pump . . . . . . . . . . . . . . . . . 15

3.4 Turbo Pump Controller $[14] \ldots \ldots \ldots$. . . . . . . . 16

3.5 Platen Dimensions . . . . . . . . . . . . . . . . . . . . 17

$3.6 \quad$ Underside of Platen . . . . . . . . . . . . . . . . 17

3.7 Chamber Shroud (arching copper sheet) and Platen (flat aluminum

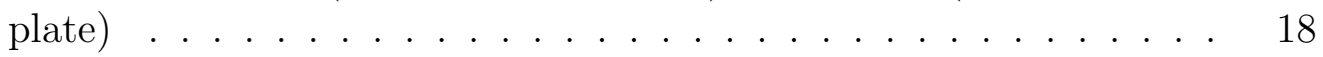

3.8 F4S/D Ramping Controller . . . . . . . . . . . . . . . 19

3.9 $\mathrm{LN}_{2}$ Chamber Plumbing . . . . . . . . . . . . . . . . . 21

3.10 Door Shroud Plumbing . . . . . . . . . . . . . . 22

3.11 Convectron and Ion Gauge Controller . . . . . . . . . . . . . 23

3.12 Convectron Gauges . . . . . . . . . . . . . . . . . . . . 24

3.13 Active Ion Gauge . . . . . . . . . . . . . . . . . . . 25

3.14 Omega HH501BJK Type K Thermocouple Reader . . . . . . . . . . 26

3.15 External Thermocouple Ports . . . . . . . . . . . . . 27

3.16 Double-Sided Male Thermocouple . . . . . . . . . . . . 27

3.17 Internal Thermocouple Ports . . . . . . . . . . . . . . . . 28

$4.1 \quad$ Experimental Test Setup . . . . . . . . . . . . . . . . . . 33

4.2 Baseplate Switches . . . . . . . . . . . . . . . . 35

4.3 Thermal Desktop Simulation Model . . . . . . . . . . . 36

4.4 Emissivity Comparison: Aluminum $60{ }^{\circ} \mathrm{C}$ Test . . . . . . . . . 38

4.5 Emissivity Comparison: Brass $60{ }^{\circ} \mathrm{C}$ Test . . . . . . . . . . 38

5.1 Aluminum $40{ }^{\circ} \mathrm{C}$ Experimental Test . . . . . . . . . . . . . 41

5.2 Aluminum $40{ }^{\circ} \mathrm{C}$ Test vs Simulation: Cylinder Temperature . . . . 42 
5.3 Aluminum $40{ }^{\circ} \mathrm{C}$ Simulation Heat Map . . . . . . . . . . . . . 43

5.4 Brass $40{ }^{\circ} \mathrm{C}$ Experimental Test . . . . . . . . . . . . 45

5.5 Brass $40{ }^{\circ} \mathrm{C}$ Test vs Simulation: Cylinder Temperature . . . . . 46

5.6 Brass $40{ }^{\circ} \mathrm{C}$ Simulation Heat Map . . . . . . . . . . . . . 46

5.7 Aluminum $60{ }^{\circ} \mathrm{C}$ Experimental Test . . . . . . . . . . . 48

5.8 Aluminum $60{ }^{\circ} \mathrm{C}$ Test vs Simulation: Cylinder Temperature . . . . 49

5.9 Aluminum $60{ }^{\circ} \mathrm{C}$ Simulation Heat Map . . . . . . . . . . . . . 49

5.10 Brass $60^{\circ} \mathrm{C}$ Experimental Test . . . . . . . . . . . . 51

5.11 Brass $60{ }^{\circ} \mathrm{C}$ Test vs Simulation: Cylinder Temperature . . . . . . 52

5.12 Brass $60^{\circ} \mathrm{C}$ Simulation Heat Map . . . . . . . . . . . . . . 52

5.13 Aluminum $80^{\circ} \mathrm{C}$ Experimental Test . . . . . . . . . . . . 54

5.14 Aluminum $80^{\circ} \mathrm{C}$ Test vs Simulation: Cylinder Temperature . . . 55

5.15 Aluminum $80{ }^{\circ} \mathrm{C}$ Simulation Heat Map . . . . . . . . . . . . 55

5.16 Brass $80^{\circ} \mathrm{C}$ Experimental Test . . . . . . . . . . . . 57

5.17 Brass $80^{\circ} \mathrm{C}$ Test vs Simulation: Cylinder Temperature . . . . . . 58

5.18 Brass $80^{\circ} \mathrm{C}$ Simulation Heat Map . . . . . . . . . . . . . . 58

5.19 Chamber and Platen Temperature Relationship . . . . . . . . . 60

C.1 Aluminum $40{ }^{\circ} \mathrm{C}$ Chamber Pressure . . . . . . . . . . . 76

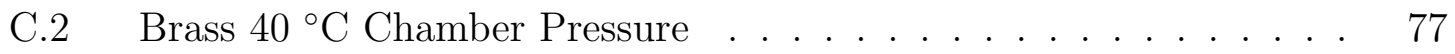

C.3 Aluminum $60{ }^{\circ} \mathrm{C}$ Chamber Pressure . . . . . . . . . . . . 77

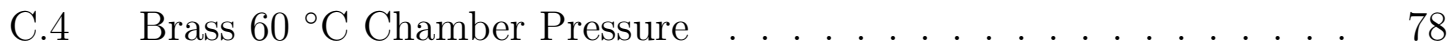

C.5 Aluminum $80{ }^{\circ} \mathrm{C}$ Chamber Pressure . . . . . . . . . . . . 78

C.6 Brass $80{ }^{\circ} \mathrm{C}$ Chamber Pressure . . . . . . . . . . . . . 79

E.1 Aluminum $40^{\circ}$ Simulation Shroud Temperature . . . . . . . . 82

E.2 Brass $40^{\circ}$ Simulation Shroud Temperature . . . . . . . . . . 83

E.3 Aluminum $60^{\circ}$ Simulation Shroud Temperature . . . . . . . . . 83

E.4 Brass $60^{\circ}$ Simulation Shroud Temperature . . . . . . . . . . . 84

E.5 Aluminum $80^{\circ}$ Simulation Shroud Temperature . . . . . . . . . . 84

E.6 Brass $80^{\circ}$ Simulation Shroud Temperature . . . . . . . . . . . 85 
Chapter 1

INTRODUCTION

\subsection{Thesis Statement}

The thermal environment of space can be very damaging to spacecraft and the payloads those spacecraft carry. Therefore, thermal engineers must be able to determine whether the spacecraft will be able to operate properly under the known temperature constraints. In order to ensure that the satellite will perform in extreme temperature conditions, each of the satellite subsystems, and the satellite as a whole, is cycled through expected temperatures in thermal vacuum chamber testing.

This thesis will be used to demonstrate some of the capabilities of the new thermal vacuum chamber donated by MDA US Systems to the Space Environments Laboratory located on the California Polytechnic State University campus. It is intended to show that the "blue chamber" can be run more effectively with fewer complexities than the High Vacuum Equipment Corporation (HVEC) vacuum chamber already present in the lab and used for thermal vacuum testing. Additionally, a thermal model will be created to simulate the testing outcomes and compare the accuracy of the chamber readouts.

\subsection{Space Environment}

The environment in which spacecraft operate is drastically different from the environment on Earth. First and foremost, there is little to no atmosphere, meaning the spacecraft must operate where no air exists. For reference, the pressure at sea level on Earth is 760 Torr, whereas in Low Earth Orbit (LEO), the pressure is on 
the order of $10^{-6}$ Torr.[9] Second, the temperature that spacecraft must survive in is not constant. As the satellite orbits the Earth, it will pass in and out of Earth's shadow, or eclipse, many times. The difference in temperature when in and out of eclipse can be dramatic and must be properly prepared for. On Earth, heat can be transferred through the atmosphere with convection. The lack of atmosphere on orbit means there is no convection and the primary mode of heat transfer shifts to radiation and conduction. Radiative heat transfer is a process by which electromagnetic (EM) waves are emitted from one source and absorbed by another. The EM waves cause the absorber to heat up or the emitter to cool down, depending on the temperature differential between the two objects.

A few radiation sources include: direct solar radiation from the sun, planetary albedo radiation (reflected off a planet), radiation from celestial bodies, and deep space temperatures (approximately 4 Kelvin).[16] Depending on where the spacecraft is flying, there is generally a dominant source of radiation heating. For example, in LEO, the direct solar and Earth albedo radiation will be much more prevalent than radiation from other celestial bodies. But for spacecraft such as Voyager, which has left our solar system, the deep space temperature will have the largest effect and direct solar radiation will have very little, if any, effect at all.

Conduction heat transfer for spacecraft occurs within materials and through contact points. This heat is either collected from radiation or created by on board heat sources such as electronics boxes, operational payloads, and heaters. In order to remove excess heat, spacecraft are designed to radiate that heat out to space or store it to be used later when the spacecraft may need to heat up once again. 


\subsection{Thermal Vacuum Chambers}

Thermal vacuum chambers (TVAC) are used to demonstrate the capability for components and satellites to survive in space. The air within the chamber is pumped out creating a low-pressure environment. Then, the environment is then cycled through high and low temperature regimes to simulate the satellite passing in and out of Earth's shadow. The temperature that the chamber runs its tests depends entirely on the orbit at which the satellite will fly. This testing is critical to each mission because it mitigates risk prior to launch. Every TVAC is fairly unique in its setup and capabilities and customized based on the desired outcomes of the testing. They all have some kind of mechanical pump to pull an initial vacuum, but once that is complete, chambers can have many different functions. Most chambers have feed-through ports on the side of the chamber that allows for electrical wiring, fluid lines, etc. to have access to the testing area. Depending on the design of the chamber, the number of ports can range from zero to more than fifteen for smaller lab size chambers. In addition to varying numbers of feed-through ports, chambers can also possess more pumps that allow the pressure to drop to lower levels. For example, the

chamber used for this thesis has a turbo pump that can lower the pressure from $10^{-3}$ Torr to $10^{-6}$ Torr. TVACs fill an important role in the design and verification process for all spacecraft, regardless of size or mission, and understanding their purpose is essential to using them efficiently.

\subsection{NASA General Environmental Verification Standard}

Satellites are tested according to the NASA General Environmental Verification Standard (GEVS) based on the temperatures they will encounter in space.[7] This document outlines many different environmental testing constraints and provides am- 
ple descriptions of why those constraints are necessary. There are different types of testing that the satellite must go through in order to be approved for launch. The first is qualification testing, which is the most rigorous test, as it requires the temperature to vary $\pm 10{ }^{\circ} \mathrm{C}$ above or below expected maximum and minimum flight temperatures. This test is only completed on non-flight hardware in an effort to preserve the integrity of the satellite so it is not over tested. Next in rigor is flight acceptance testing, which is less strenuous and is completed on components that will be part of the finished product. This testing procedure requires that the temperature vary \pm 5 ${ }^{\circ} \mathrm{C}$ above or below expected flight temperatures. The testing duration depends on how low of a pressure can be attained. The standard states that below $1 \times 10^{-5}$ Torr, a dwell time of 4 hours is required for component testing. If the testing is completed at ambient pressures, the dwell time must be increased to 6 hours. Therefore, any testing completed between $1 \times 10^{-5}$ Torr and ambient pressure will require a dwell time between 4 and 6 hours.

\subsection{Motivation}

Completing the refurbishment of the blue thermal vacuum chamber will provide ample opportunities for graduate research projects as well as undergraduate education. The current TVAC that exists in the Space Environments laboratory is not ideal for properly teaching students about vacuum chamber functions because there are many nuances and complexities involved. The blue chamber is simple to understand and operate and has easy access for maintenance. The thermal modeling

completed in Thermal Desktop can also provide a deeper understanding of how the chamber operates and what to expect when running a new test. 
Chapter 2

\section{BACKGROUND}

\subsection{Vacuum Heat Transfer}

Thermal heat transfer occurs in one of three methods: convection, conduction, and radiation. Due to the lack of air pressure, convection does not affect the temperature of the spacecraft in any way because there is no fluid for the heat to move through. Therefore, radiation and conduction are the only methods of heat transfer spacecraft design must take into consideration.

The amount of radiation a spacecraft will face varies based on the occupied orbit and location within that orbit. Radiation is a result of electromagnetic (EM) waves being absorbed by or emitted from different surfaces.[2] Every material used to design a spacecraft has an associated absorptivity and emissivity value, both ranging from 0.0 to 1.0. Absorptivity refers to the percentage of total radiation energy that strikes the surface of the material that will be absorbed as heat. Therefore, higher absorptivity materials or coatings, such as black paint, will get much hotter than low absoptivity materials or coatings, such as white paint. Emissivity is the percentage of total energy that will be radiated out of a body. There are times when spacecraft will be too hot in their environment and they need to be cooled to maintain their optimal operating temperature; the emissivity of the materials on board will play a large role in the efficiency of that cooling process. The Stefan-Boltzmann Law is used to determine the radiative energy, Q, that is emitted from a surface using the emissivity of the material, $\epsilon$, the Stefan-Boltzmann constant, $\sigma$, the surface area of emittance, A, and the absolute temperature, $\mathrm{T}_{a b s}$ in Kelvin or Rankin depending on the other units.[15] Equation 2.1 shows the relationship between those variables. 


$$
Q=\epsilon \sigma A T_{a b s}^{4}
$$

Another important part of radiation heat transfer is that heat energy out is equivalent to the heat energy in. Therefore, incoming radiation energy, from the sun for example, can be calculated and adequately designed for. EM waves also travel in a straight path, so when surfaces are at an angle to one another, the percentage of the total energy can be calculated using a view factor.

The EM waves mentioned above can have different wavelengths depending on the type of radiation. Shorter wavelengths encompass gamma rays and $\mathrm{X}$ rays and longer wavelengths include radio waves. The radiation for each of these wavelengths is different because the frequency of the radiation depends on the wavelength. Thermal radiation, which is the focus for satellite thermal analysis, is encompassed in a wavelength range of approximately $0.3 \mu \mathrm{m}$ to $50 \mu \mathrm{m}$. This range contains infrared, visible light, and part of the ultraviolet regime as seen in Figure 2.1. The second law of thermodynamics demonstrates that a maximum radiant energy exists for a given temperature at a given wavelength.[3]

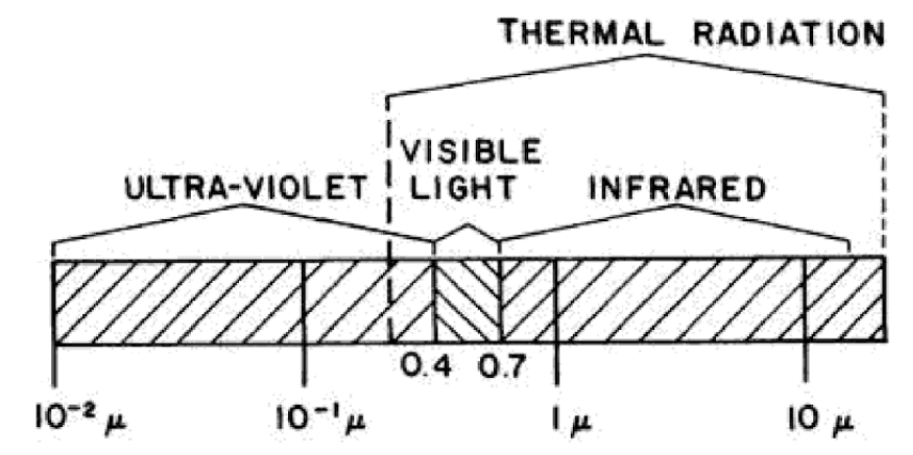

Figure 2.1: Thermal Radiation Wavelength[3]

At any given wavelength, according to Kirchoff's law, the spectral emittance and absorptance are equal. It is most common to refer to these two values in the solar 
band $(0.3 \mu \mathrm{m}$ to $3 \mu \mathrm{m})$ as absorptance, $\alpha$, and in the infrared band ( $3 \mu \mathrm{m}$ to $8 \mu \mathrm{m})$ as emittance, $\epsilon$. The first law of thermodynamics states that energy in must equal energy out during heat transfer. So, the maximum amount of energy a test article inside a vacuum chamber will receive is determined by Equation 2.1 where $\mathrm{T}_{a b s}$ is the temperature difference between the hot and cold (relatively) surfaces with each temperature raised to the fourth power.[16]

The final source of thermal heat transfer is conduction, which occurs at the physical interfaces of the spacecraft. It occurs as a result of on-board heat loads as well as heat that is collected from radiation. The process that occurs in space is the same as on Earth. When one surface gets hot, it will transfer heat to any colder surface it is in contact with. Conduction is a time varying energy transfer based on Fourier's Law.[16] The equation for a steady state, one dimensional heat transfer is shown in Equation 2.2 where $\mathrm{Q}_{x}$ is the energy per second that is transferred, $\mathrm{k}$ is the thermal conductivity of the material, $\mathrm{A}$ is the cross sectional area where the conduction is taking place, and $\frac{d T}{d x}$ is the temperature change in the $\mathrm{x}$ direction.

$$
Q_{x}=-k A \frac{d T}{d x}
$$

As mentioned in the previous paragraph, there are times when the spacecraft must radiate heat to space. To get heat to the proper side of the spacecraft to complete that cooling process, conduction through the body of the spacecraft is required. More detailed analysis can be done to look at conduction across multiple dimensions or even transient conduction that occurs over a set period of time. 


\subsection{Previous TVAC Work at Cal Poly}

Prior to this thesis, there were only two TVACs on Cal Poly's campus located in the Cal Poly CubeSat lab and in the Spacecraft Environments lab. The HVEC TVAC, mentioned in Section 1.1 and seen in Figure 2.2, was worked on by Lauren Glenn for her thesis project.[11] The blue chamber is being evaluated as a replacement for HVEC TVAC for undergraduate and graduate research because of multiple complexities that are associated with the HVEC chamber.

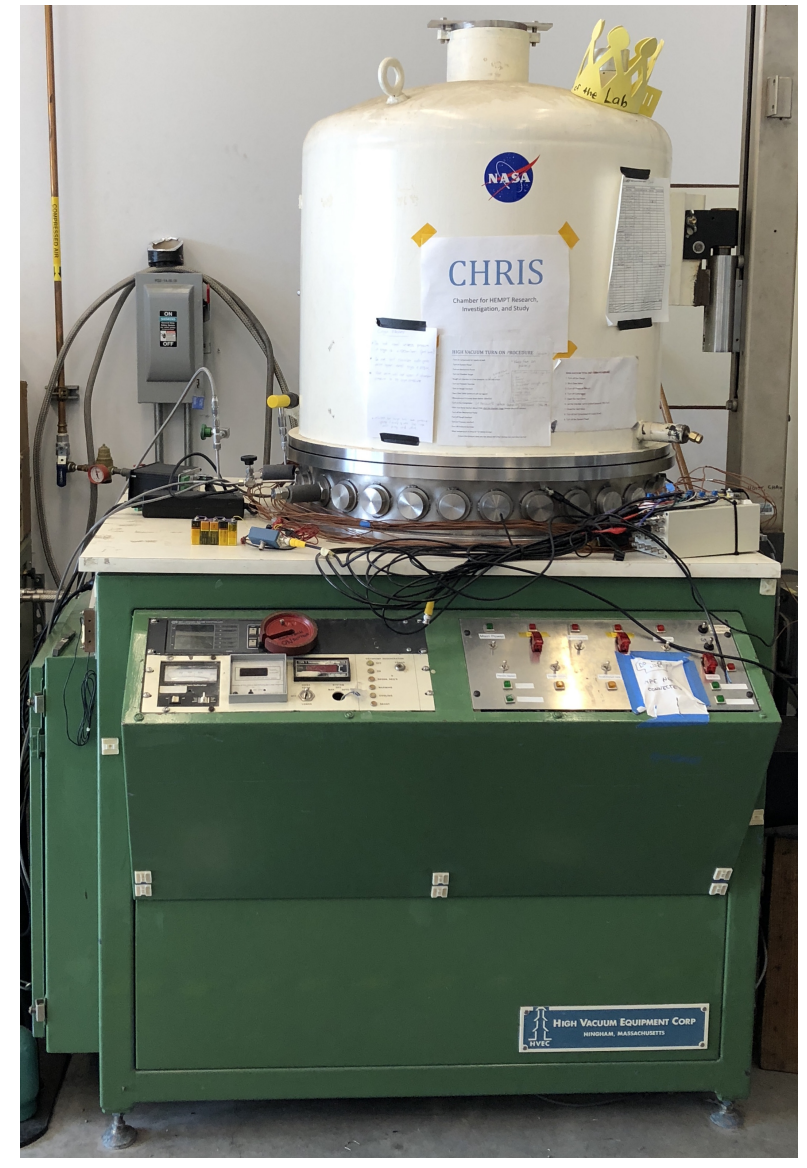

Figure 2.2: HVEC Thermal Vacuum Chamber

The procedures to run and maintain the HVEC chamber are fairly intensive. With more steps, switches, and valves involved in the procedures, the risk of operator error increases dramatically. In addition, the ATS chiller cooling system for the chamber 
is an external system to the chamber itself and has its own complex procedures for operation and maintenance. Should the chamber break while being used for an educational lab, it will not be simple to fix the problem and resume the lab quickly. With the blue chamber, the procedures for operating it are very simple and very easy to follow. Since most of the refurbishment work has been completed, no maintenance has been required over the past four months.

Another major issue with the HVEC and ATS chiller system are the problems they have had with leaks. The main source of leaking from the chamber takes place at the electrical feed-throughs. BNC cables were attached to mitigate a majority of those leaks, however, the problem seems to still occur at times. Leaking from the chamber is bad for testing because it does not allow the chamber to reach the lowest possible pressure, which is always desired. Even the smallest of leaks can prevent a chamber from dropping in pressure from $1 \times 10^{-4}$ Torr to $1 \times 10^{-6}$ Torr. The ATS chiller, on the other hand, has had a different leaking issue. The purpose of the chiller is to pump cold fluid through the chamber to reduce the internal temperature, thus simulating the colder regions of on orbit travel. The fluid that is pumped through the chiller is Galden HT-110, and it is very expensive to purchase. When the monetary cost is coupled with leaking issues, the problem becomes more serious. The fluid would leak out of the chiller rendering it unable to be reused and recycled. So far, the blue chamber has shown no signs of major leaks. The o-ring on the door of the chamber seems highly susceptible to leaking in its current state, however, a replacement is in the process of being obtained. Even with deteriorated door o-ring, the chamber can reach pressures as low as $10 \mu$ Torr. As for the cooling system, it is entirely internal to the chamber except for the liquid nitrogen tank. Without having tested the cooling system, it is not certain whether there are leaks in the plumbing, but the system shows no visible signs of deterioration.

Finally, there is an electrical wiring issue with the lid of the HVEC chamber. The 
lid is operated by a set of buttons, however, only one of the buttons works properly. A switch had to be put in place to change the direction the button will make the lid move. When bringing the lid down for testing, it is not perfectly aligned with the bottom of the chamber so it must be manually placed in the right spot. If it is not placed in the right spot, the chamber will leak and not be able to pull a vacuum properly. Since the blue chamber has been plugged in, there has only been one electrical issue, which is discussed in the refurbishment appendix. The fix was simple and there have been no issues since. The door of the blue chamber is opened and closed manually and uses a metal latch to ensure it is closed in the correct location every time.

Overall, the HVEC TVAC is much more complex procedurally and operationally than the blue chamber. Though it does accomplish its testing requirements, the blue chamber can complete similar requirements without the unnecessary complications.

\subsection{Thermal Desktop}

Thermal Desktop (TD) is a program created by C\&R Technologies that allows engineers get an idea of what thermal loads the satellite or component being tested is likely to see on orbit. This work is critical to mitigating risk for the mission because it allows the engineers to analyze the spacecraft design prior to and following testing. The program will be utilized in this thesis to validate testing results from the blue TVAC.

The main design program behind TD is AutoCad. AutoCad can be used to create parts, drawings, and models in both 2D and 3D. Thermal Desktop runs on top of the AutoCad software by taking a part from AutoCad and analyzing it based on given thermal constraints. There are two major subset modules that TD incorporates in its analysis. RadCAD, which calculates all of the radiation exchanges between surfaces 
and orbital heating, and FloCAD, which creates the flow networks and calculates convection rates. All of the data from RadCAD, FloCAD, and TD are passed into a solver also created by C\&R Technologies called SINDA/FLUINT. This solver is the industry standard for thermal and fluid analysis.[1]

SINDA is the only solver required for TVAC analysis and it uses finite difference methods to anaylyze the data it receives. This method is much faster than using finite element models and takes much less time to iterate to a solution. The program relies on thermal "nodes" that lie on the model to complete the calculations. The location, quantity, and type of node is defined by the user based on what information is desired. There are three different types of nodes that can be used in TD: diffusion nodes, arithmetic nodes, and boundary nodes. Each node has a different purpose and must be used appropriately. The diffusion node represents any normal material that changes temperature based on its surrounding environment or contacts. This is the most common node used in TD for this thesis. Arithmetic nodes represent zero thermal mass, meaning the node will respond instantaneously to any change in energy balance. Boundary nodes have infinite capacitance and will remain at a constant user defined temperature or time-varying temperature depending on the input.[1]

When all of the nodes are defined, the program relies on contactors to determine where the heat transfer will take place. This is done between the physical connections of the chamber model and the test article. All radiative heating is calculated automatically by RadCAD and SINDA. Heat loads can be identified in the model to represent heat sources, such as strip heaters or an operational payload.

TD also has the ability to program an orbit if the testing is meant to verify the thermal environment at a specific location. However, for this thesis, the orbit parameters were not investigated as no payload or component testing needed to be completed. 
Chapter 3

EXPERIMENTAL APPARATUS

\subsection{Overview}

All experiments conducted for the purpose of this thesis were completed inside the blue thermal vacuum chamber. The chamber was donated to Cal Poly by MDA US Systems. A plaque on the side of one of the chamber panels reads, "This chamber was used in the development of the Mars exploration rovers[sic] robotic arm. The two rovers, Spirit and Opportunity landed on Mars on Jan. 4 and 25, 2004 respectively." Documentation about the chamber's test history or operational procedures was not provided. Each of the parts described in this section are either internal to the chamber or were an external feature required for experimentation. External components required for the data collection included convectron gauges, an ion gauge, a Granville-Phillips 307 Vacuum Gauge Controller, and an Omega HH501BJK Type K thermocouple reader and thermocouple wires.

\subsection{Thermal Vacuum Chamber}

The blue thermal vacuum chamber has many different components. This section outlines each of those components and how they impact the experimental apparatus.

The chamber itself has been around for a while and some of its parts were outdated either technologically or just due to deterioration. Section 3.5 covers all of the refurbishment work completed on the chamber to date. If issues arise in the future, that section might be a helpful guide to solving the problem. A few of the fixes that were made were small and could easily be forgotten after a period of time. 
Figure 3.1, below, is the schematic for the chamber that lays out the connections for each part of the chamber.

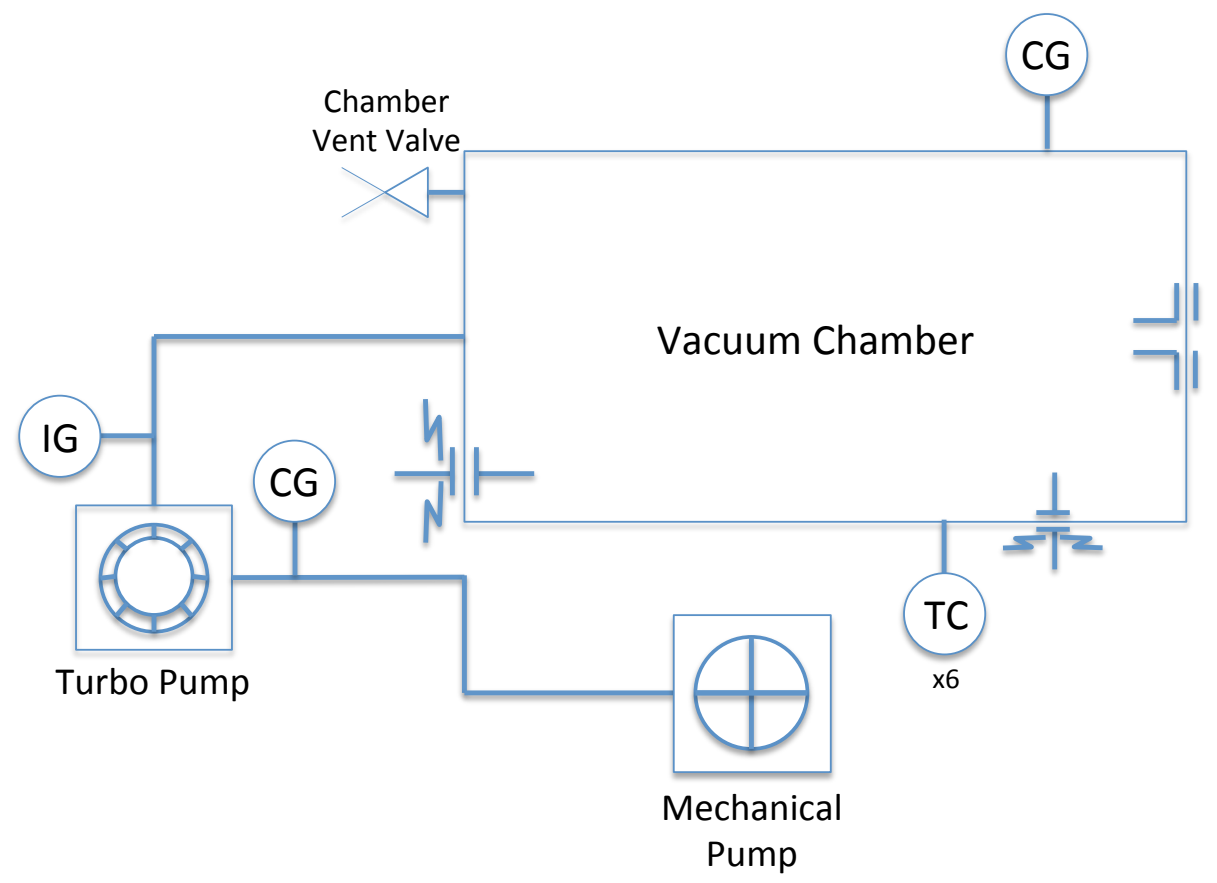

Figure 3.1: Chamber Schematic

\subsubsection{Mechanical Pump}

The mechanical pump for this chamber is a Galiso Inc. single phase induction motor. These motors are made up of a rotor, a capacitor, and two windings: a main winding and an auxiliary winding usually made of copper and placed perpendicularly to each other. When $\mathrm{AC}$ current passes through main winding of the motor, two oppositely rotating magnetic fields are created. A single magnetic field in one direction will cause the rotor to spin, however the two magnetic fields cancel out. To combat this, a capacitor is used to offset the current of the auxiliary winding and main winding by 90 degrees. This forces one of the magnetic fields created by the auxiliary winding to cancel out one of the magnetic fields for the main winding and the other auxiliary winding field to add to the other main winding field. This allows the rotor to begin 
turning and the motor to start.[12]

The motor, seen in the Figure 3.2, is the main feature for reducing pressure inside the chamber. It can run for hours, or even days, with no harm to it or the chamber, so there is no need to worry about leaving it on for an extended period of time. This feature is extremely useful for testing because it allows the chamber to pump down to a fairly low steady state pressure before activating the turbo pump, if that is desired. It was found that after pumping down for eight to ten hours, the chamber was often at a pressure of about 3-5 mTorr. It is not required to pump down for this long in order to run the chamber, though. The chamber will reach pressures around 40 mTorr after 30 minutes and 20 mTorr after two hours.

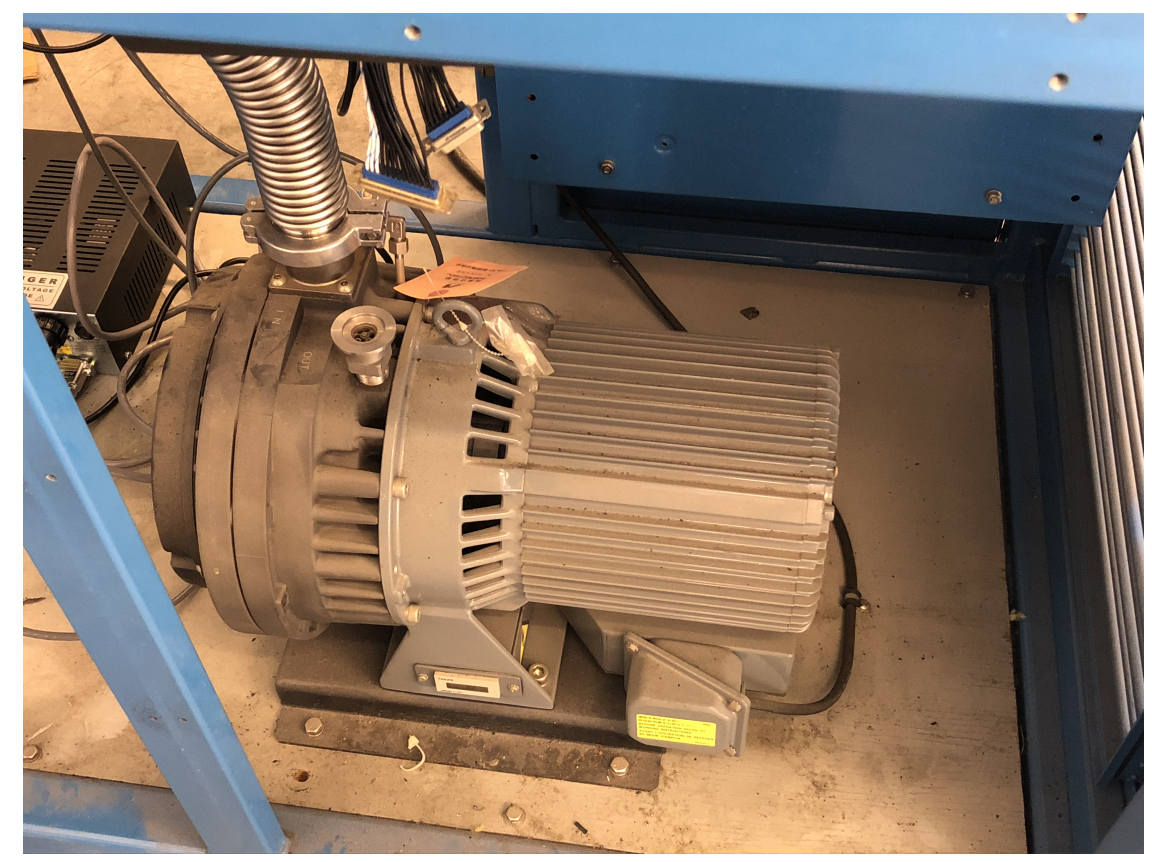

Figure 3.2: Mechanical Pump

\subsubsection{Turbo Pump}

The Leybold Turbovac 151 turbo pump, or turbomolecular pump, is activated only when the mechanical pump has brought the chamber pressure below 20 mTorr.[13] 
This pump is designed solely for low pressure use and can easily break if it is not operated properly. Turbos are comprised of multiple stacks of rotor blades and stator, or stationary, blades. The pump works similar to a compressor by capturing gas and successively compressing the gas as it moves through the pump until it reaches the pressure in the roughing line. When the pump is running at full speed for a couple hours, the chamber will reach pressures around $30 \mu$ Torr, but has been seen as low as $10 \mu$ Torr. After testing is complete and the turbo pump is turned off, the mechanical pump must run for 15-20 minutes to let the turbo pump completely stop. The turbo runs at extremely high RPMs and higher pressures will create heat friction and break the blades. An external view of the turbo pump is shown in Figure 3.3.

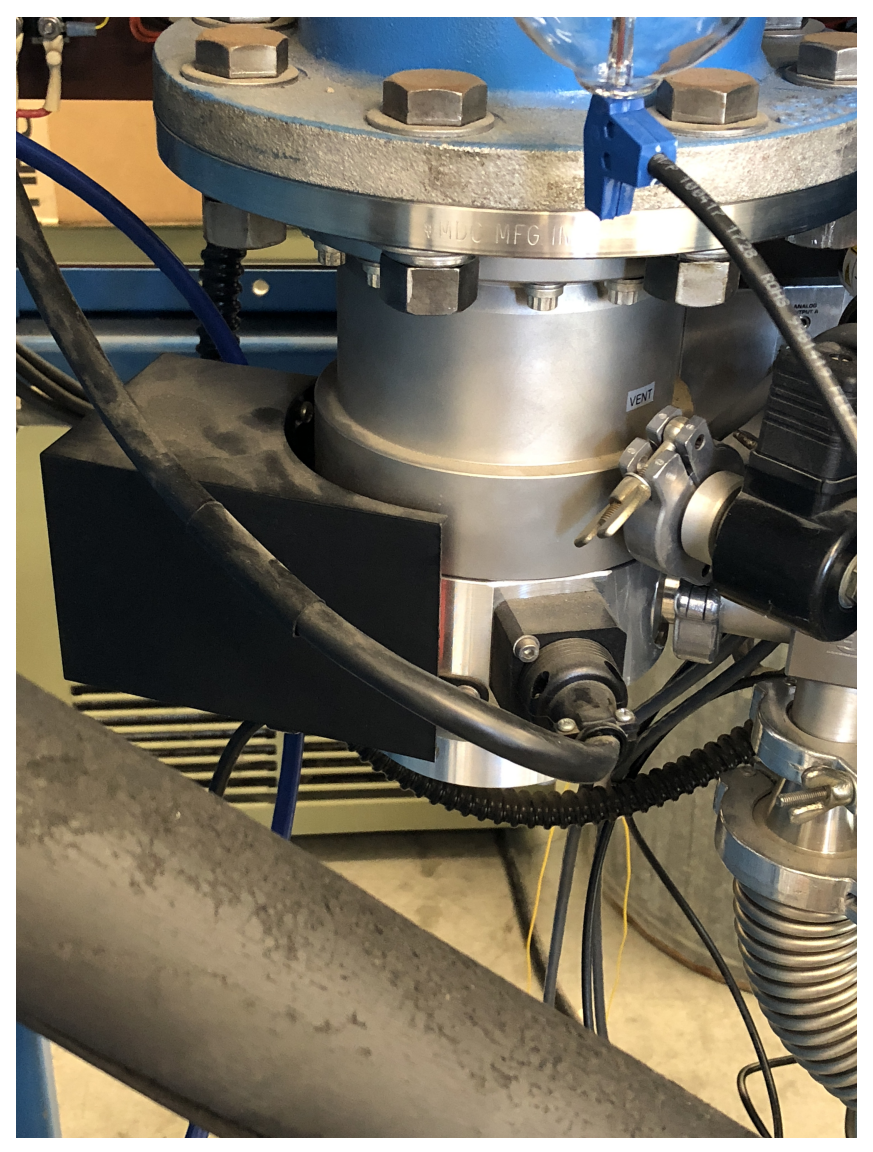

Figure 3.3: Turbo Pump

The turbo pump is controlled by a Turbotronik NT 20 controller, pictured in 
Figure 3.4 on the main control panel of the chamber. The controller is equipped with buttons to start, stop, and heat the turbo pump. All other displays on the controller are indicators for how the pump is performing. When the turbo pump is started, the load indicator lights will flash green starting from the bottom and represent increasing load as more lights turn on toward the top of the panel. It is normal for the pump to reach a very high loading when it is turned on. When the pump starts to pull a lower vacuum in the chamber, the load lights will progress back down toward the lowest load level. The heating button is for baking out the pump in an effort to obtain very low temperatures. Water cooling must be active during the heating process.[14]

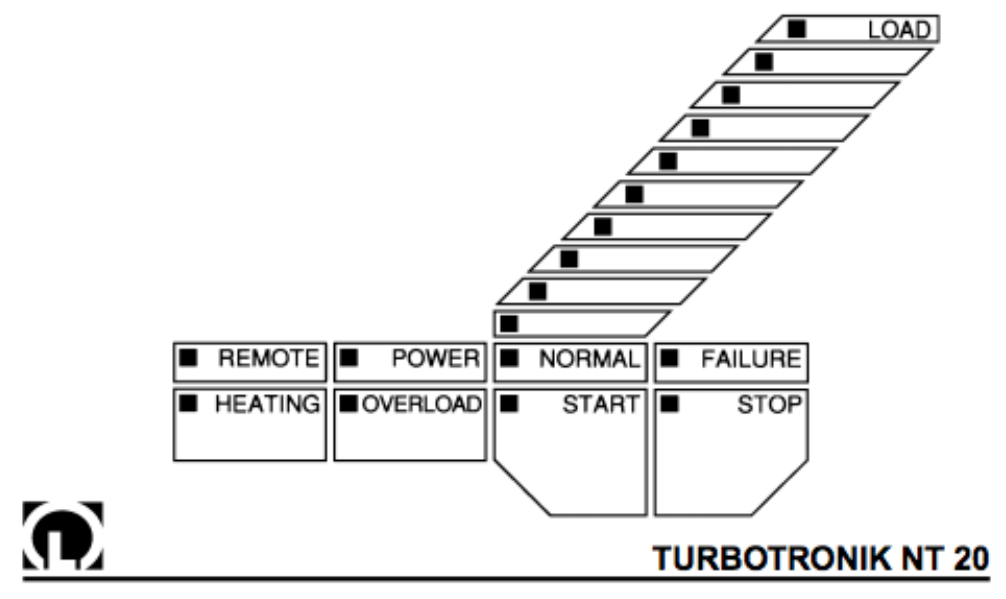

Figure 3.4: Turbo Pump Controller [14]

\subsubsection{Platen}

Crafted out of aluminum, this metal plate is used as the test section for all experiments. It is located in the center of the chamber and plays the largest role for the heating system via the heat strips underneath. There are also tubes running through the platen for the cooling system, however the exact routing of those tubes could not be determined without removing the plate itself.

The rectangular plate is approximately fourteen inches wide, one and a half inches 
thick, and extends two feet deep into the chamber. There are three cut outs in the bottom of the platen approximately every six inches towards the back of the chamber for the heat strips. More detailed dimensions of the platen in metric units can be seen in the Figures 3.5 and 3.6 below.

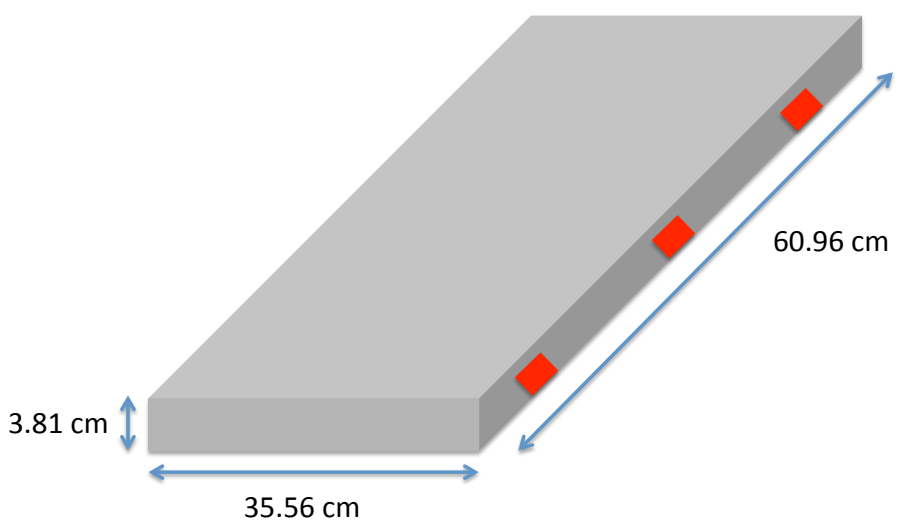

Figure 3.5: Platen Dimensions

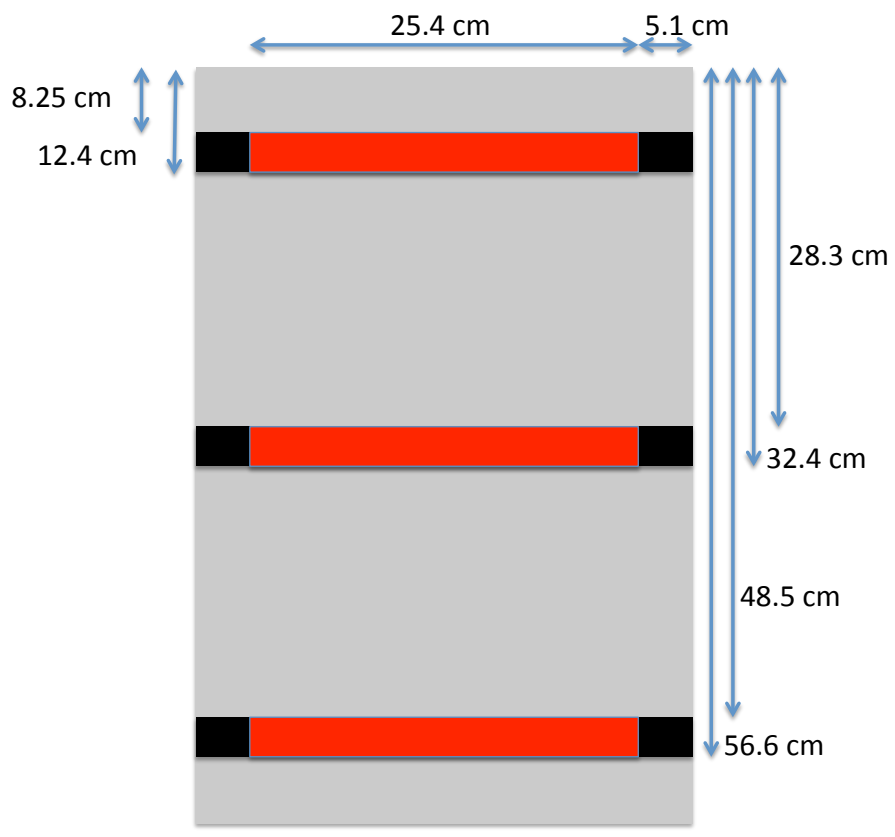

Figure 3.6: Underside of Platen 


\subsubsection{Shroud}

The shroud for this chamber is a half cylinder sheet made of copper that sits above the platen. The purpose of the shroud is to contain the thermal environment around the test article. In addition, tubing runs along the top of the shroud for the cooling system that is discussed later in this section. The shroud increases the efficiency of the chamber to heat and cool the test section, which ultimately reduces the overall testing time. These tests will last many hours, so any time that can be saved is useful.

The shroud is $18.42 \mathrm{~cm}$ tall providing a total test volume of approximately $121 \times 10^{3}$ $\mathrm{cm}^{3}\left(0.121 \mathrm{~m}^{3}\right)$ In Figure 3.7, the shroud is the copper sheet seen above the platen.

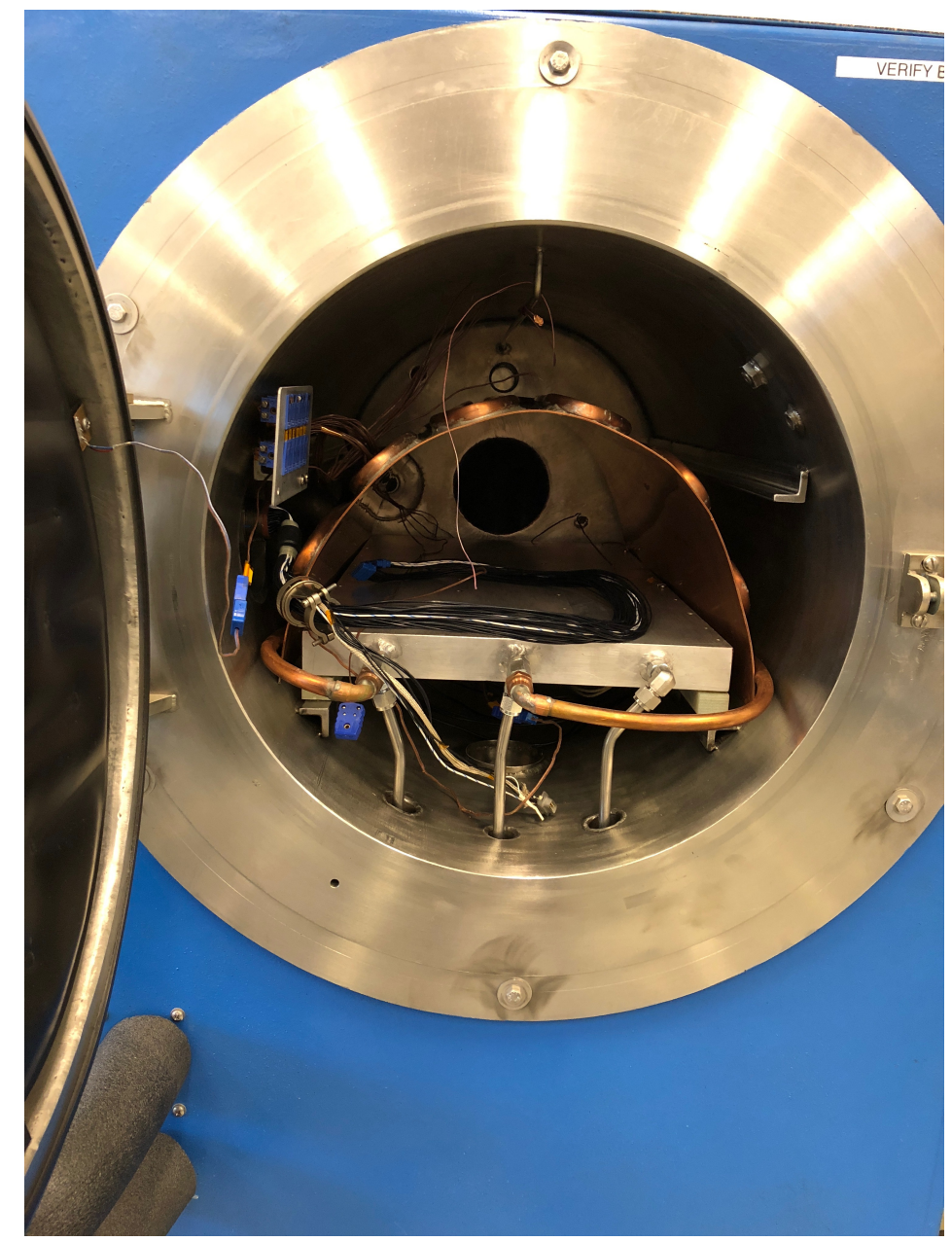

Figure 3.7: Chamber Shroud (arching copper sheet) and Platen (flat aluminum plate) 


\subsubsection{Control Panel}

The chamber controller is a series F4S/D Ramping Controller designed by Watlow Winona for temperature control in industrial applications.[17] Pictured in Figure 3.8, it provides ample capability for the experiments run in this vacuum chamber as it allows the user to specify the desired temperature profile based on ramp time, ramp rate, and soak duration.

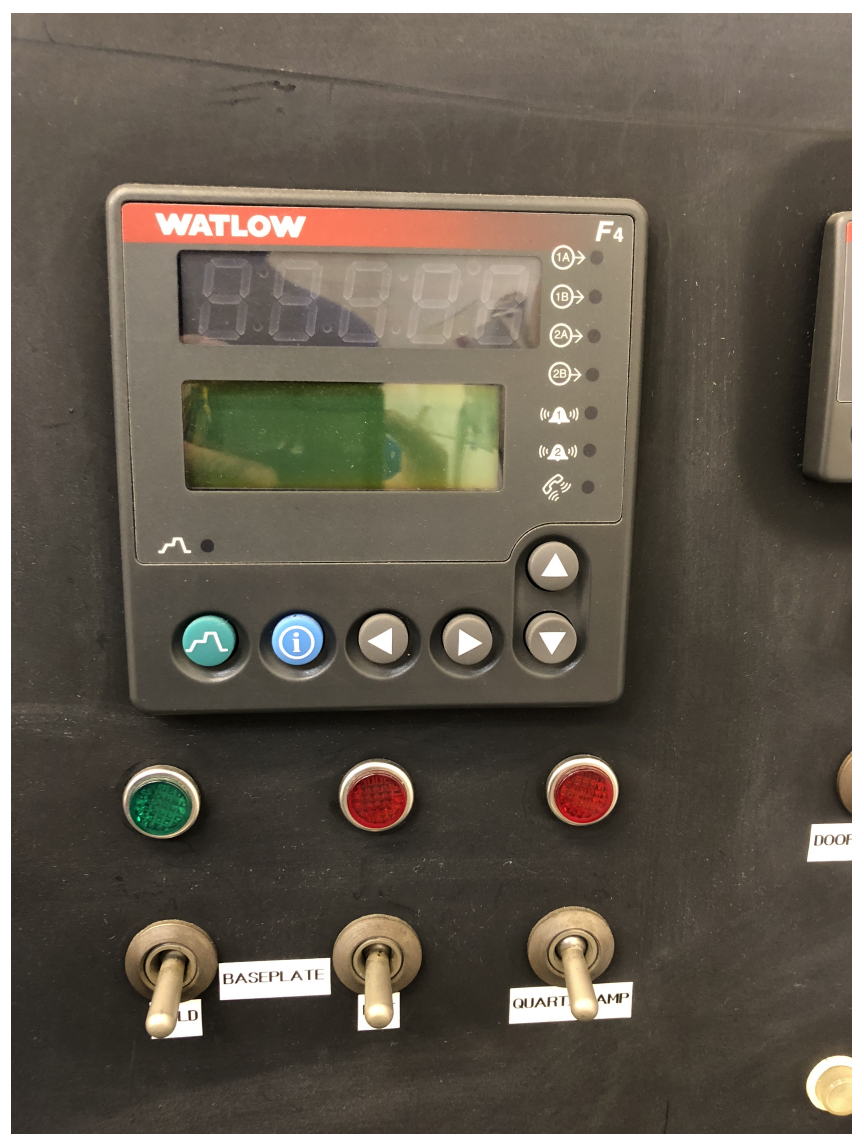

\section{Figure 3.8: F4S/D Ramping Controller}

A profile can be designed with six different step types that include autostart, ramp time, ramp rate, soak, jump, and end. Autostart specifies a time and date at which to begin the profile. Ramp time changes the temperature set point over a specified amount of time. Ramp rate alters the temperature at a specified unit/minute rate. Soak maintains the temperature set point for a period of time that is defined by the 
user. Jump allows the user to jump to another profile or step and repeat that jump multiple times. Finally, end terminates the profile and returns the user to the main page.

For additional help with profile programming beyond the procedure in Appendix B, "Chapter 4: Profile Programming" of the controller user's manual is very helpful.[17]

\subsubsection{Heating System}

The chamber is heated using three Ogden 475 Watt (240 Volt) strip heaters underneath the platen. They are equally spaced along the length of the platen in order to evenly apply heat to the system. The heat strips transfer heat through conduction to the platen, which then radiates to the test section. The chamber controller determines how much power to apply to the heat strips based on the desired heating set point. Additionally, there is a PID controller that can be tuned manually or automatically depending on the desired profile. For this thesis, all experiments

were run with an autotuned PID controller. This resulted in a slight overshoot of the desired platen temperature before returning to the set point and reaching steady state. The controller is only able to control the platen temperature, not the chamber temperature, which is a very important distinction when conducting tests.

\subsubsection{Cooling System}

The active cooling system for this chamber uses liquid Nitrogen $\left(\mathrm{LN}_{2}\right)$. The coolant moves through the plumbing, shown in Figure 3.9, to reduce the internal temperature of the chamber. 


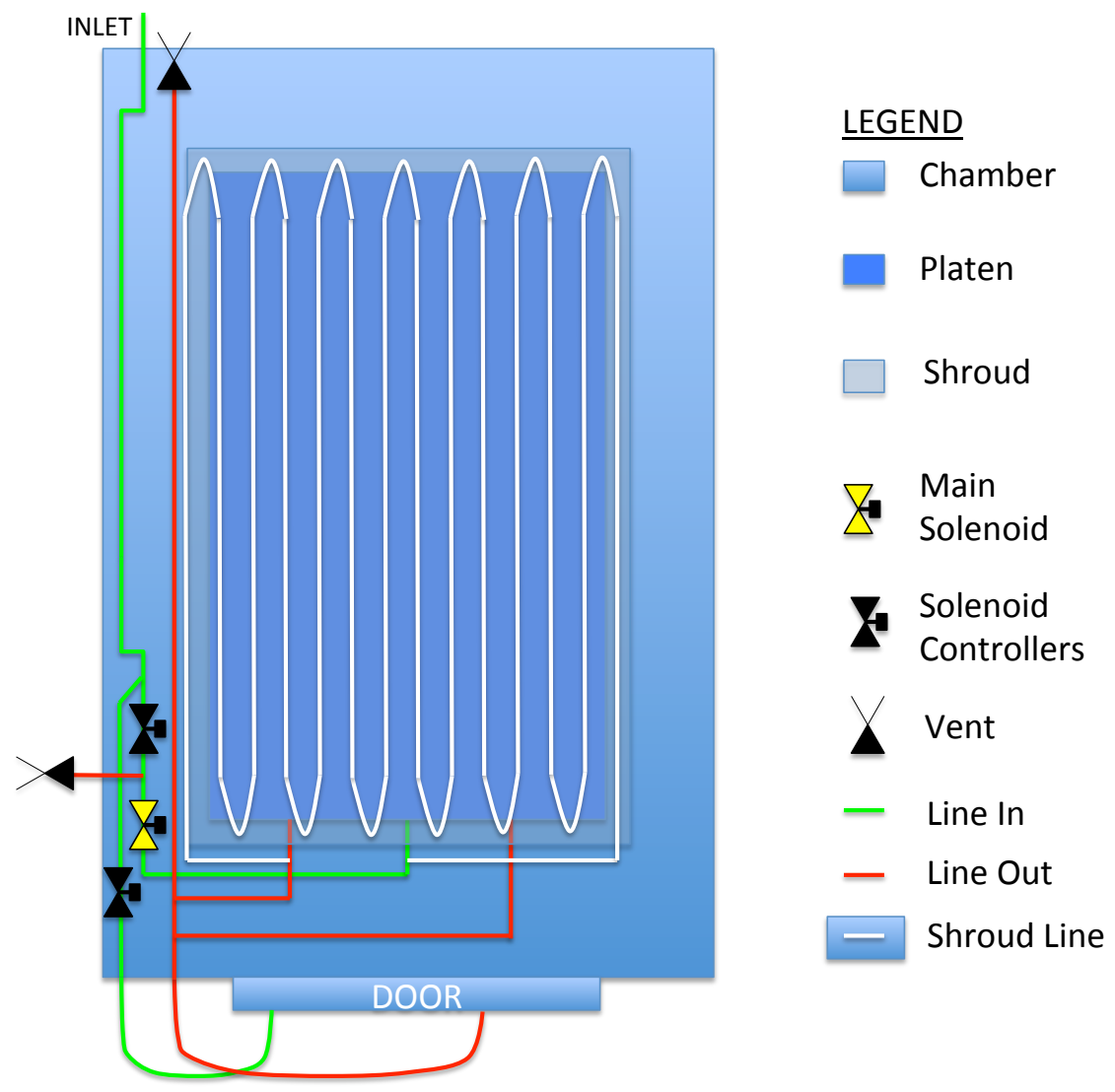

Figure 3.9: $\mathrm{LN}_{2}$ Chamber Plumbing

$\mathrm{LN}_{2}$ enters the chamber plumbing through the green line where it reaches the solenoids. Solenoids are electric coils of wire that, when connected to a battery, create a magnetic field that activates a valve. When the battery is disconnected, the valve is closed. The chamber controller sends an electrical signal to these solenoids to allow the $\mathrm{LN}_{2}$ to pass into the chamber. The green line on the left sends the $\mathrm{LN}_{2}$ to the door shroud, shown in Figure 3.10, that provides additional cooling to the test section of the chamber. The green line on the right enters the platen and the shroud. As mentioned previously, the internal plumbing of the platen is unknown, and therefore is not shown here. The white line is the tubing on the top side of the shroud, as seen in Figure 3.7. Once the $\mathrm{LN}_{2}$ has reached the end of the white line, it merges with the red venting line to leave the chamber from the platen. The $\mathrm{LN}_{2}$ 
leaving the door shroud also merges with this red line and all of the residual coolant is vented out of the top of the chamber.

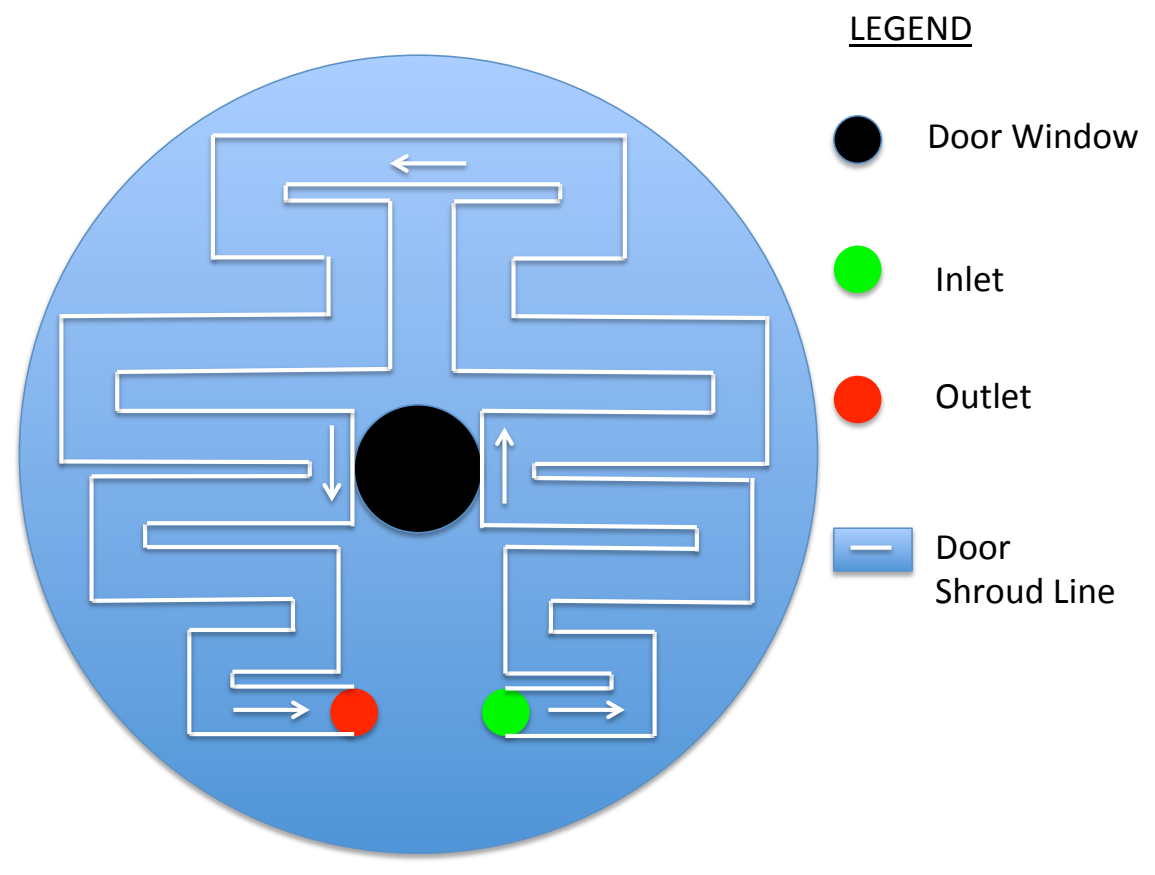

Figure 3.10: Door Shroud Plumbing

As in the first plumbing figure, the $\mathrm{LN}_{2}$ will enter the door at the green inlet mark and exit at the red outlet. The white barriers are approximations of the path through the door.

\subsection{Convectron and Ion Gauge Controller}

The gauge controller for this chamber is a Granville-Phillips 307 Vacuum Gauge Controller. Pictured in Figure 3.11 on the side of the chamber, this controller displays the pressure data for the chamber, roughing line, and the ion gauge when it is turned on. 


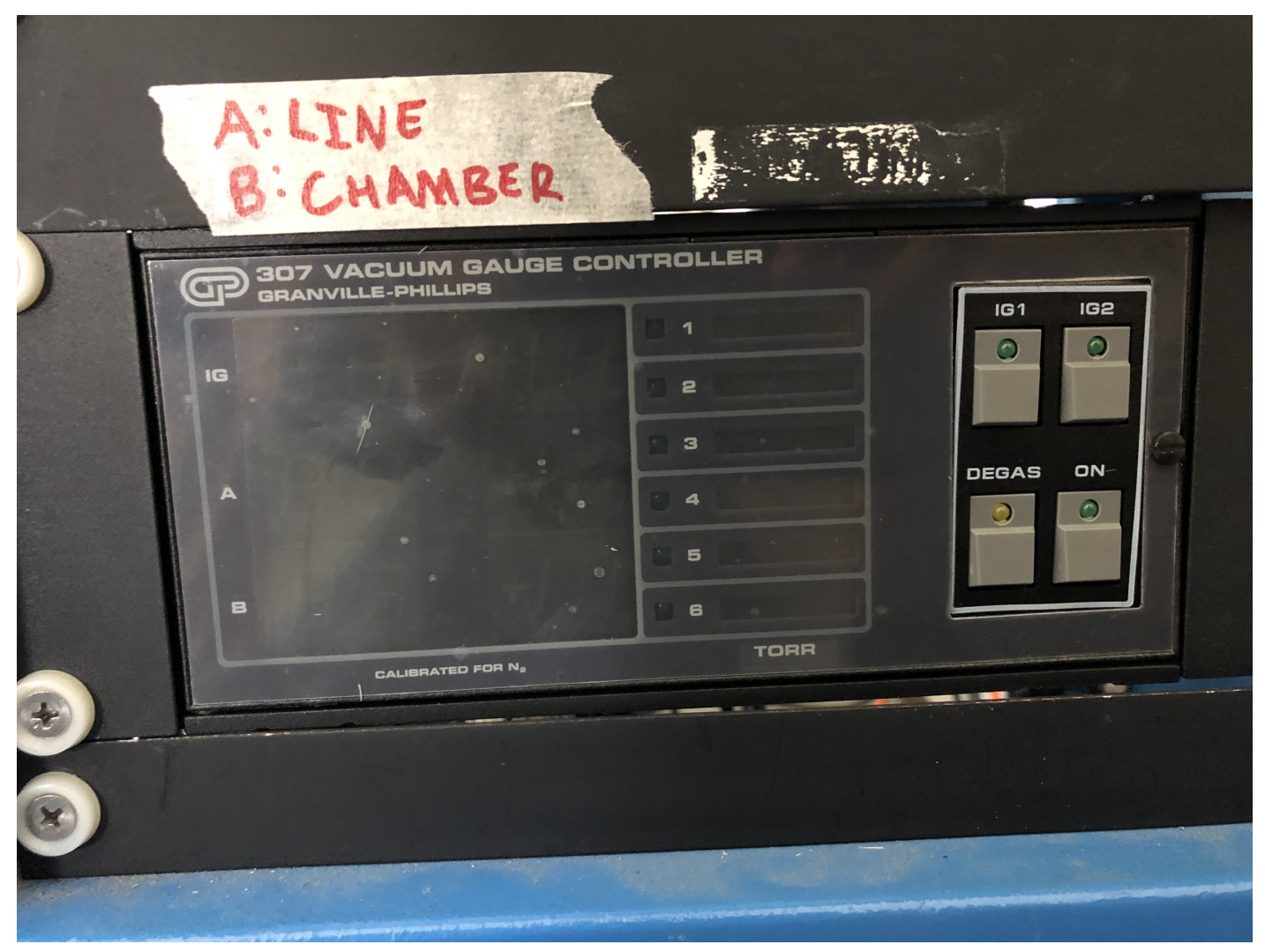

Figure 3.11: Convectron and Ion Gauge Controller

\subsubsection{Convectron Gauges}

Operation of the gauge controller is very simple. When the main chamber power is on, turning the controller on will show the pressure readings from the two convectron gauges, shown in Figure 3.12, located on top of the chamber (left image) and before the turbo pump on the roughing line (right image). The readings are in Torr, so atmospheric readings should show a value near $7.60+02$ on the display. The convectron gauges and digital controller that are currently on the chamber replaced the old gauges and analog control boxes that came with the chamber. The masking tape above the controller in Figure 3.11 shows to what pressure display each convectron gauge is connected. 

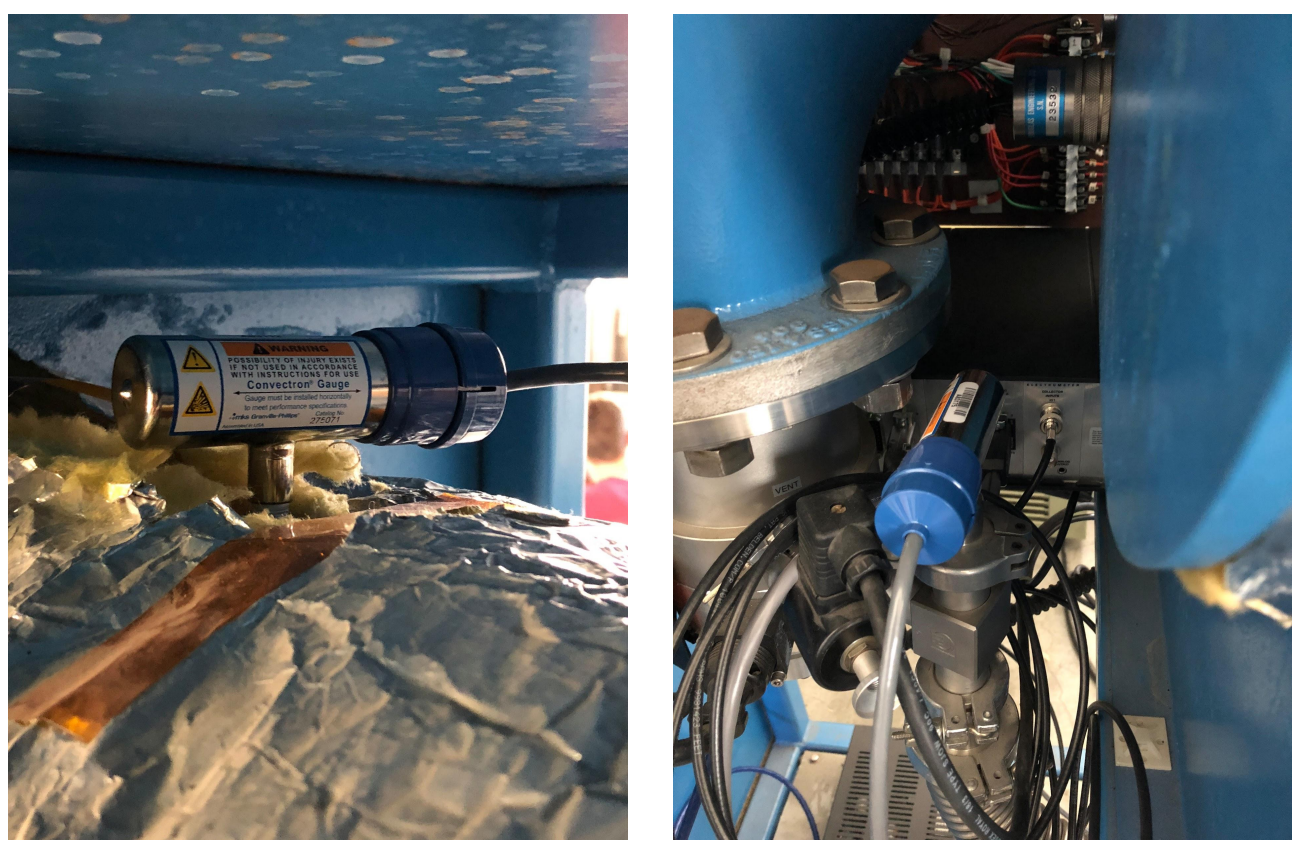

Figure 3.12: Convectron Gauges

\subsubsection{Ion Gauge}

When the mechanical and turbo pumps are both activated and the convectron gauge showing the pressure reading for the chamber bottoms out (displays all zeros), the ion gauge can be turned on. After ensuring the wiring to the gauge is correct, turn on the gauge labeled "IG1" (assuming the gauge is connected to that output). The ion gauge will light up and after a few seconds, a pressure reading will display allowing the user to see pressures below $1 \times 10^{-3}$ Torr. The ion gauge that arrived with the chamber has also been replaced by a new ion gauge. An image of the new ion gauge when it is on can be seen in Figure 3.13. 


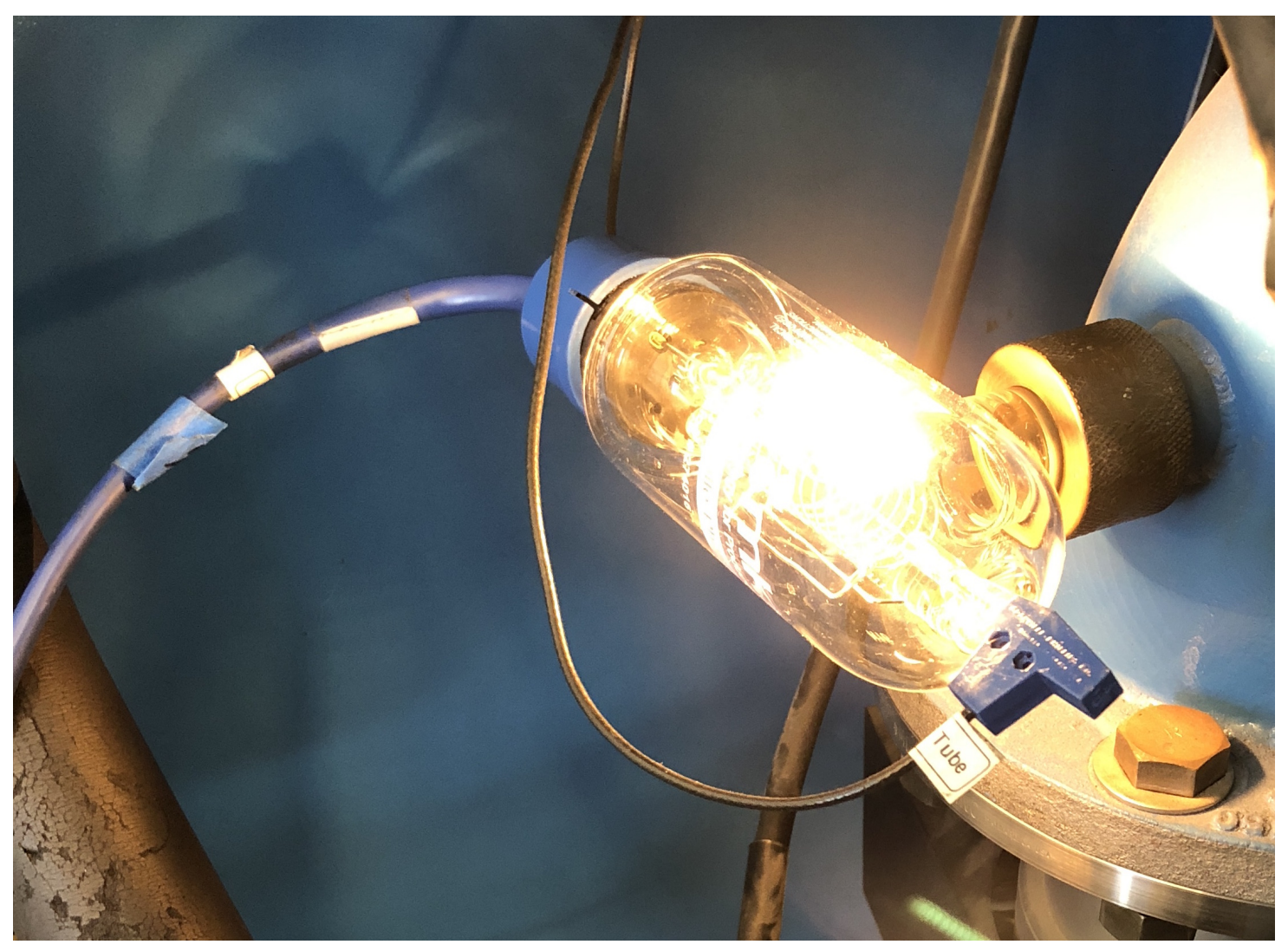

Figure 3.13: Active Ion Gauge

\subsection{Thermocouple Controller}

Internal temperature readings from the chamber are completed using an Omega HH501BJK Type $\mathrm{K}$ thermocouple reader. There is a known error of $\pm 1^{\circ} \mathrm{C}$ associated with this reader, which is taken into account in the analysis of the results. The reader, displayed in Figure 3.14, uses standard thermocouple plug-ins to display the data. 


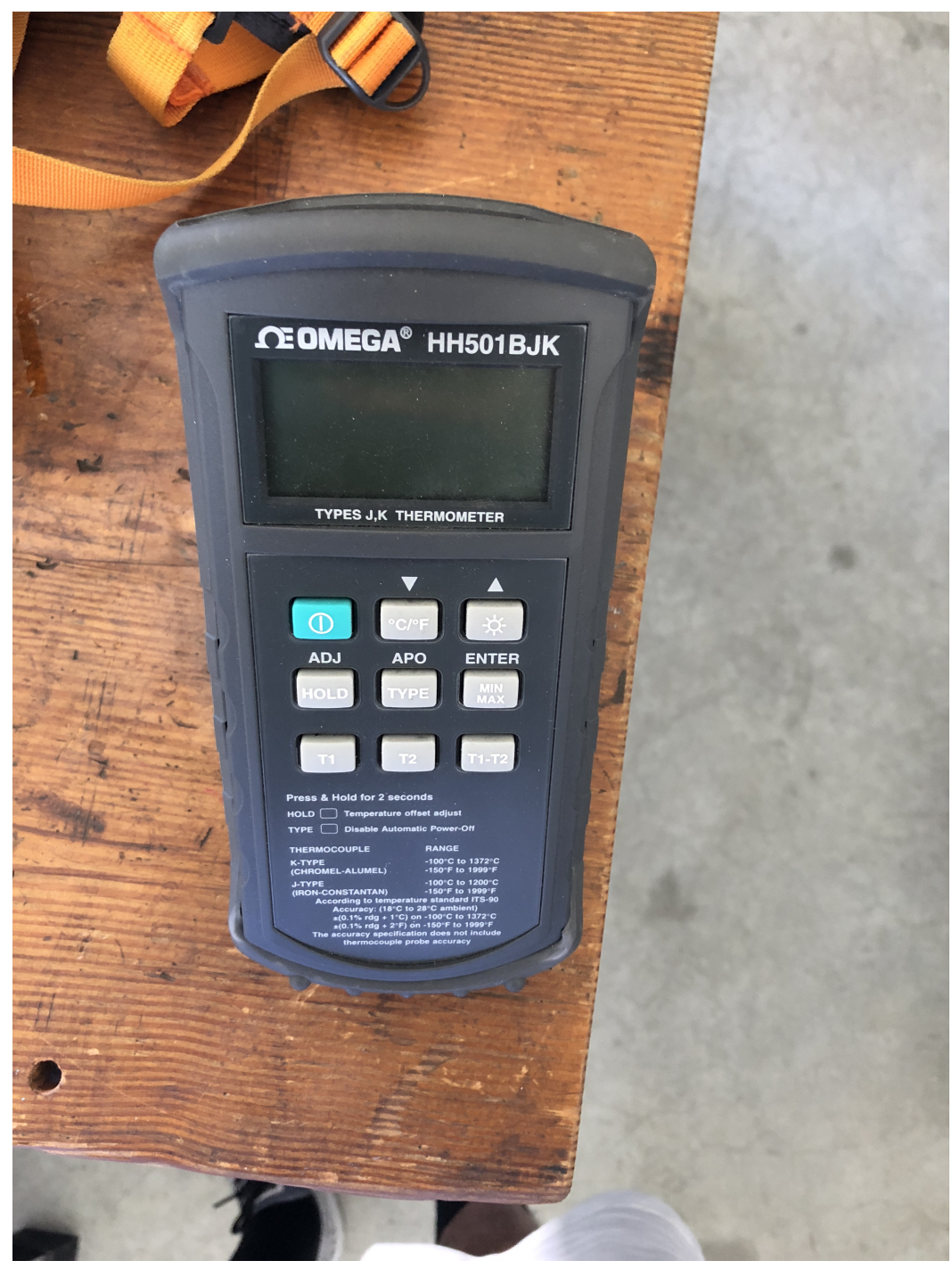

Figure 3.14: Omega HH501BJK Type K Thermocouple Reader

In order to get temperature readings from inside the chamber, two thermocouples had to be rewired. The chamber has external ports that require a male thermocouple end to connect to it, the same connections required for the thermocouple reader. This process was completed for only two ports because the necessary temperature data to be collected was for the test article and the chamber. However, up to six thermocouples could be active at once with a DAQ system or multiple readers to display the outputs. Figures 3.15 and 3.16 below, show the external ports of the chamber and the double-sided male wires required to connect the reader to the ports. 


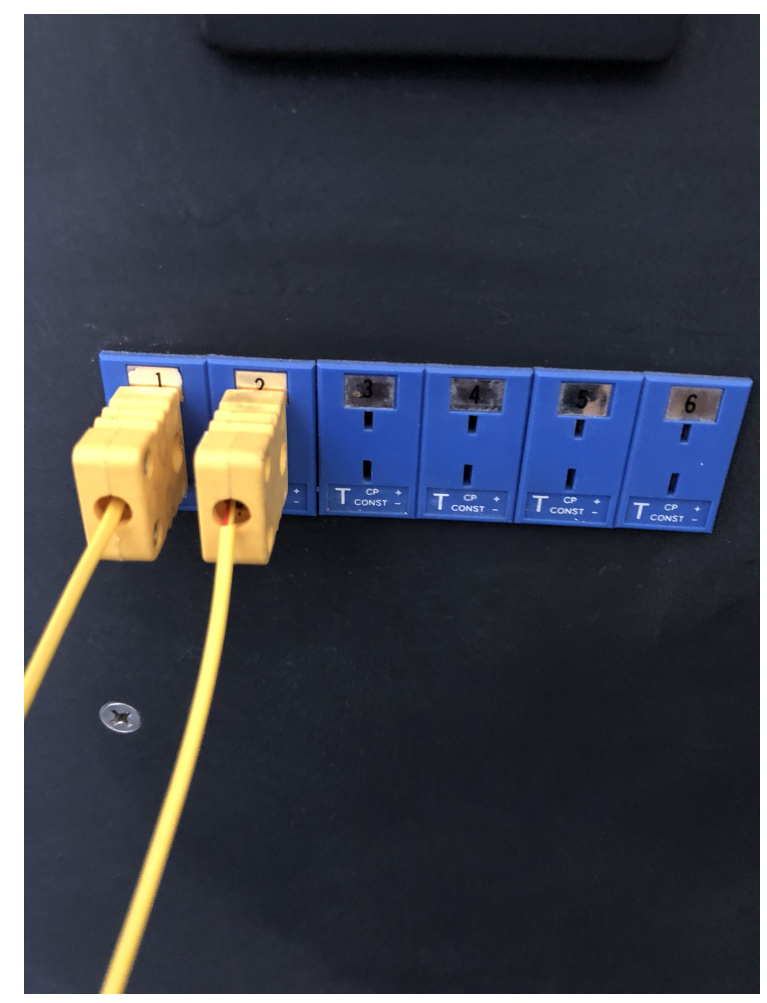

Figure 3.15: External Thermocouple Ports

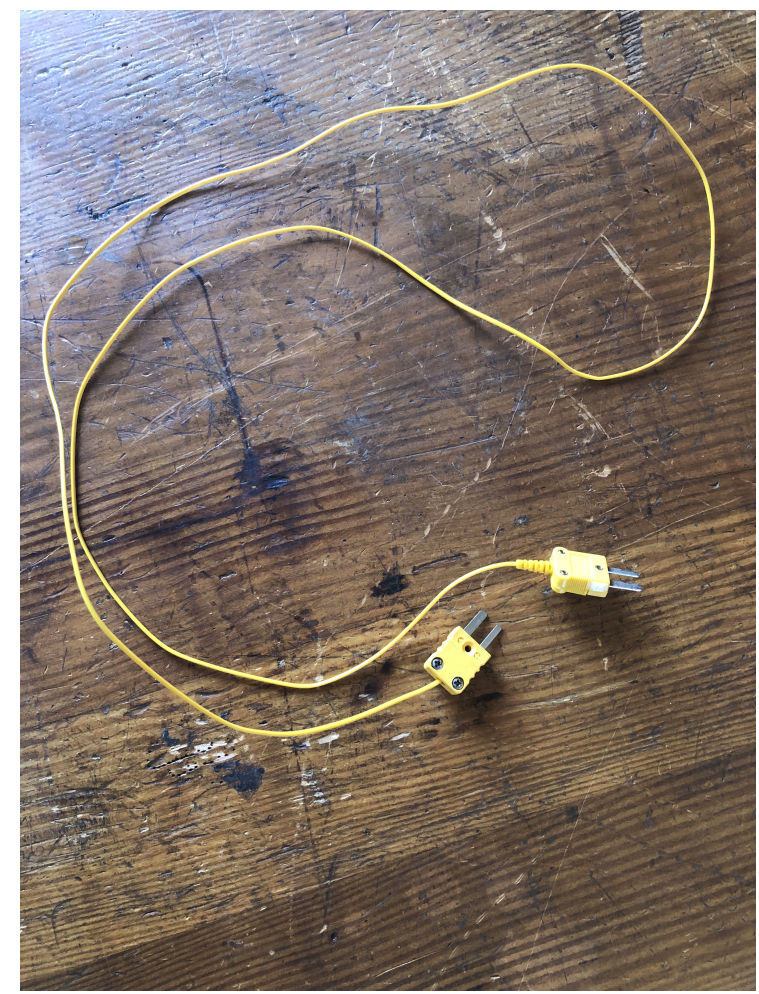

Figure 3.16: Double-Sided Male Thermocouple 
The external ports are numbered and lead to more numbered ports inside the chamber. By connecting to the same numbered port, the temperature data transfer is complete. The internal ports, pictured in Figure 3.17, have an additional six ports, numbered seven through twelve, however, it is unclear at this time how to obtain data from them. Standard one-sided male thermocouples are attached to these ports for use inside the chamber. Ports one through six have all been tested and work properly.

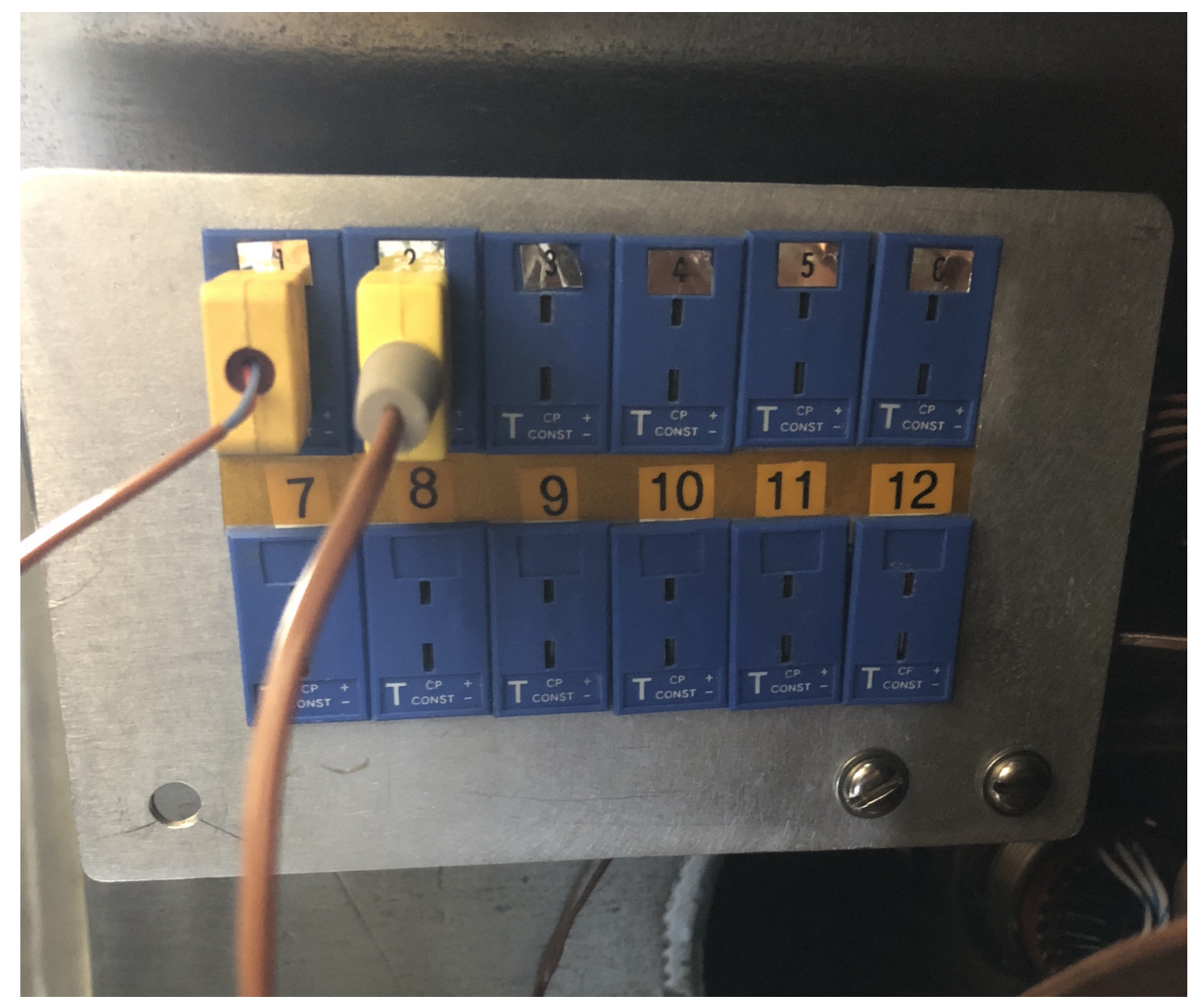

Figure 3.17: Internal Thermocouple Ports

\subsection{Blue Chamber Refurbishment}

When the blue chamber was delivered to Cal Poly, it came with no installation or user's manual of any kind. The entirety of the refurbishment process was completed by the author with the help of the committee members and Cal Poly technical staff. 
The chamber was moved into the Space Environments Lab at Cal Poly where no electrical system existed to match the current and voltage requirements for the chamber. The first thing that needed to be tested was whether or not the chamber could hold a sufficient vacuum for testing. However, the mechanical pump on the chamber could not be turned on until the chamber was plugged in. The only other option to run this test was to use an external pump to test the chamber's capabilities. After removing all exterior panels on the chamber, a mechanical pump was taken from one of the Student Vacuum chambers in the lab and connected to the blue chamber. The hose was removed from the blue chamber's internal pump connected to the external pump with a convectron gauge to read the pressures. A Granville-Phillips 316 Vacuum Gauge Controller was used to display the pressures received from the convectron gauge. There were initial issues with the convectron gauges and controller readouts, but this was solved by attaching all new devices to the chamber.

The external pump was started and the chamber pressure began to drop. After about an hour, the chamber pressure had dropped from 792 Torr to 3.1 Torr (much too high for testing purposes, but a vacuum nonetheless). Initial assumptions were that there was a leak somewhere or that there was some internal function of the chamber that required power to hold lower vacuums.

In order to combat the possibility of a leak, the o-rings in the chamber were greased with DOW Corning High Vacuum Grease. During that process, there was noticeable deterioration on the front door o-ring, which required replacement.

Wiring in the lab was completed in order to accommodate the electrical system of the chamber and the internal pump was reconnected. The main power was turned on, however, there was an issue with the electrical panel door causing the chamber to not switch on entirely. There is a safety switch that engages when the door is closed and if the door does not properly hit the switch, the chamber will not turn on. 
Once the safety switch is engaged, there is a noticeable pressure in the main power switch that is felt when turning on the chamber. It is believed that the switch causes an internal valve to close allowing to the chamber to hold pressure. The mechanical pump was turned on and after three hours, the chamber reached a pressure of 16.9 mTorr. 
Chapter 4

TESTING

\subsection{Experimental Testing}

The focus of this thesis lies in the experimental testing. There are two main goals: prove that the chamber can pull a test level vacuum according to the NASA GEVS standards and prove that the heating components of the chamber work properly and can be analyzed.

Six tests were completed to display the capabilities of the chamber and the controller. Three heating profiles were created and run once each for two different materials, black coated aluminum and black coated brass. The reasoning for using two different materials is to ensure that the computer model is truly an accurate representation of any material put in the chamber, not just for one test. The profiles attempted to reach steady state chamber temperatures of $40{ }^{\circ} \mathrm{C}, 60{ }^{\circ} \mathrm{C}$, and $80{ }^{\circ} \mathrm{C}$. However, the chamber controller is only able to set the temperature of the platen, so the final chamber temperature had to be approximated. With the help of the testing data, a better understanding of the relationship between platen temperature and chamber temperature has been developed, but a more accurate model will need to be created over time with more data points.

It is important to note that there was no background data for this chamber showing past run times, experimental data, or issues that arose. Therefore, most of the chamber had to be checked before and after each test to ensure nothing was broken or failing in a way that could result in the chamber being out of commission for a period of time. As more tests were completed, and the robustness of the chamber became more well known, these checks were not as necessary. Initially, a majority 
of the checks were simply looking for leaks in the system and ensuring that the lines to the pump were connected soundly. Near the end of the testing period, checks revolved more so around the convectron gauges and thermocouple connections. No major issues arose during this time causing delays in testing.

\subsubsection{Test Setup}

For each test, a small polymethyl methacrylate (PMMA or Plexiglas) plate was placed on the center of the platen. The test article was set on the top of the Plexiglas plate to help isolate it from conduction through the platen. The goal of this setup was to create an environment where the temperature of the test article was affected solely by radiation, as is the case in space. A thermocouple was attached to the center of the test article to gather data throughout the test. Another thermocouple was placed to measure the temperature inside the chamber.

The test articles are small cylinders made of aluminum and brass and coated with a black finish. Both cylinders measured 1.5 inches tall and 0.75 inches in diameter. The external coating is important to note as the optical properties of the cylinder are the main drivers in radiation heating and cooling. The only difference between the test articles is the conductivity, specific heat, and density of the materials, which affects how long the material takes to reach steady state and what its final temperature can reach in a given time period.

Figure 4.1 displays the test setup inside the chamber. The test article is sitting on the Plexiglas with a thermocouple attached to it. Plexiglas has a melting temperature of about $160{ }^{\circ} \mathrm{C}$, so there is no risk of melting for these tests. The other thermocouple is the wire to the left of the Plexiglas that is extended into the chamber from the platen and used to collect the chamber temperature data. 


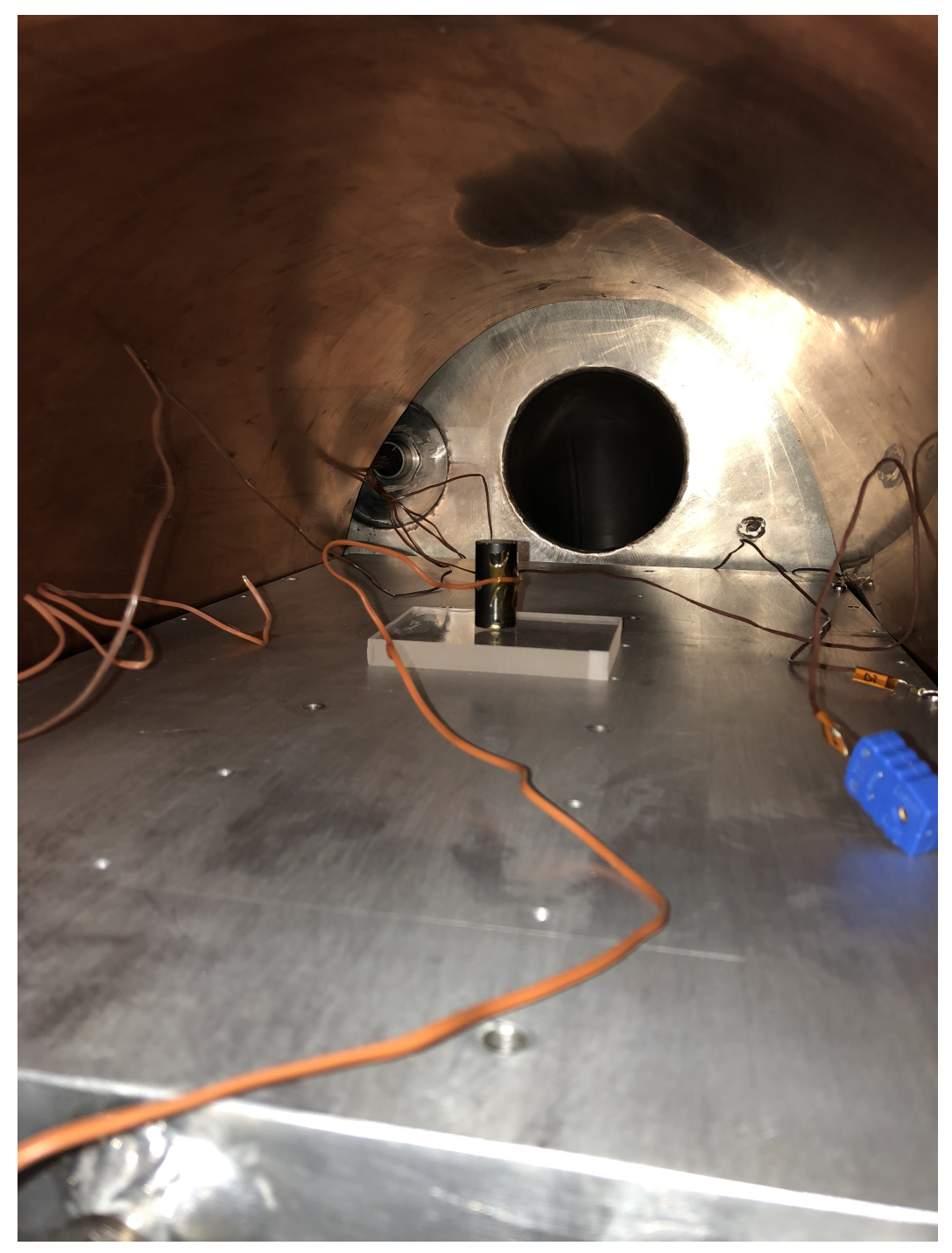

Figure 4.1: Experimental Test Setup

The door and manual vent valve are then sealed and the mechanical pump is turned on. Usually, the pump is left on overnight to ensure the turbo pump could be activated without any issues. Generally, turbo pumps should not be started until the chamber pressure has reached around 20 mTorr or so, however, it is safer to let the chamber continue to pump down to lower pressures. After an overnight pump down, the chamber is generally around 3 or 4 mTorr and there have been no problems starting up the turbo pump. When the convectron gauge reading the chamber pressure shows all zeros, the ion gauge can be activated to continue observing the pressure. 
Most of the time, the turbo pump would be left running for a couple hours to reach somewhat of a "steady state" before starting a test. But, no real steady state was found as the chamber was seen to go as low as $10 \mu$ Torr and most tests began around $30 \mu$ Torr.

Recall that the NASA GEVS state that a pressure less than $10 \mu$ Torr is required to run this test appropriately and a temperature soak at that pressure must last for at least four hours. The time requirement to run adequate temperature profiles at ambient pressure is a six hour soak. [7] Since the there is only a two hour difference between the soak times required for a $10 \mu$ Torr test and an ambient pressure test, it was assumed that only 5-10 minutes would need to be added to a $30 \mu$ Torr test. However, since no electrical or component testing was taking place, the extra 5-10 minutes was disregarded as it was insignificant to the final test results. Additionally, there was no indication from working with the chamber that suggested it could not complete the 6 hour soak if necessary. A simple adjustment in the chamber controller would be the only change necessary to allow the test to proceed longer.

The final step to setting up the test properly is programming the heating/cooling profile into the chamber controller. Using a variety of step types in the controller, this can be achieved and the test can be initiated. If the chamber is attempting to heat up, the switch labeled "HOT" on the right of the "BASEPLATE" label must be flipped up and vice versa for cooling. These switches can be seen in Figure 4.2. Once initial data measurements are made and the profile is started on the controller, data recording can begin. 


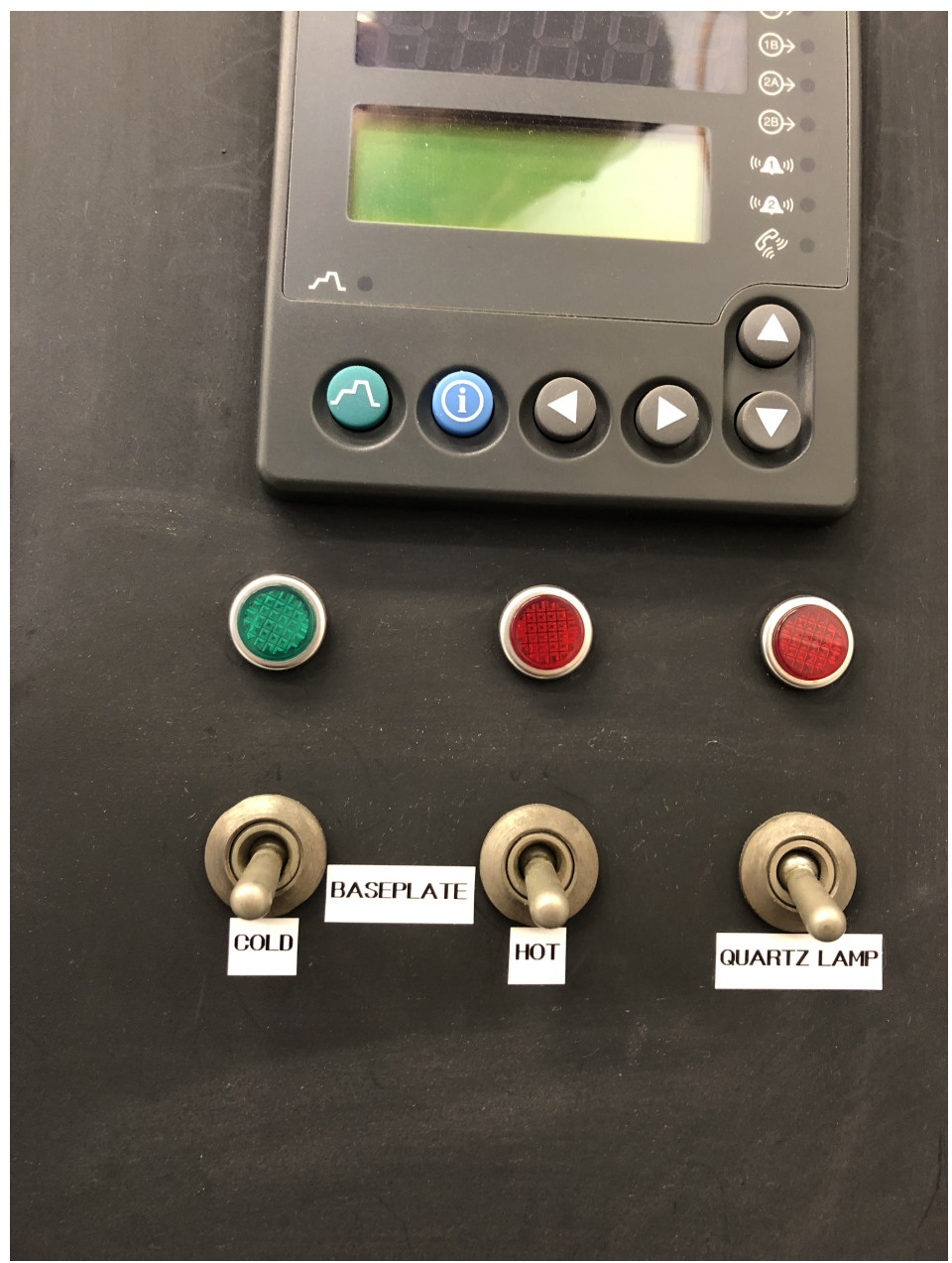

Figure 4.2: Baseplate Switches

\subsection{Validation of Testing}

Simulations for the chamber testing were completed in Thermal Desktop. The model, shown in Figure 4.3, represents the test setup for the chamber. The clear cylinder surrounding the platen and shroud represents the chamber walls. Without this in place, heat in the simulation would radiate out to "space" continually resulting in little to no temperature increase on the test article. The platen is the silver plate containing three red strip heaters along its length. The shroud can be seen in yellow covering the platen and test article. Finally, the small blue plate represents the thermally isolating Plexiglas and the black cylinder is the test article. Small spheres 
seen mounted on various surfaces are the nodes that the program uses for its finite difference method to determine the temperature at those locations. Increasing the number of nodes results in better temperature accuracy for the simulation, however, it takes more computing power and longer to run each simulation. Higher mesh accuracy is not required for this test as the test article should see uniform heat distribution regardless of the number of nodes. More nodes is more desirable when there is a large temperature gradient across a surface or interface.

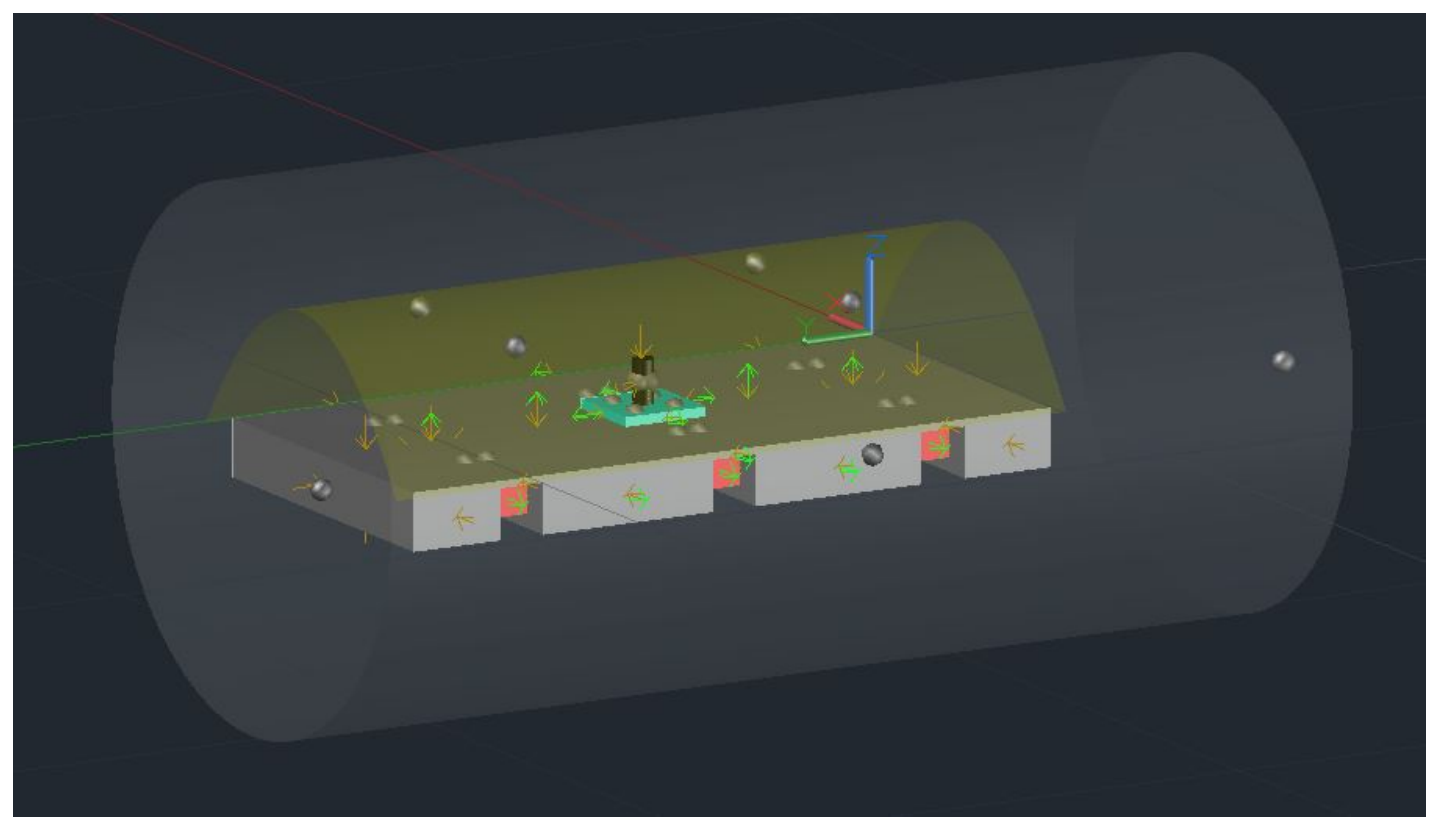

Figure 4.3: Thermal Desktop Simulation Model

The properties of each material in the chamber were chosen from tables of known property values. The two cylinders are 6061-T6 aluminum and alloy 360 brass both powder-coated flat black. The material property values used in the simulation for each material are presented in Table 4.1. 
Table 4.1: Simulation Material Properties

\begin{tabular}{|l|l|l|l|l|l|}
\hline Material & $\begin{array}{l}\text { Conductivity } \\
\left(\frac{W}{m * K}\right)\end{array}$ & $\begin{array}{l}\text { Density } \\
\left(\frac{k g}{m^{3}}\right)\end{array}$ & $\begin{array}{l}\text { Specific } \\
\text { Heat }\left(\frac{J}{k g * K}\right)\end{array}$ & Emissivity & Absorptivity \\
\hline Aluminum[5] & 237 & 2700 & 921.09 & 0.15 & 0.12 \\
\hline Brass[6] & 119.9 & 8470 & 380 & 0.04 & 0.5 \\
\hline Copper[6] & 401 & 8960 & 0.39 & 0.03 & 0.18 \\
\hline Plexiglas[4][8] & 0.18 & 1180 & 1450 & 0.86 & 0.5 \\
\hline $\begin{array}{l}\text { Black } \\
\text { Coating[10] }\end{array}$ & N/A & N/A & N/A & 0.95 & 0.9 \\
\hline
\end{tabular}

It was determined that the aluminum was either highly or roughly polished and, therefore, should have an emissivity from 0.09-0.18. For the final results of the simulation, an emissivity value of 0.15 for the aluminum produced the most accurate temperature results. A comparison of the simulation results for the both the 60 degree aluminum and brass tests can be seen in Figures 4.4 and 4.5, respectively. The red line in both plots is the measured experimental temperature of the cylinder that the simulation is attempting to replicate. If an emissivity value of 0.16 (blue line) was chosen, the simulation would be too high for the brass test. Equally, if an emissivity value of 0.14 (green line) was chosen, the simulation would be too low for the aluminum test. To avoid favoring one test over the other, 0.15 was chosen as the emissivity value for aluminum in the simulation. Further analysis of the testing results takes place in Chapter 5 . The copper values for the shroud are values consistent with polished copper and the black coating values were determined based on a range of values for black coatings in space. 


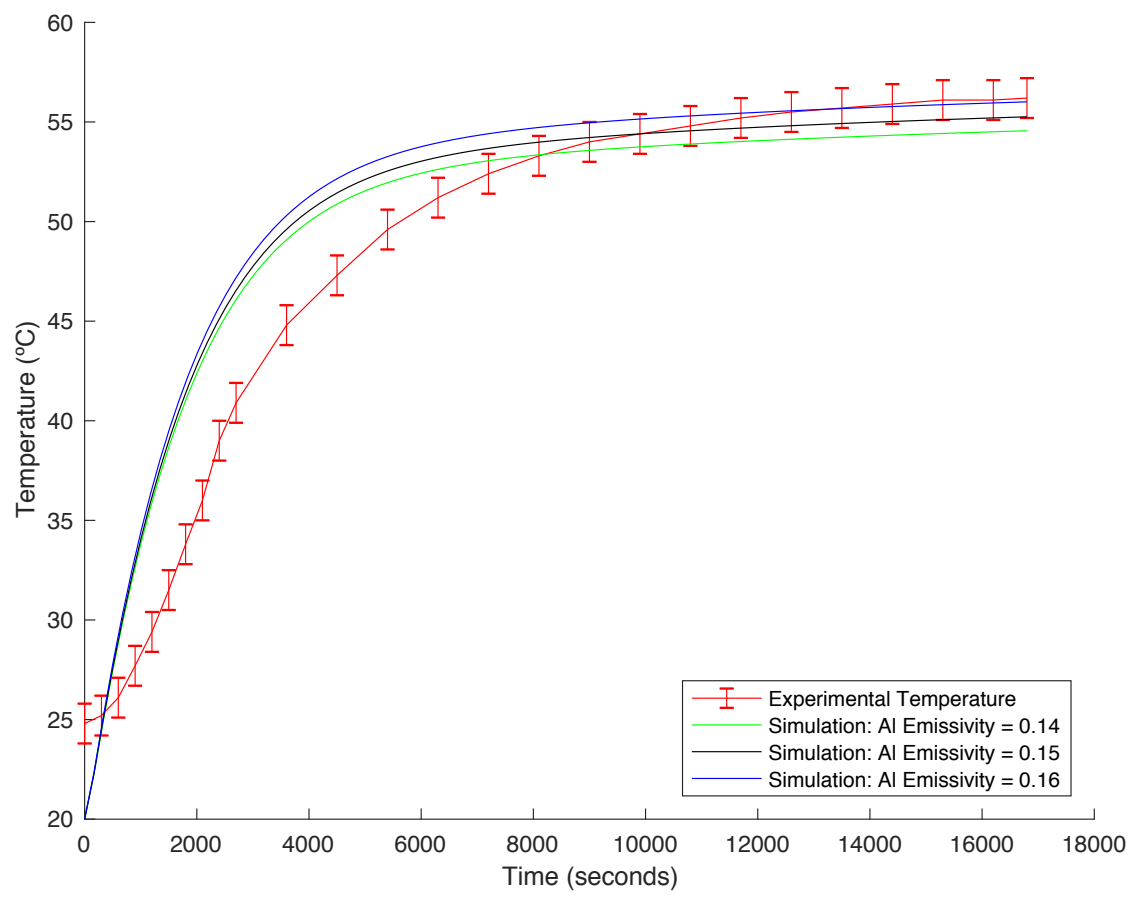

Figure 4.4: Emissivity Comparison: Aluminum $60{ }^{\circ} \mathrm{C}$ Test

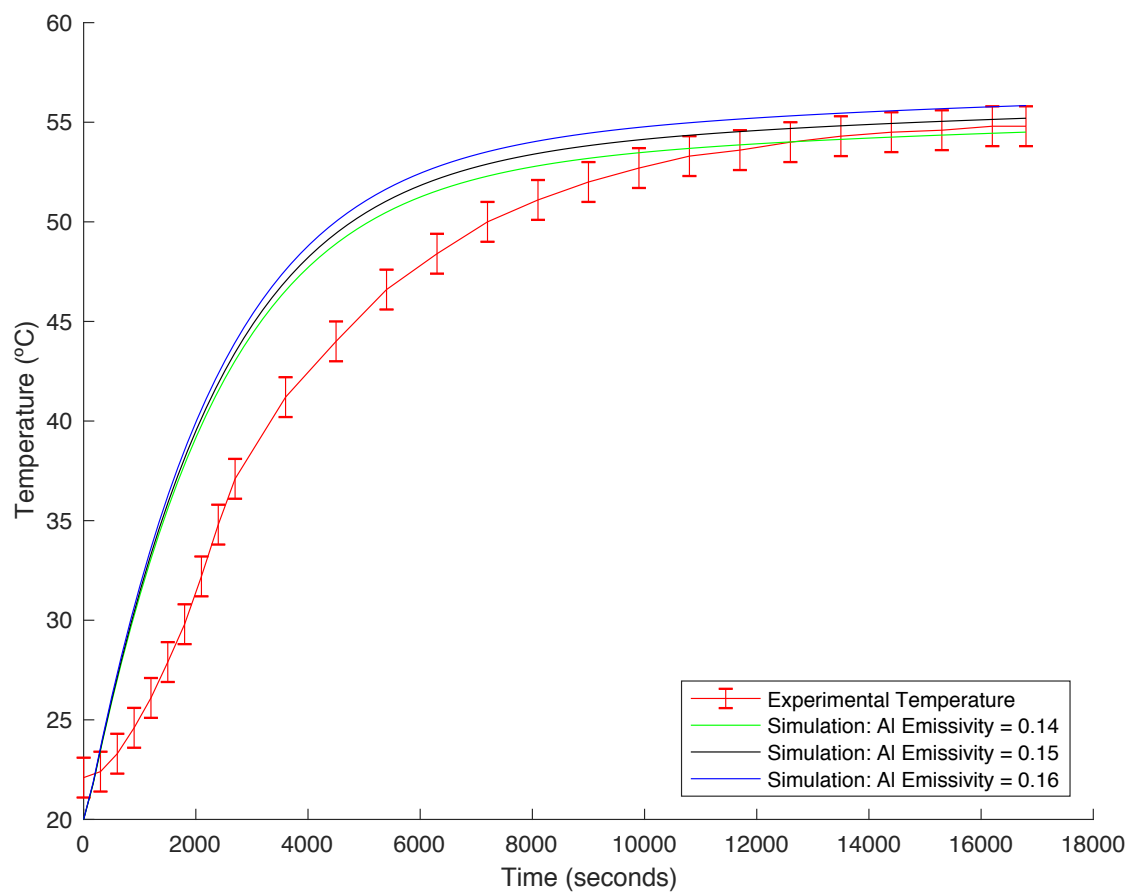

Figure 4.5: Emissivity Comparison: Brass $60^{\circ} \mathrm{C}$ Test 
The same model was used for all tests run through the simulation. The only variable changes were the material of the cylinder, the temperature of the nodes on the heat strips, and the length of the test. The test duration change was required because the higher temperature tests took longer to reach their final soak temperature. The submodel directory in Thermal Desktop made these changes very simple to complete between runs.

This simulation serves as a means to not only validate the tests being done in the chamber, but also to help predict future tests. Once the model is fully validated, analysis can be completed prior to experimental testing to determine if the tests will be safe to run for the satellite hardware. This will allow the testing process with this chamber to be more efficient and more effective as the proper temperatures can be reached for testing. 
Chapter 5

RESULTS

The results for the six tests conducted and the comparison with the simulations completed for each will be discussed in this section. The tests for both the aluminum and brass cylinders attempted to be conducted at chamber temperatures of $40{ }^{\circ} \mathrm{C}, 60$ ${ }^{\circ} \mathrm{C}$, and $80{ }^{\circ} \mathrm{C}$. The real final temperature of the chamber will be presented as well as a relationship that has been developed for the chamber and platen temperatures.

To meet the NASA GEVS standards, the soak must be maintained for at least four hours. The experiment was considered to be in the soak phase as soon as it passed the desired set point for the platen temperature.

\section{$5.140{ }^{\circ} \mathrm{C}$ Aluminum Test}

With very little initial data as to the relationship of chamber temperature and platen temperature, an estimate had to be made to set the platen temperature for this test and the $40{ }^{\circ} \mathrm{C}$ brass test. Figure 5.1 shows the recorded test data for the physical experiment. The red line represents the cylinder temperature, the blue line represents the chamber temperature, and the green line is the platen temperature that was displayed on the side of the chamber. The error bars are required for the \pm 1 ${ }^{\circ} \mathrm{C}$ error for the thermocouples attached to the cylinder and the chamber. The profile for the platen temperature was set so the platen would reach a final steady state of $52{ }^{\circ} \mathrm{C}$. The error for the platen temperature displayed on the controller is $\pm 0.1{ }^{\circ} \mathrm{C}$. The soak begins around 1,200 seconds when the platen temperature rises above the steady state temperature. As the controller works to bring the platen temperature back down, the chamber and cylinder also begin to display a steady state temperature, 
though still slightly increasing.

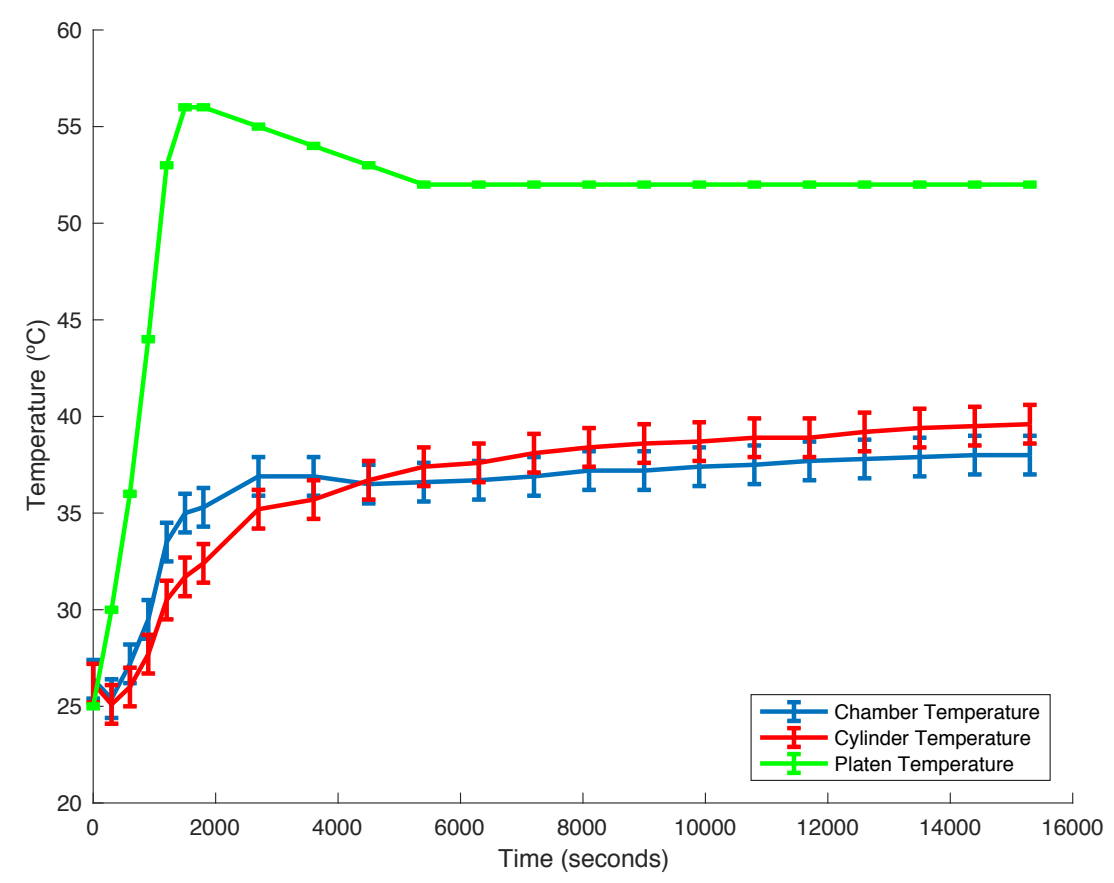

Figure 5.1: Aluminum $40{ }^{\circ} \mathrm{C}$ Experimental Test

Thermal Desktop predicted a final cylinder temperature of $37.7^{\circ} \mathrm{C}$, which ended up being lower than the experimental temperature by $1.9^{\circ} \mathrm{C}$. Figure 5.2 shows the experimental cylinder temperature, in red, and the simulation cylinder temperature, in black. The two lines generally track each other throughout the course of the four hour and fifteen minute test, which is a good sign for the accuracy of the simulation. However, the discrepancy in temperature value could be caused by the simulation material properties or by the way the simulation completes the heating process. A difference in the emissivity value of the platen could alter the final temperature and the overall plot. The heating process was modelled to achieve a constant temperature across the platen, however, this would not be the case experimentally as there would be a temperature gradient from the heaters out to the edge of the platen. Finally, Figure 5.3 is an image of the heat map generated by Thermal Desktop. This image shows how important it is to have the Plexiglas underneath the test article. Without 
that piece, the conduction directly from the platen would cause the final cylinder temperature increase dramatically.

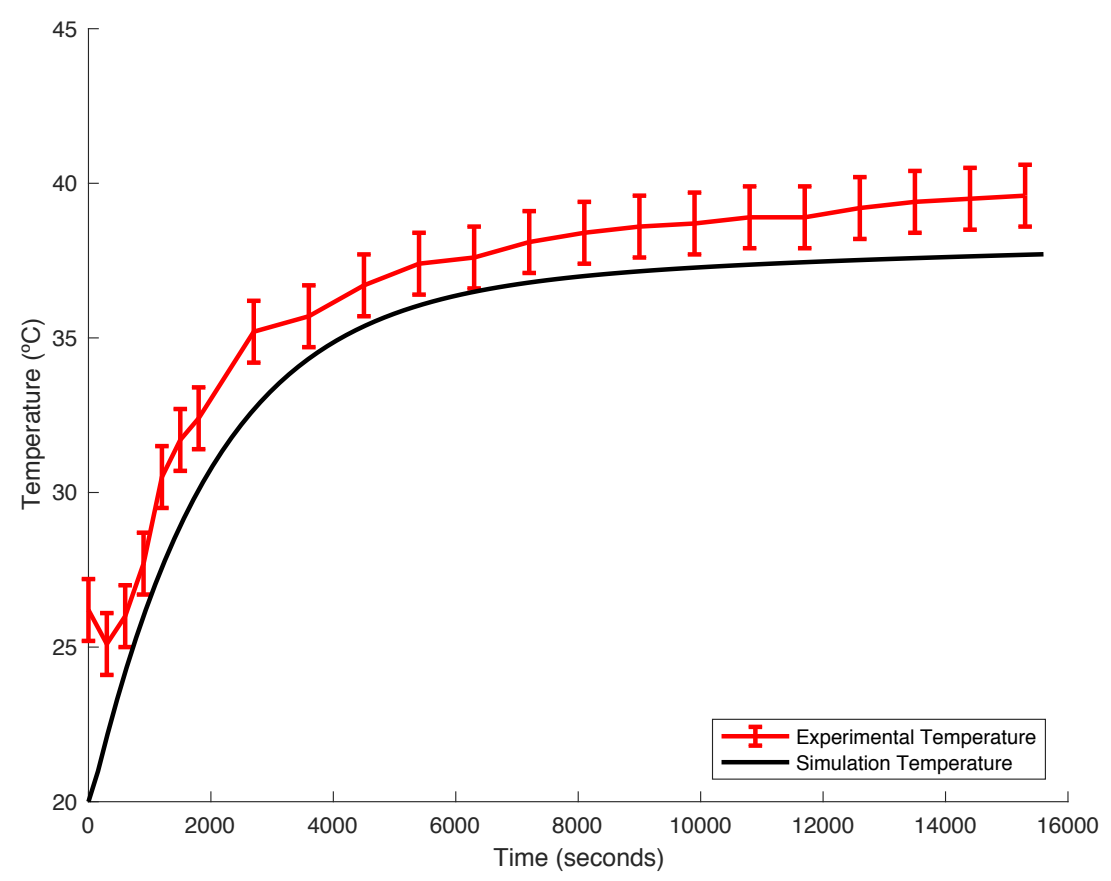

Figure 5.2: Aluminum $40^{\circ} \mathrm{C}$ Test vs Simulation: Cylinder Temperature 


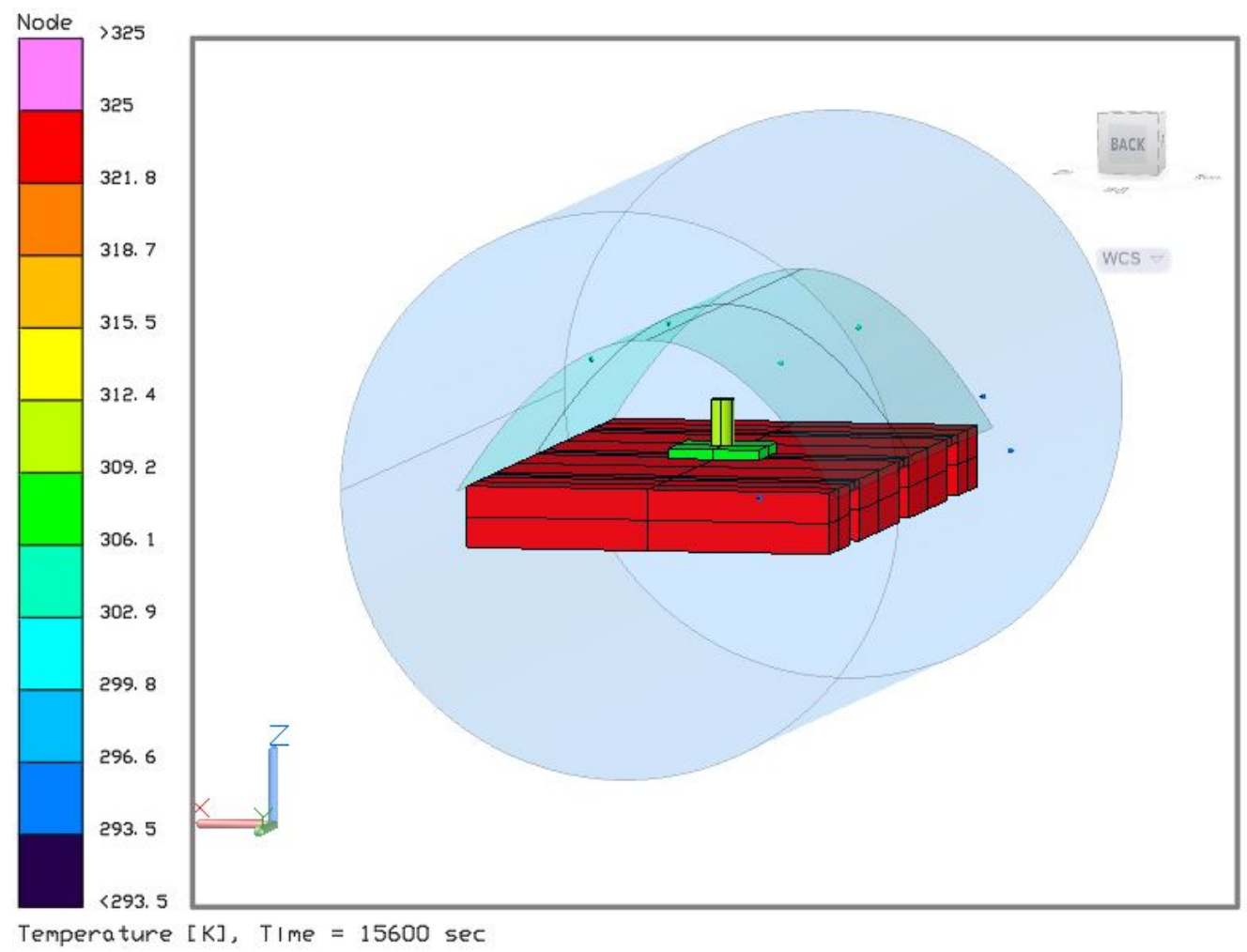

Figure 5.3: Aluminum $40{ }^{\circ} \mathrm{C}$ Simulation Heat Map

Table 5.1 is a summary of the important values from this test.

Table 5.1: $40{ }^{\circ} \mathrm{C}$ Aluminum Cylinder Test

\begin{tabular}{|l|l|l|l|l|l|}
\hline Total & Average & Final & Final & Final & Final Sim- \\
Test & Chamber & Chamber & Platen & Cylinder & ulation \\
$($ hh:mm $)$ & $\begin{array}{l}\text { Pressure } \\
(\mu \text { Torr })\end{array}$ & $\begin{array}{l}\text { Temp. } \\
\left({ }^{\circ} \mathrm{C}\right)\end{array}$ & $\begin{array}{l}\text { Temp. } \\
\left({ }^{\circ} \mathrm{C}\right)\end{array}$ & $\begin{array}{l}\text { Temp. } \\
\left({ }^{\circ} \mathrm{C}\right)\end{array}$ & $\begin{array}{l}\text { Cylinder } \\
\text { Temp. }\left({ }^{\circ} \mathrm{C}\right)\end{array}$ \\
\hline $4: 15$ & 42.27 & $38.0 \pm 1$ & $52 \pm 0.1$ & $39.6 \pm 1$ & 37.7 \\
\hline
\end{tabular}

\section{$5.240{ }^{\circ} \mathrm{C}$ Brass Test}

Regardless of the knowledge that the $40{ }^{\circ} \mathrm{C}$ aluminum test did not produce the desired chamber temperature, the same heating profile was run for this test so the re- 
sults could be adequately compared. It was also desirable to observe the repeatability of the chamber performance from test to test.

Figure 5.4 shows the experimental results from this test. The platen temperature responded nearly identically to the first test, which is a good sign for the chamber performance. The final chamber temperature, however, reached a much higher temperature than the previous test by nearly $2{ }^{\circ} \mathrm{C}$. There was an odd pressure spike that was not seen in any of the other tests in which the pressure inside the chamber reached over $200 \mu$ Torr at its peak. For reference, the highest peak of any other test was $100 \mu$ Torr. Even with the additional chamber temperature, the brass cylinder did not reach the same temperature as the aluminum cylinder. Although the cylinder is made of a different material, the black coating is the main driver for the cylinder temperature. The slight difference in final temperature for the two cylinders is a result of their internal specific heats. The plots for the chamber and cylinder temperature were noticeably less smooth for this test as well. The noticeable decline in the chamber temperature that occurred around 5000 seconds corresponded to a switch in thermocouple readers during the test. The two readers were not calibrated the same, therefore, the results were slightly different. 


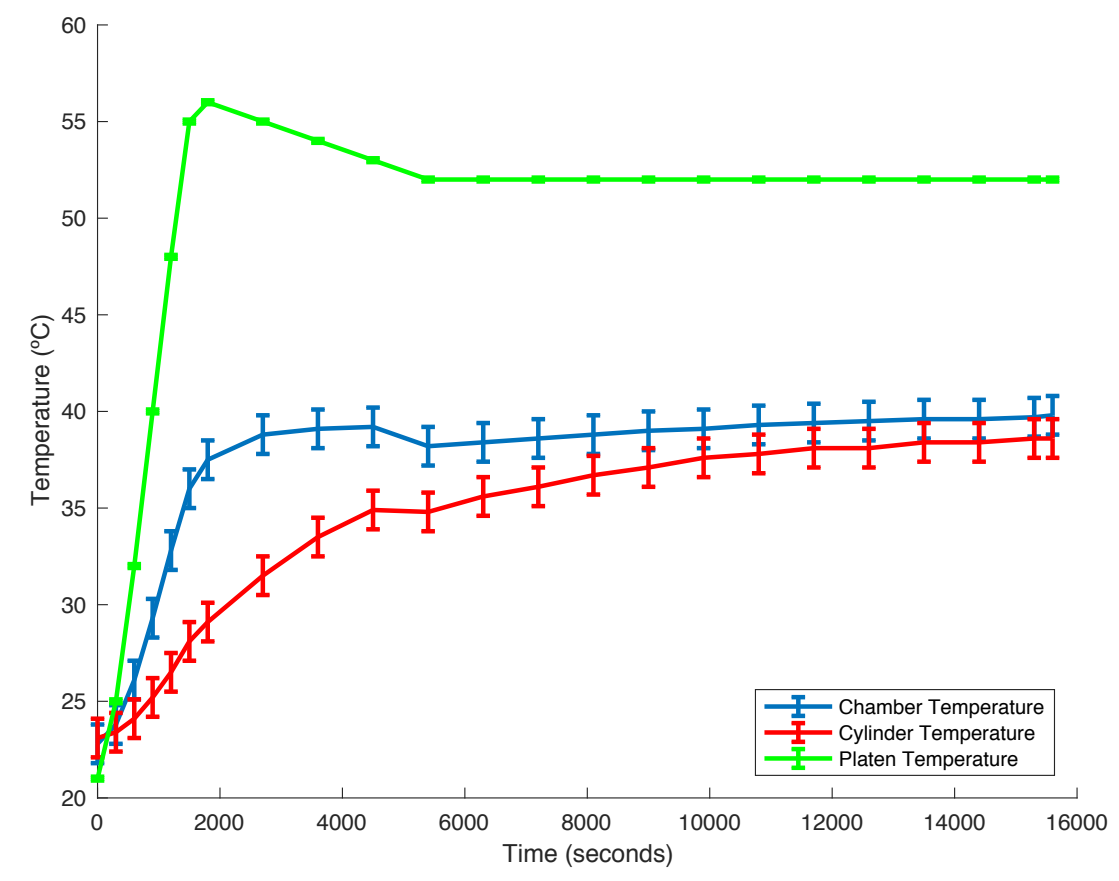

Figure 5.4: Brass $40{ }^{\circ} \mathrm{C}$ Experimental Test

Figures 5.5 and 5.6 show the results from the brass $40{ }^{\circ} \mathrm{C}$ simulation. The simulation line tracked the experimental line extremely well at the beginning of the test until the cylinder continued to a higher steady state near the end. The final temperatures for the simulation and the experimental test were off by $1{ }^{\circ} \mathrm{C}$. Again, the slight dip in temperature can be more clearly seen at 5000 seconds when the reader was switched. The difference in final temperature is likely due to a higher than expected chamber temperature. This is the third time a test has been run at this temperature during the course of this thesis due to a necessary rerun, and it is a clear outlier in final chamber temperature. The platen and chamber temperature relationship plot in Section 5.9 shows the three chamber temperature data points at the $52{ }^{\circ} \mathrm{C}$ platen temperature. The heat map is very similar to that of the aluminum test with the platen in the red temperature range and the cylinder thermally isolated by the Plexiglas. 


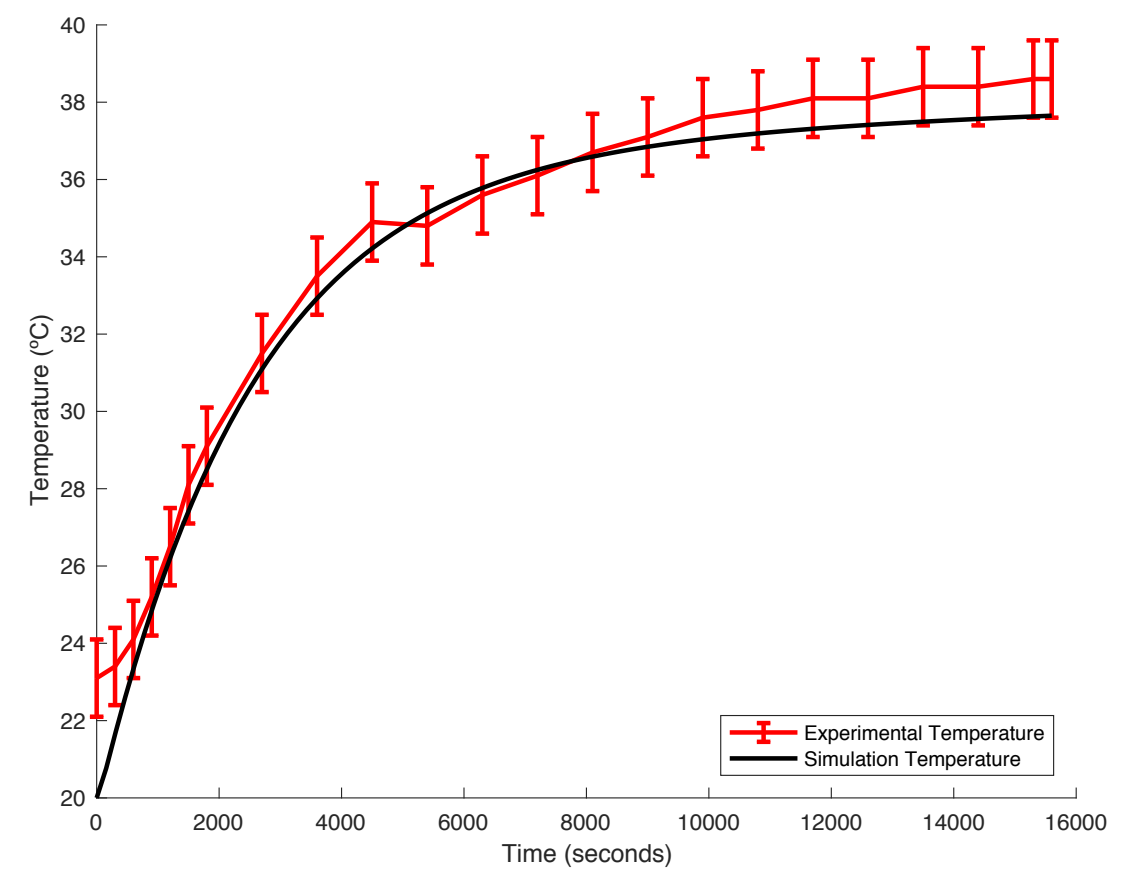

Figure 5.5: Brass $40{ }^{\circ} \mathrm{C}$ Test vs Simulation: Cylinder Temperature

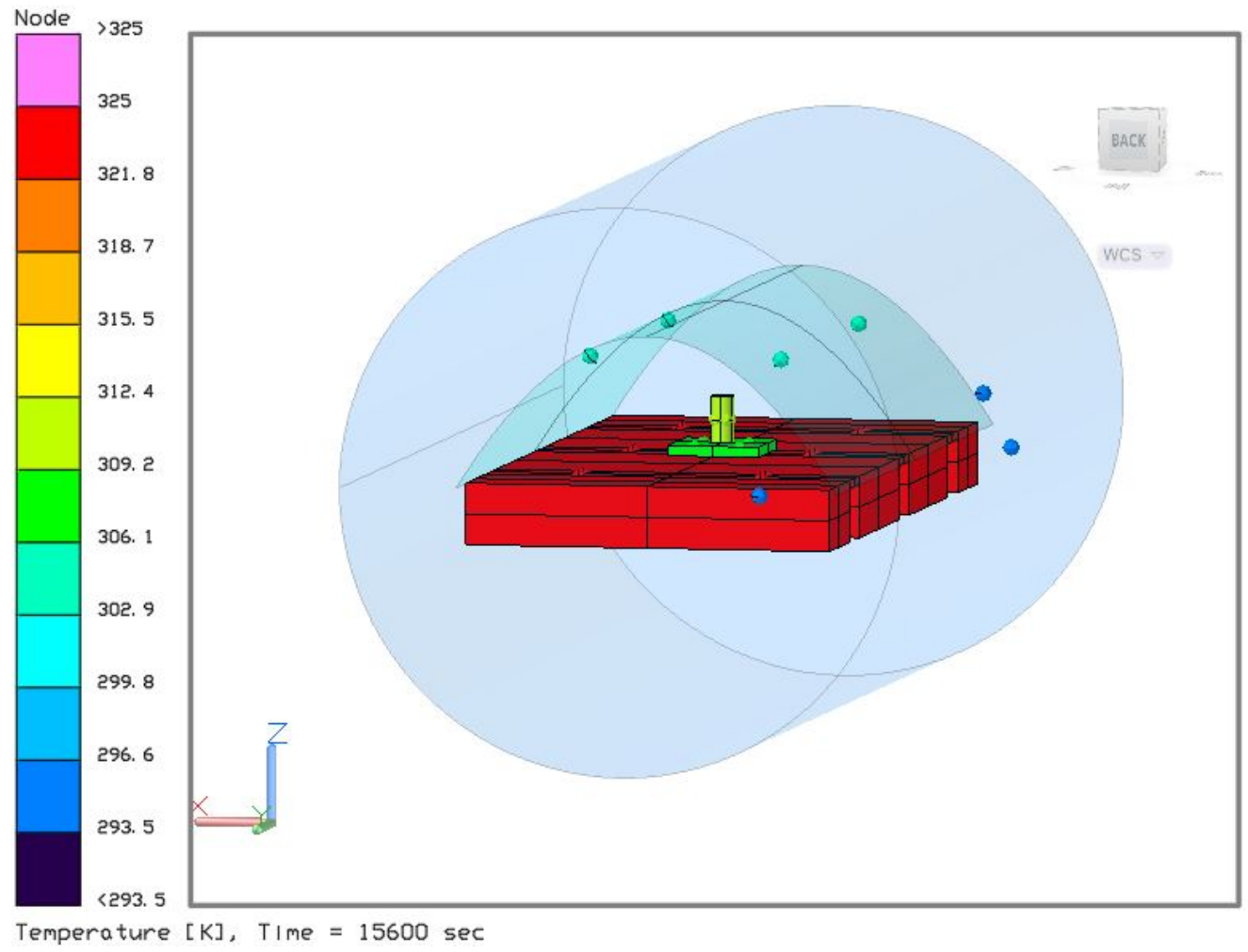

Figure 5.6: Brass $40{ }^{\circ} \mathrm{C}$ Simulation Heat Map 
Table 5.2 is a summary of the important values from this test.

Table 5.2: $40{ }^{\circ} \mathrm{C}$ Brass Cylinder Test

\begin{tabular}{|l|l|l|l|l|l|}
\hline Total & Average & Final & Final & Final & Final Sim- \\
Test & Chamber & Chamber & Platen & Cylinder & ulation \\
Time & Pressure & Temp. & $\begin{array}{l}\text { Temp. } \\
\left({ }^{\circ} \mathrm{C}\right)\end{array}$ & $\begin{array}{l}\text { Temp. } \\
\left({ }^{\circ} \mathrm{C}\right)\end{array}$ & $\begin{array}{l}\text { Cylinder } \\
\text { Temp. }\left({ }^{\circ} \mathrm{C}\right)\end{array}$ \\
\hline $4: 20$ & 68.6 & $39.8 \pm 1$ & $52 \pm 0.1$ & $38.6 \pm 1$ & 37.6 \\
\hline
\end{tabular}

\section{$5.360{ }^{\circ} \mathrm{C}$ Aluminum Test}

In the $40{ }^{\circ} \mathrm{C}$ tests, the platen temperature was set $12{ }^{\circ} \mathrm{C}$ above the desired chamber temperature. Since the desired temperature was not reached, a margin of $20{ }^{\circ} \mathrm{C}$ between the chamber and platen temperature was applied for the $60{ }^{\circ} \mathrm{C}$ tests.

Figure 5.7 shows the platen temperature, in green, settling at a steady state of 80 ${ }^{\circ} \mathrm{C}$. Even with the additional margin, the chamber temperature, in blue, was unable to reach $60{ }^{\circ} \mathrm{C}$. This is helpful information because it shows that the relationship between the two temperatures is not exactly linear. In order to reach a chamber temperature of $60{ }^{\circ} \mathrm{C}$, based on the relationship that was created from testing, the platen temperature would have to be set around $90{ }^{\circ} \mathrm{C}$. The final chamber temperature for this test was $54.9 \pm 1{ }^{\circ} \mathrm{C}$, which resulted in a cylinder temperature of $56.2 \pm 1{ }^{\circ} \mathrm{C}$. 


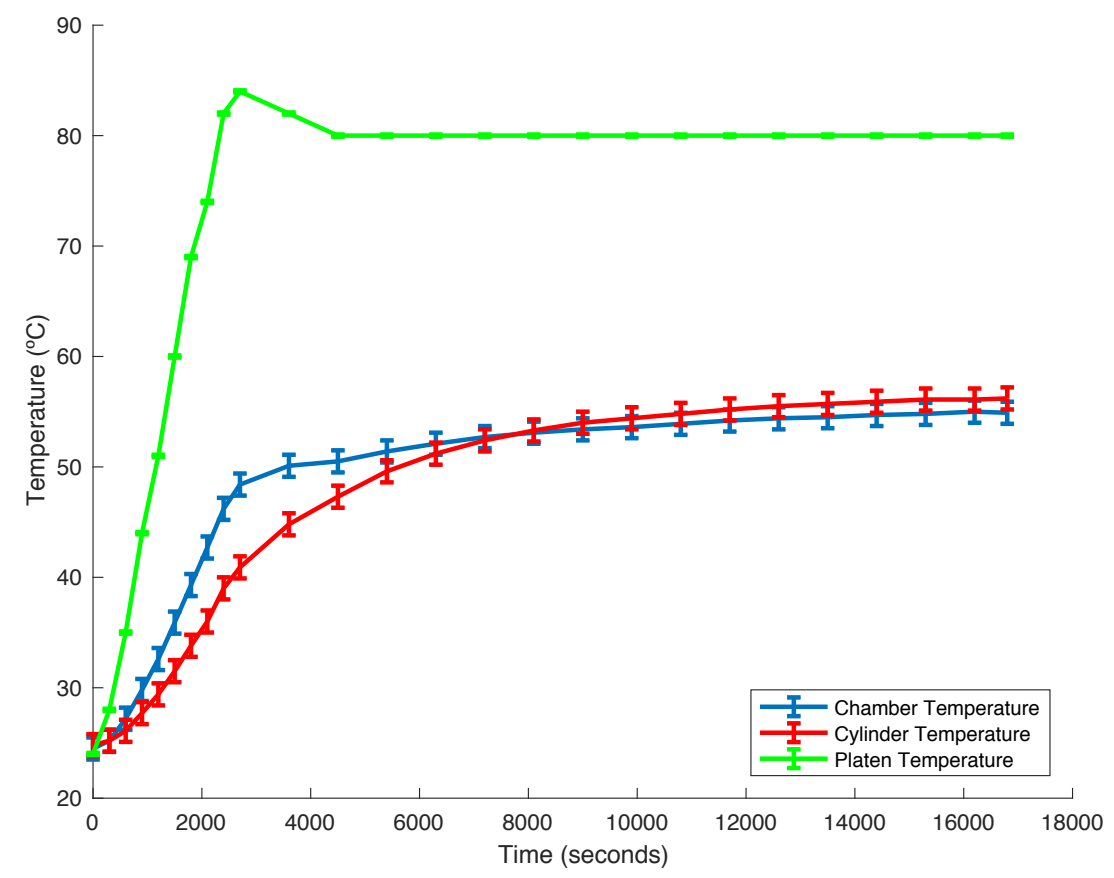

\section{Figure 5.7: Aluminum $60{ }^{\circ} \mathrm{C}$ Experimental Test}

The simulation predicted a slightly lower temperature than was experimentally produced, but still within the error bounds of the thermocouple error. Figure 5.8 shows the two curves with the same general trend in the beginning of the test with a sharp increase as the chamber heats up. However, as the platen reaches a steady state, the experimental test continues at a steeper slope than the simulation. This is the result, once again, of the heating process in the simulation. The simulation heating process is much less gradual compared to the experimental test. Therefore, the simulation reaches its steady state long before the experimental temperature. The final 1800 seconds of the experimental test shows a steady state being achieved allowing the final temperatures to be compared. The heat map for this test is shown in Figure 5.9. The shroud begins to play a larger role as more heat is trapped and radiated back towards the test article. 


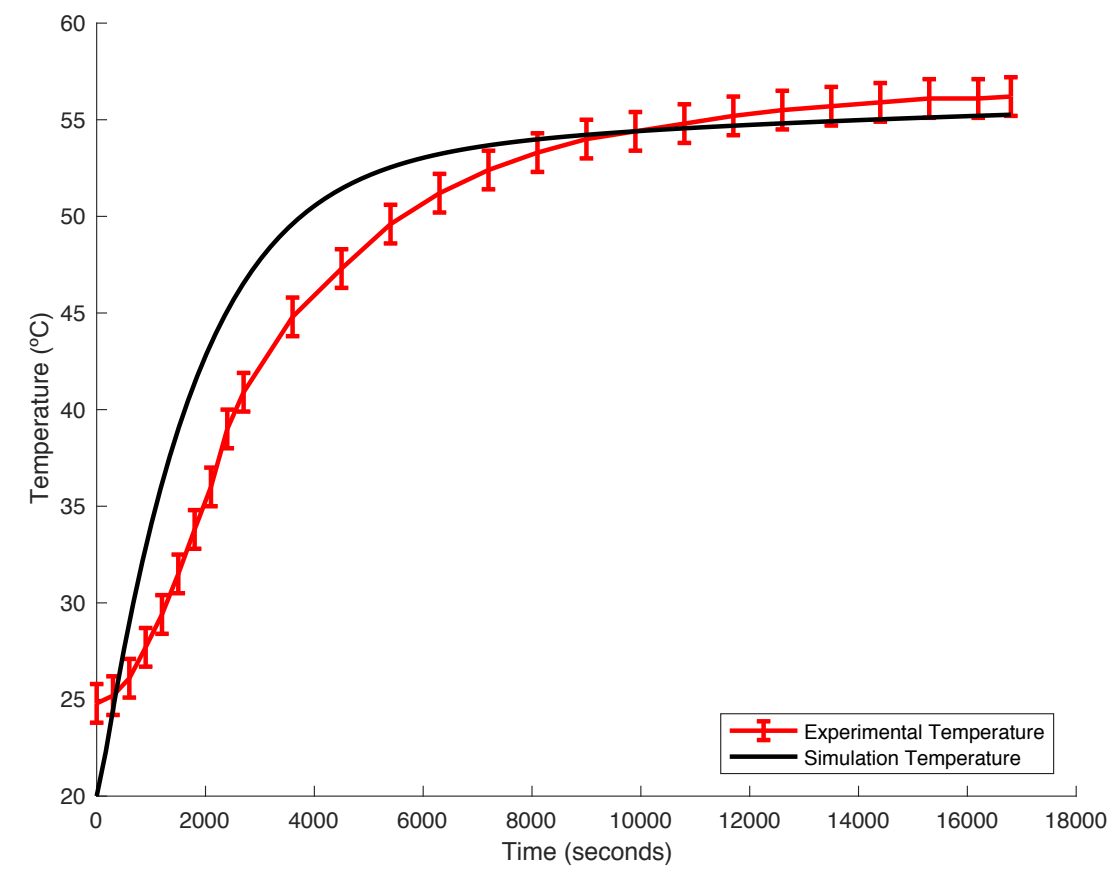

Figure 5.8: Aluminum $60{ }^{\circ} \mathrm{C}$ Test vs Simulation: Cylinder Temperature

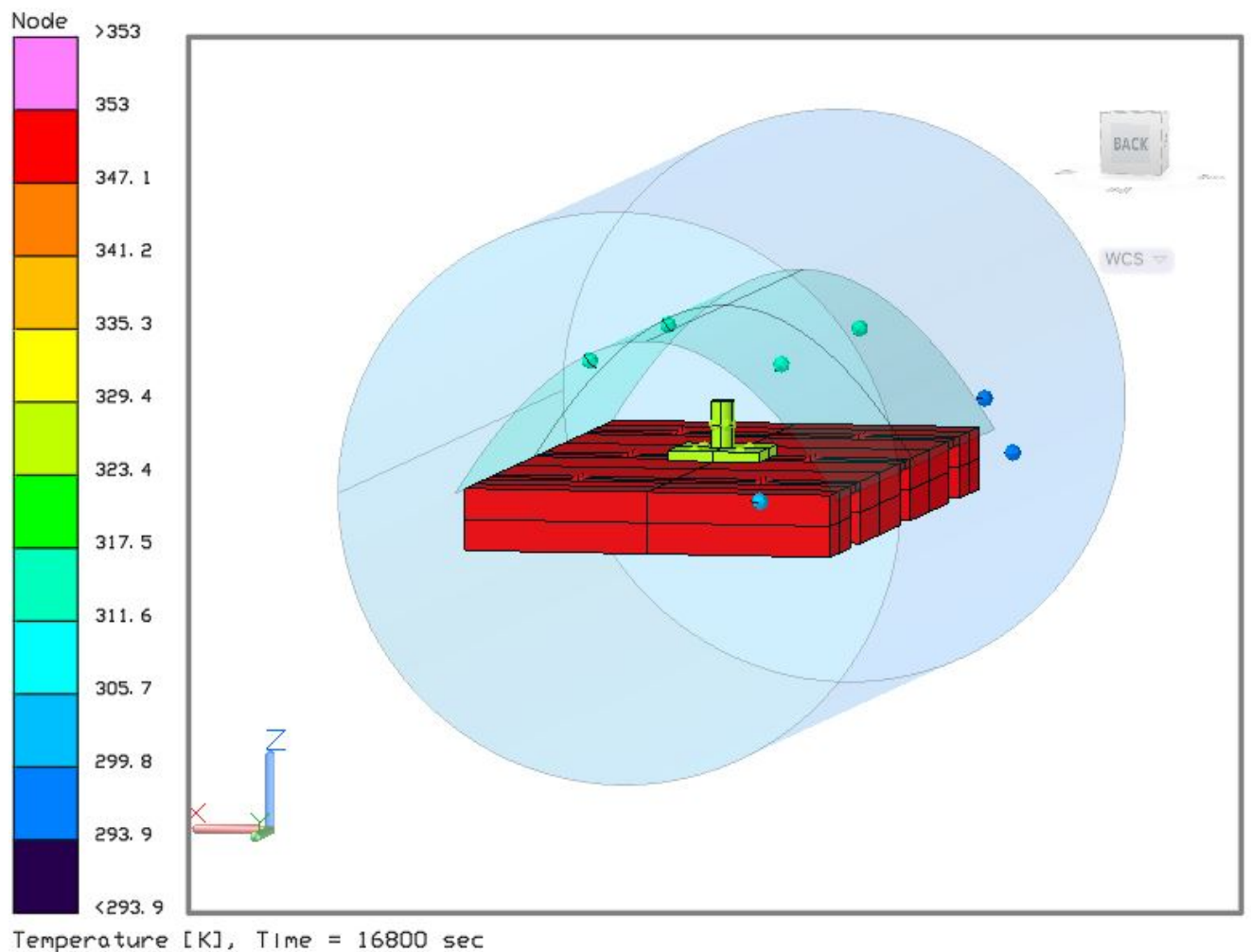

Figure 5.9: Aluminum $60{ }^{\circ} \mathrm{C}$ Simulation Heat Map 
Table 5.3 is a summary of the important values from this test.

Table 5.3: $60{ }^{\circ} \mathrm{C}$ Aluminum Cylinder Test

\begin{tabular}{|l|l|l|l|l|l|}
\hline Total & Average & Final & Final & Final & Final Sim- \\
Test & Chamber & Chamber & Platen & Cylinder & ulation \\
Time & Pressure & Temp. & $\begin{array}{l}\text { Temp. } \\
\left({ }^{\circ} \mathrm{C}\right)\end{array}$ & $\begin{array}{l}\text { Temp. } \\
\left({ }^{\circ} \mathrm{C}\right)\end{array}$ & $\begin{array}{l}\text { Cylinder } \\
\text { Temp. }\left({ }^{\circ} \mathrm{C}\right)\end{array}$ \\
\hline $4: 40$ & 46.92 & $54.9 \pm 1$ & $80 \pm 0.1$ & $56.2 \pm 1$ & 55.3 \\
\hline
\end{tabular}

\section{$5.460{ }^{\circ} \mathrm{C}$ Brass Test}

The platen profile was again set to $80^{\circ} \mathrm{C}$ to see if the repeatability of the chamber improved, worsened, or stayed the same as the temperature increased. The tests also had the same run time, so the final chamber temperatures should, ideally, have come out the same. Unfortunately, this was not the case. The final chamber temperature for this test was $53.5 \pm 1^{\circ} \mathrm{C}$ as compared to the $54.9 \pm 1{ }^{\circ} \mathrm{C}$ final chamber temperature recorded in the $60{ }^{\circ} \mathrm{C}$ aluminum test. Just like the $40{ }^{\circ} \mathrm{C}$ tests, the brass cylinder did not reach the same temperature as the aluminum cylinder due to the fact that the final chamber temperature was lower and given its internal properties. The graph of this data can be seen below in Figure 5.10. 


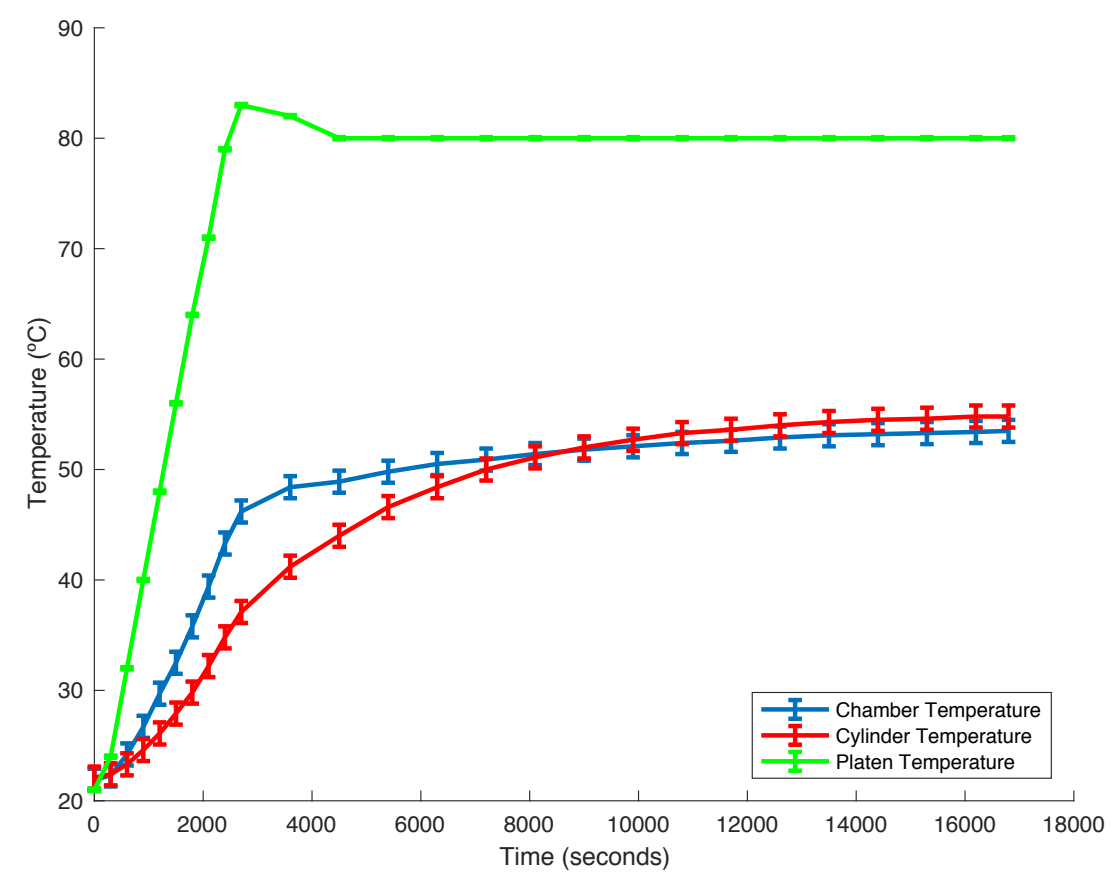

Figure 5.10: Brass $60{ }^{\circ} \mathrm{C}$ Experimental Test

Figure 5.11 shows that the simulation data did produce a resulting temperature within four tenths of a degree of the experimental temperature, which is very accurate for test modelling. The simulation, again, reached the steady state much faster than the experiment, but the slope of the two lines in steady state appear to be nearly the same. Due to the slightly higher chamber pressure, the chamber temperature did not reach the same final temperature as the aluminum $60{ }^{\circ} \mathrm{C}$ test. This resulted in a slightly lower cylinder temperature that corresponded with the simulation well. The heat map created by the simulation is shown in Figure 5.12. 


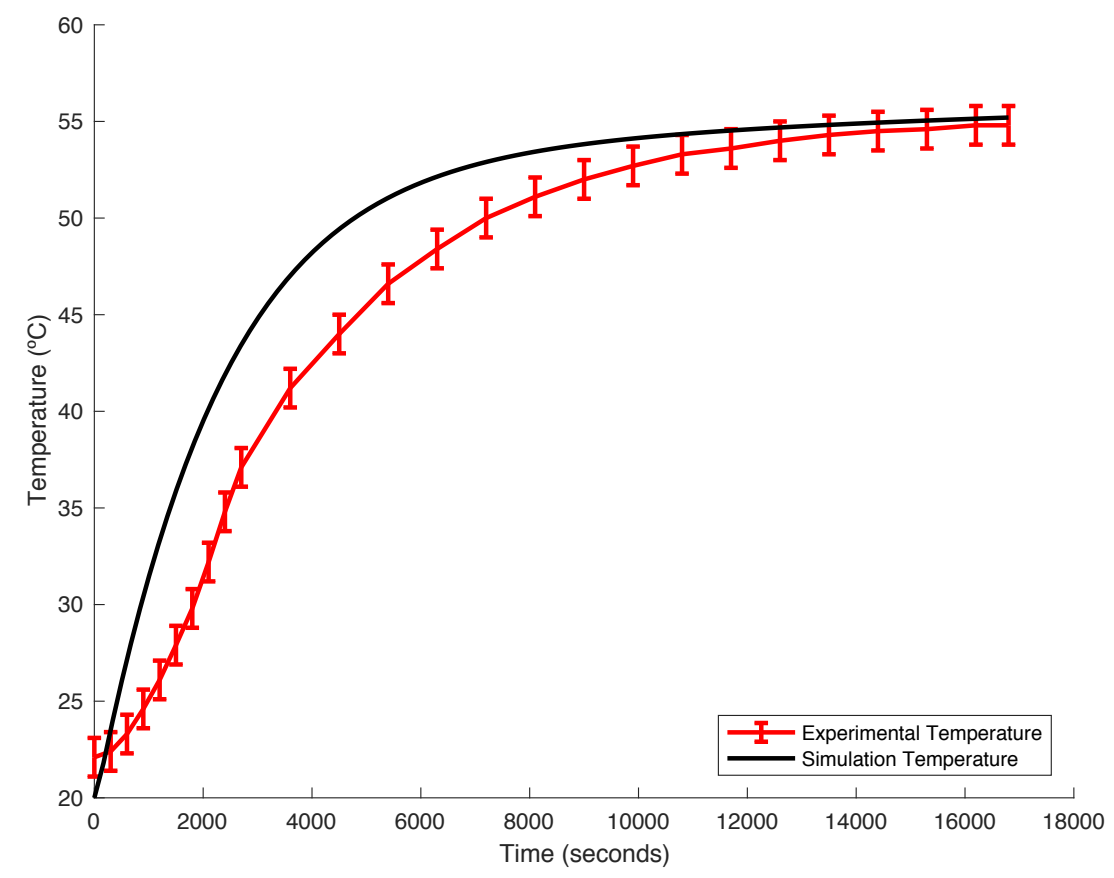

Figure 5.11: Brass $60{ }^{\circ} \mathrm{C}$ Test vs Simulation: Cylinder Temperature

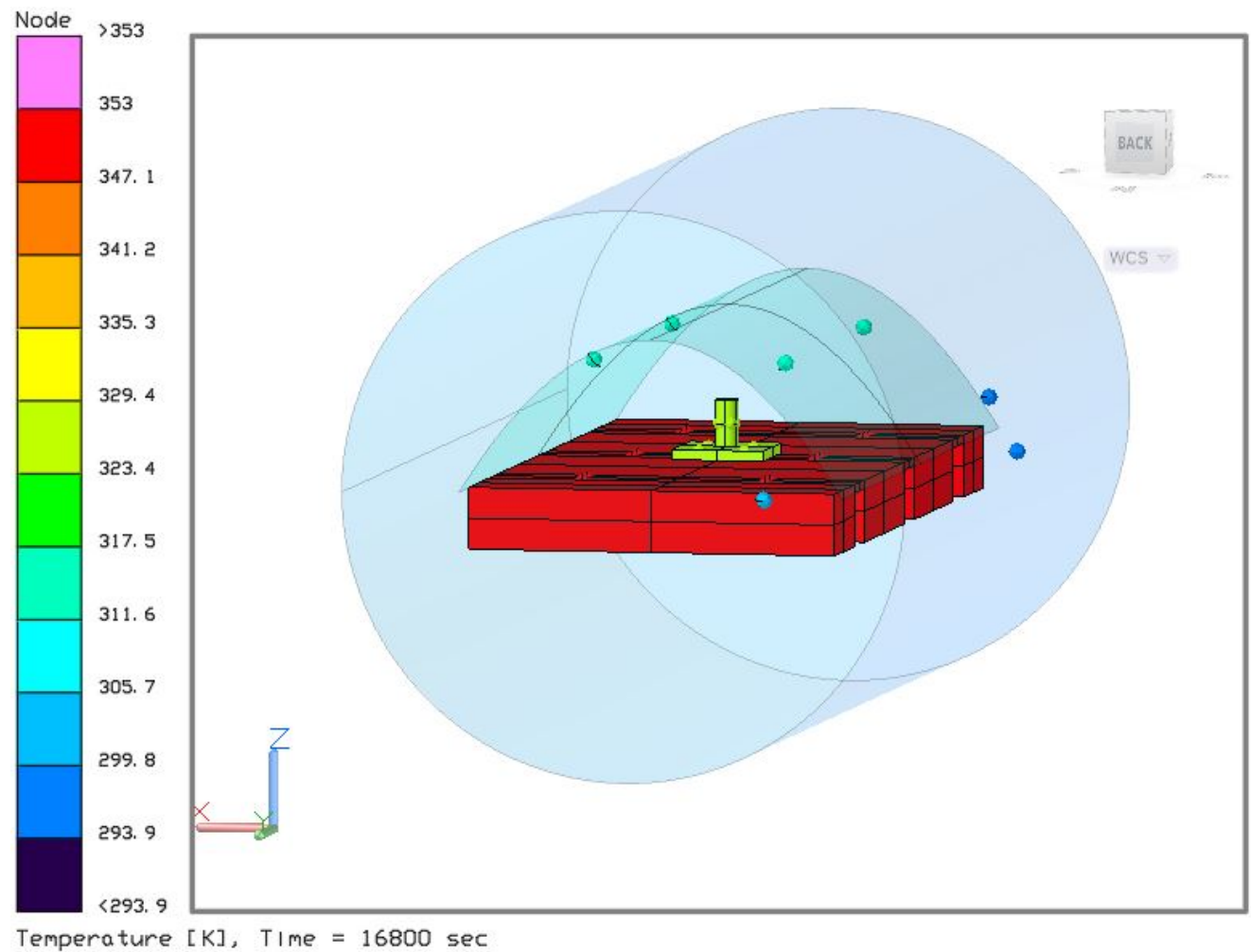

Figure 5.12: Brass $60{ }^{\circ} \mathrm{C}$ Simulation Heat Map 
Table 5.4 is a summary of the important values from this test.

Table 5.4: $60{ }^{\circ} \mathrm{C}$ Brass Cylinder Test

\begin{tabular}{|l|l|l|l|l|l|}
\hline Total & Average & Final & Final & Final & Final Sim- \\
Test & Chamber & Chamber & Platen & Cylinder & ulation \\
Time & Pressure & Temp. & Temp. & $\begin{array}{l}\text { Temp. } \\
\left({ }^{\circ} \mathrm{C}\right)\end{array}$ & $\begin{array}{l}\text { Cylinder } \\
\text { Th:mm })\end{array}$ \\
$(\mu$ Torr $)$ & $\left({ }^{\circ} \mathrm{C}\right)$ & $\left({ }^{\circ} \mathrm{C}\right)$ \\
\hline $4: 40$ & 56.88 & $53.5 \pm 1$ & $80 \pm 0.1$ & $54.8 \pm 1$ & 55.2 \\
\hline
\end{tabular}

\section{$5.580{ }^{\circ} \mathrm{C}$ Aluminum Test}

The final two tests to take place attempted to reach a final chamber temperature of $80{ }^{\circ} \mathrm{C}$. Using data from the previous tests, the simulation was run to determine what platen temperature would be required to meet the desired chamber temperature. Unfortunately, the required platen temperature was above the "Hot Limit" that is set on the chamber. The chamber has a "Hot Limit" and "Cold Limit" display on the control panel that each have separate thermocouples attributed to them. These controllers turn off heating or cooling capabilities for the chamber if the set point is at or above the limit. It is possible that the limits could be reprogrammed to different boundaries, however, to minimize risk in harming the chamber, this route was not taken. The hot limit that is currently set on the chamber is $115{ }^{\circ} \mathrm{C}$. Therefore, the platen profile was set to reach a steady state of $115^{\circ} \mathrm{C}$, which would provide the maximum chamber temperature possible. It was discovered that the hot limit is exceeded when the platen attempts to remain at that limit. Triggering the hot limit results in the chamber turning off the heat strips and decreasing the temperature of the platen, as seen in Figure 5.13. The profile was quickly reprogrammed to a set point of $114{ }^{\circ} \mathrm{C}$ and restarted in the ramp rate phase. The platen temperature promptly reached a steady state and the test continued as planned. 


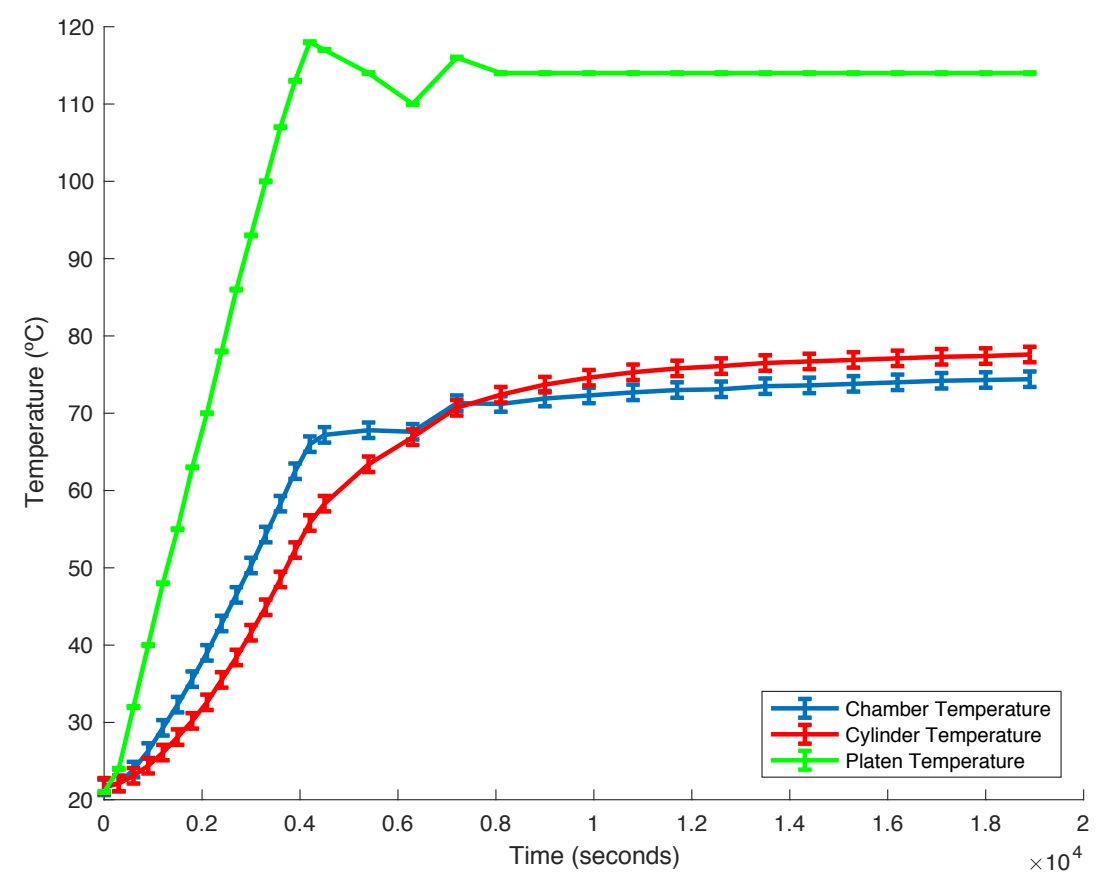

Figure 5.13: Aluminum $80^{\circ} \mathrm{C}$ Experimental Test

It is not certain how large of an effect the temperature decline had on the final temperature of the cylinder and the chamber. The simulation, presented in Figure 5.14 , predicted the temperature of the cylinder to be slightly higher, so it is possible that there was a noticeable effect. The final simulation cylinder temperature was outside of the error bounds for the experimental temperature by $0.03{ }^{\circ} \mathrm{C}$. At higher temperatures, the simulation does not track the initial temperature increase for the experiment. The slopes of the two lines are similar, however, the simulation temperature is less gradual at the beginning of the test. The heat map for this test is shown in Figure 5.15. By collecting more heat, the shroud plays a larger role in the final chamber and cylinder temperatures. 


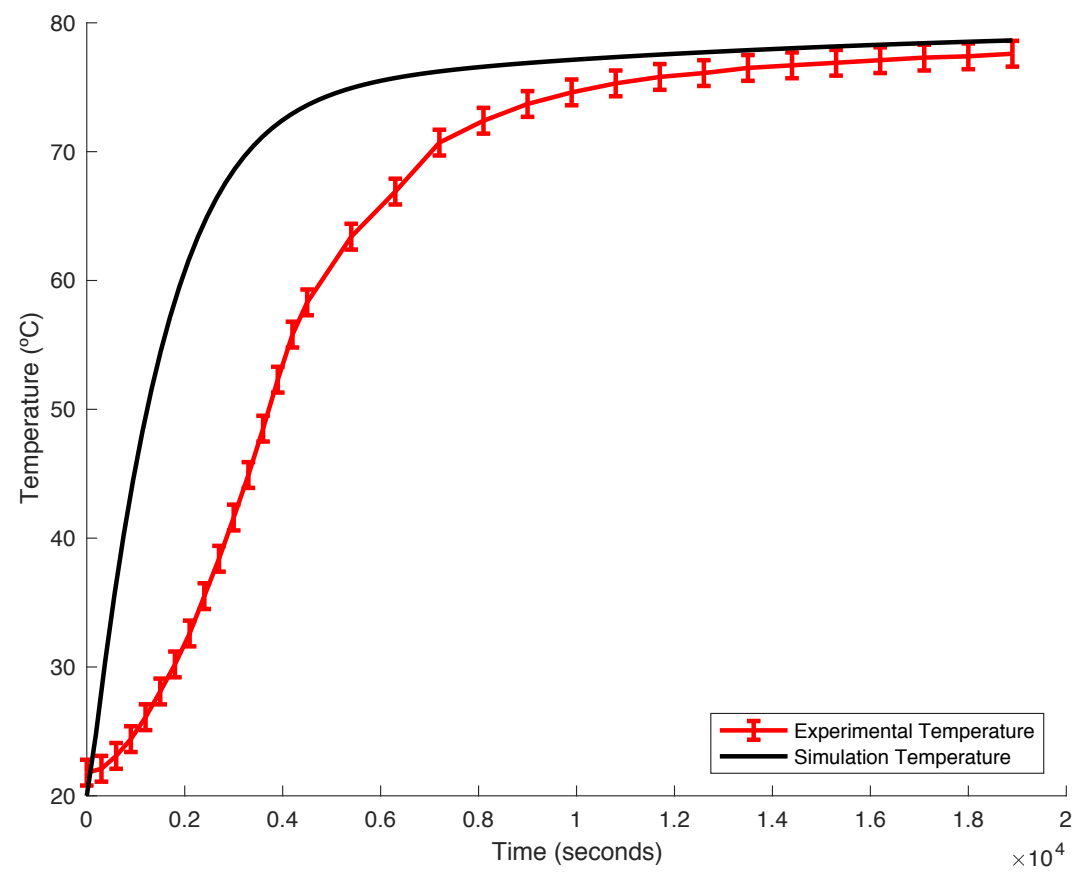

Figure 5.14: Aluminum $80{ }^{\circ} \mathrm{C}$ Test vs Simulation: Cylinder Temperature

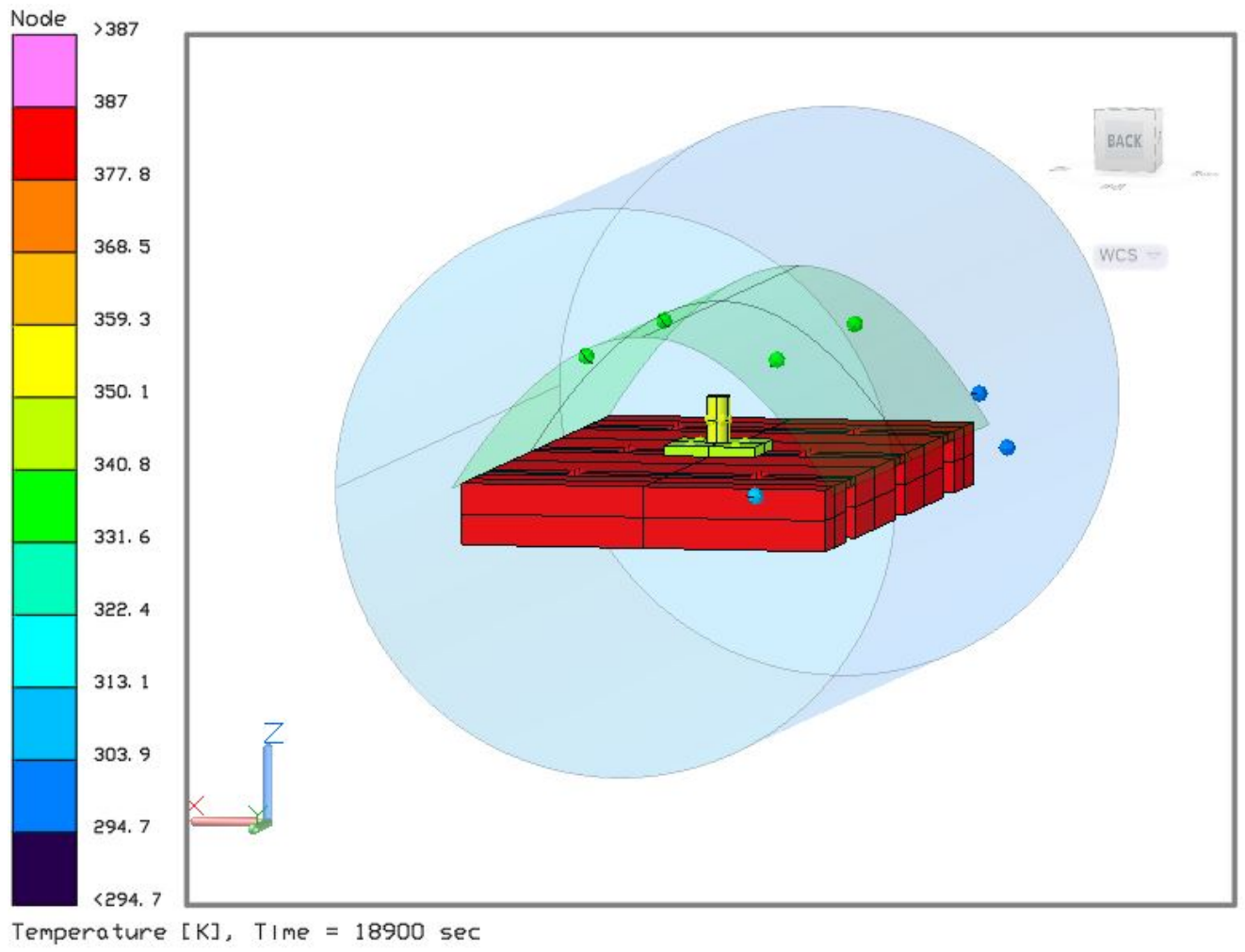

Figure 5.15: Aluminum $80{ }^{\circ} \mathrm{C}$ Simulation Heat Map 
Table 5.5 is a summary of the important values from this test.

Table 5.5: $80{ }^{\circ} \mathrm{C}$ Aluminum Cylinder Test

\begin{tabular}{|l|l|l|l|l|l|}
\hline Total & Average & Final & Final & Final & Final Sim- \\
Test & Chamber & Chamber & Platen & Cylinder & ulation \\
Time & Pressure & Temp. & $\begin{array}{l}\text { Temp. } \\
\left({ }^{\circ} \mathrm{C}\right)\end{array}$ & $\begin{array}{l}\text { Temp. } \\
\left({ }^{\circ} \mathrm{C}\right)\end{array}$ & $\begin{array}{l}\text { Cylinder } \\
\text { Temp. }\left({ }^{\circ} \mathrm{C}\right)\end{array}$ \\
\hline $5: 15$ & 54.71 & $74.4 \pm 1$ & $114 \pm 0.1$ & $77.6 \pm 1$ & 78.63 \\
\hline
\end{tabular}

\section{$5.680{ }^{\circ} \mathrm{C}$ Brass Test}

With more knowledge about how the hot limit works, this profile was run to a platen temperature of $114{ }^{\circ} \mathrm{C}$, the same as the reprogrammed profile from the $80{ }^{\circ} \mathrm{C}$ aluminum test. This test was the first time the platen temperature did not settle right at the set point when steady state was first achieved. After the PID controller kicked in as it normally does, the temperature was brought back down to $113{ }^{\circ} \mathrm{C}$ for over two hours of the four hour soak. It was not until this point that the platen did ultimately achieve the set point temperature of $114^{\circ} \mathrm{C}$. By observing the data in Figure 5.4, it does not appear that there were any major effects on the final temperatures of the chamber and the cylinder. In fact, the brass cylinder for this test reached a higher final temperature, at $79.2 \pm 1^{\circ} \mathrm{C}$, than the aluminum cylinder. 


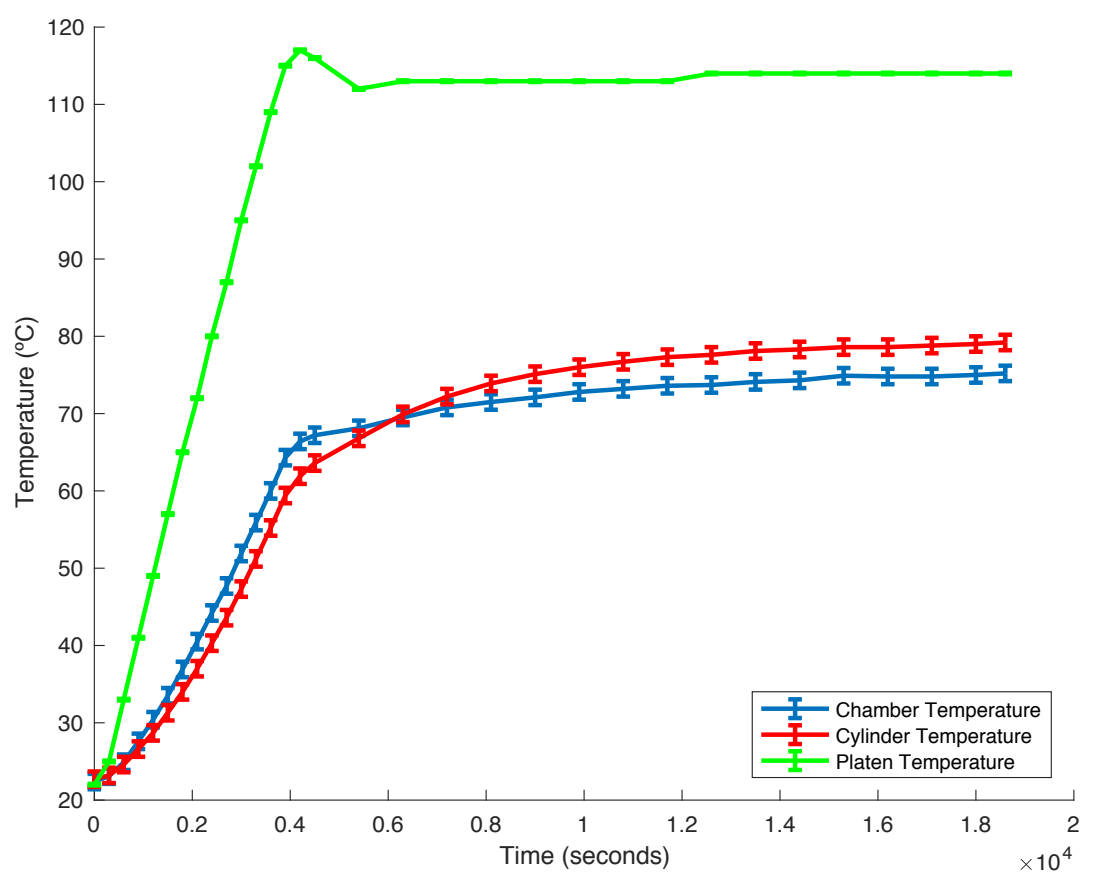

Figure 5.16: Brass $80{ }^{\circ} \mathrm{C}$ Experimental Test

The simulation, shown in Figure 5.17, predicted a slightly lower final temperature for the brass cylinder but stayed within the error bounds. As in the aluminum simulation for this test profile, the simulation does not ascend gradually like the experiment does, but reaches the same end point. Of all of the simulation versus experimental plots, this was the closest one in terms of the overlap of the two lines. As the platen profile temperature was increased, the simulation was more accurate. It is not clear at this point why the lower temperature simulations do not correspond as well as the higher temperature simulations. This is definitely something that will need to be investigated further to create a higher fidelity model of the chamber. The heat map in Figure 5.18 also produced similar results to the $80{ }^{\circ} \mathrm{C}$ aluminum simulation. 


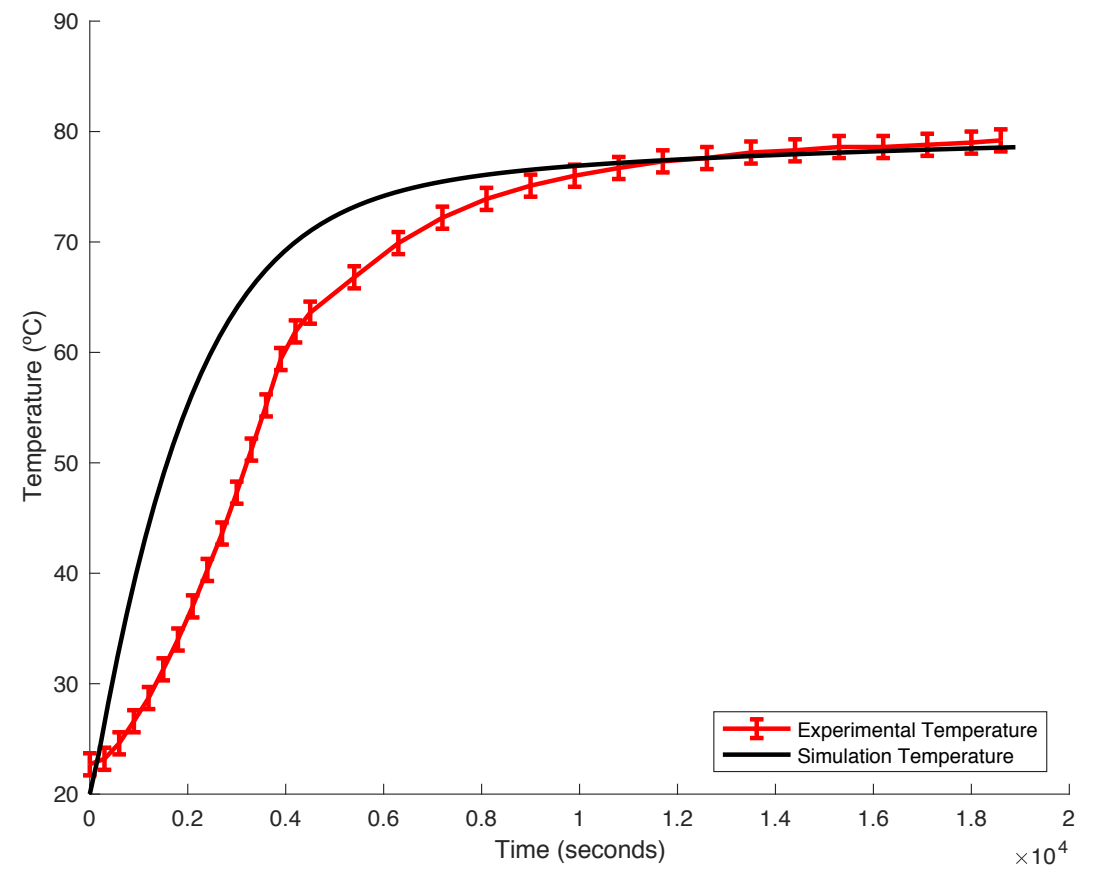

Figure 5.17: Brass $80^{\circ} \mathrm{C}$ Test vs Simulation: Cylinder Temperature

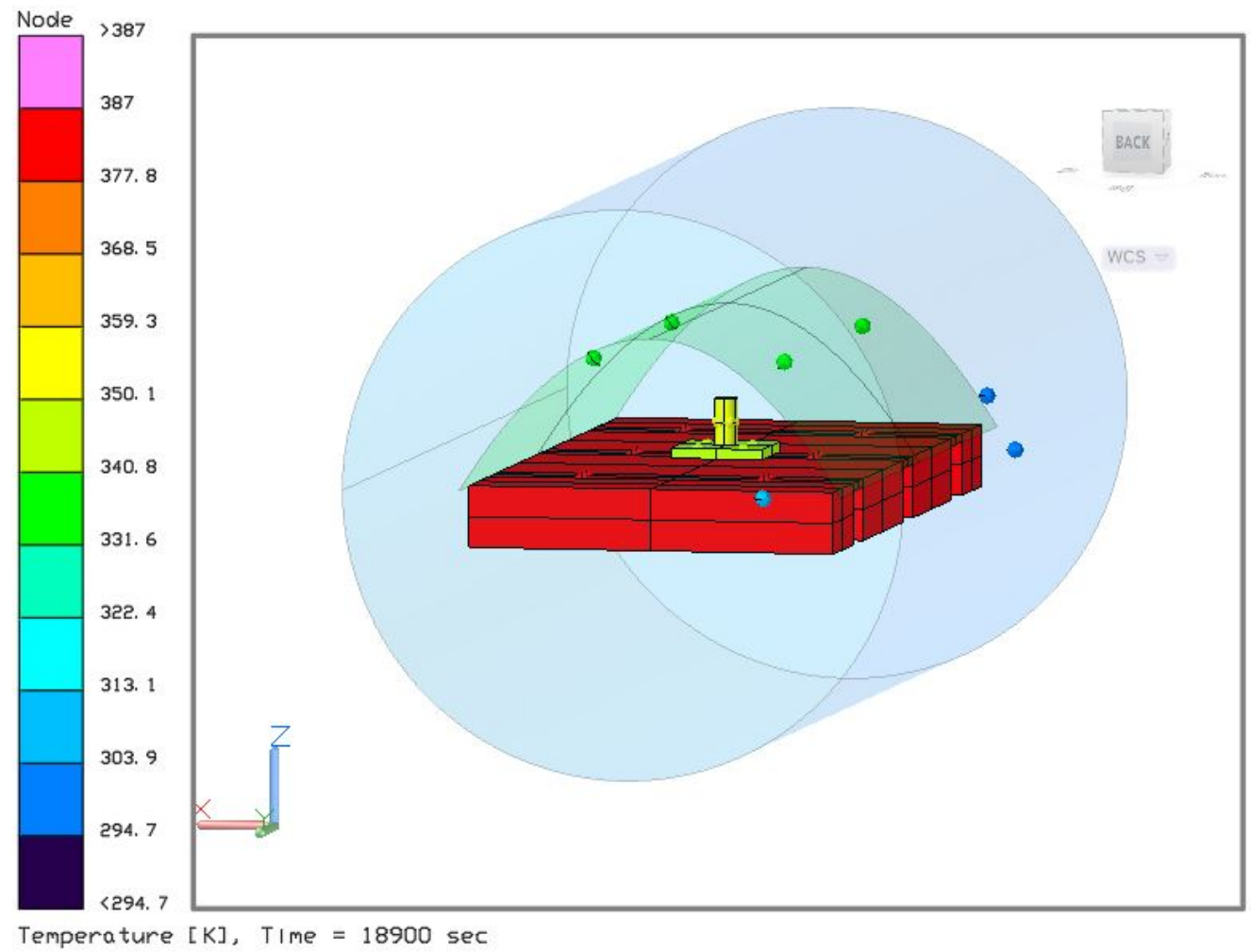

Figure 5.18: Brass $80{ }^{\circ} \mathrm{C}$ Simulation Heat Map 
Table 5.6 is a summary of the important values from this test.

Table 5.6: $80{ }^{\circ} \mathrm{C}$ Brass Cylinder Test

\begin{tabular}{|l|l|l|l|l|l|}
\hline Total & Average & Final & Final & Final & Final Sim- \\
Test & Chamber & Chamber & Platen & Cylinder & ulation \\
Time & Pressure & Temp. & $\begin{array}{l}\text { Temp. } \\
\left({ }^{\circ} \mathrm{C}\right)\end{array}$ & $\begin{array}{l}\text { Temp. } \\
\left({ }^{\circ} \mathrm{C}\right)\end{array}$ & $\begin{array}{l}\text { Cylinder } \\
\text { Temp. }\left({ }^{\circ} \mathrm{C}\right)\end{array}$ \\
\hline $5: 10$ & 49.56 & $75.2 \pm 1$ & $114 \pm 0.1$ & $79.2 \pm 1$ & 78.58 \\
\hline
\end{tabular}

\subsection{Chamber Pressure-Temperature Correlation}

While looking through the data for all experiments, the tests that were conducted with lower average chamber pressures ultimately reached higher temperatures for both the cylinder and the chamber, with the exception of the chamber temperature in the brass $40{ }^{\circ} \mathrm{C}$ test. This result is not surprising as radiation is far more effective with fewer air particles in the chamber. Should this testing be repeated in the future, more emphasis on ensuring similar chamber pressures should be present.

\subsection{Plexigals Thermal Isolation}

For the lower temperature tests, the Plexigals plate did a farily good job of isolating the cylinder from the platen temperature due to its low conductivity. However, as the platen was increased to higher temperatures, the Plexigals plate was not as effective. Looking at the heat maps of the higher temperature simulation models, it was clear that the Plexiglas was reaching higher temperatures than expected and imparting some of that heat to the test cylinder through conduction. The extra heat load on the cylinder caused it to reach higher a higher temperature than the chamber in most tests. 


\subsection{Platen-Chamber Temperature Relationship}

As mentioned in the previous section, the relationship between the platen temperature and resulting chamber temperature is not perfectly linear. Figure 5.19 shows that relationship based on all of the data points collected from testing. The first data point shown at $40{ }^{\circ} \mathrm{C}$ for the platen temperature was found in initial testing when it was unclear what the temperature the control panel was displaying. Over time, as more data is collected, the best fit line for this plot will become more accurate.

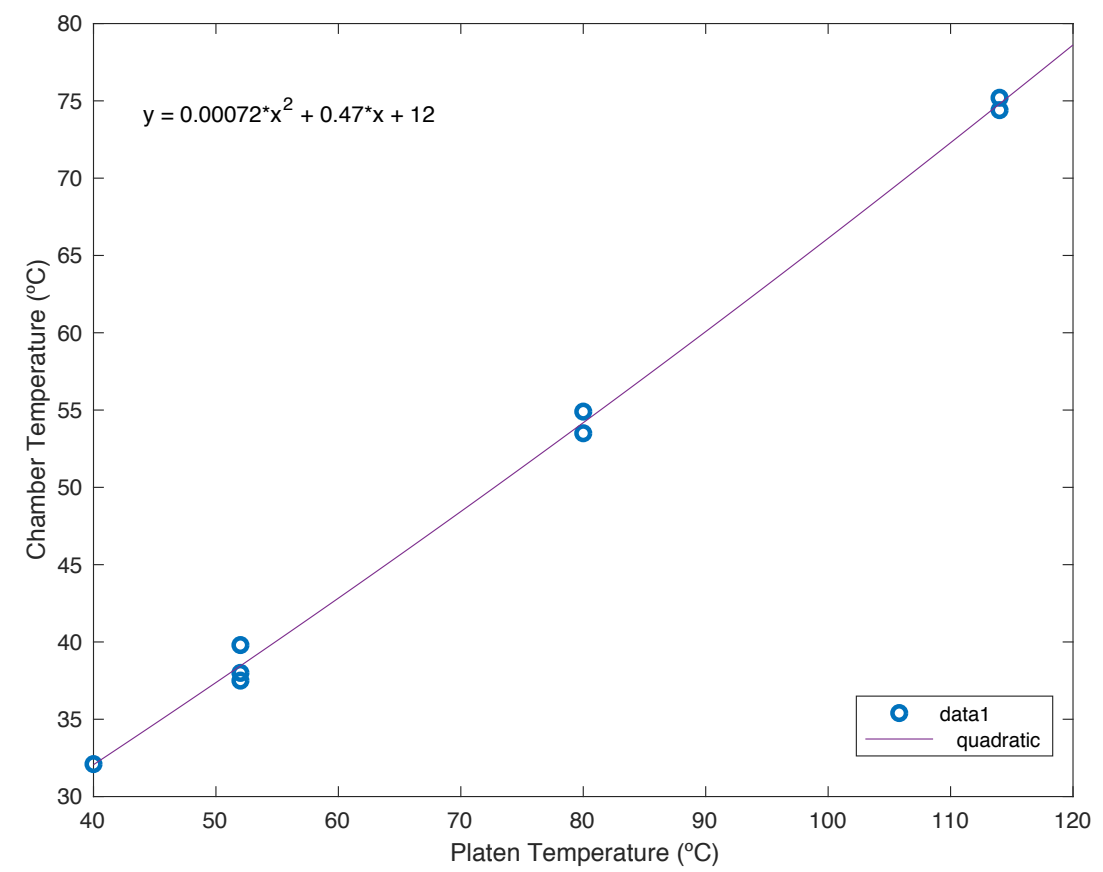

Figure 5.19: Chamber and Platen Temperature Relationship 


\section{Chapter 6}

\section{CONCLUSION}

Successful tests were completed to prove the heating capabilities and repeatability of the chamber. Three heating profiles were programmed into the chamber controller to test a variety of data points. For each of the profiles, two tests were run with different test articles. The two test articles are small black coated cylinders made of aluminum and brass. The black coating resulted in similar cylinder temperature results for each test of the same profile with slight variations due to the thermal properties of the cylinder. The largest difference between the two cylinder temperatures was $2.2 \pm 2{ }^{\circ} \mathrm{C}$, which occurred during the $80{ }^{\circ} \mathrm{C}$ heating profile. A relationship, based on minimal data, was plotted between the programmed platen temperature and the chamber temperature. This will allow future testing to be more accurate and conducted at the appropriate temperature.

A simulation was created in Thermal Desktop to model the heating profiles and the response each cylinder would have based on the material type. The cylinder temperature data was recorded from the simulation and plotted against the experimental results. A majority of the time, the simulation was accurate and within the error bounds of the thermocouple. When the predicted temperature from the simulation was outside of those bounds, it was never by more than $0.9{ }^{\circ} \mathrm{C}$.

Throughout the course of the refurbishment and testing process, the chamber performed very well. There was no breakdown of major parts or testing equipment that required long downtime or extensive repairs. Compared to the HVEC TVAC, the blue chamber is much more straightforward to operate from a procedure and maintenance standpoint. There are not nearly as many problems with the blue chamber that will cause testing to be delayed. The robustness of this chamber allows it to easily be 
incorporated into undergraduate learning opportunities as well as graduate research and even small satellite or satellite component testing. 


\section{Chapter 7}

\section{FUTURE WORK}

Though much work has been done to refurbish the chamber, there is still a lot left to do.

\subsection{Cooling System}

The most important work that needs to be done is getting the cooling system up and running. The internal plumbing for the chamber looks to be in good shape, but additional hoses will need to be attached to the chamber inlet and outlet. There has been some discussion about where the $\mathrm{LN}_{2}$ will be stored and where it will vent after passing through the chamber, but no decision has been made quite yet. $\mathrm{LN}_{2}$ is safe enough to store and vent inside the lab if there is proper air conditioning running. At this point, since the lab does not have air conditioning, Cal Poly risk management will likely want the $\mathrm{LN}_{2}$ stored outside and vented outside after passing through the chamber. If this is the case, hoses that are long enough to reach the chamber from the door of the lab will be required. Also, after speaking with Dave Pignatelli from Cal Poly CubeSat, it was recommended that external venting be done to the roof of the lab. This would require Cal Poly Facilities Services to get involved so that might

need to get started right away. Just in case the chamber has to move around the lab, it would be ideal to have the vent to the roof be fixed and have an attachable hose to the chamber instead of fixing the chamber in one spot. The cooling system is required to run full cycle testing, the main purpose of the chamber.

After heating the chamber up and transitioning to the cold section of the profile, there will be a lot of heating energy stored in both the platen and the shroud. This 
energy must be dissipated in order to reach the cold temperatures that are desired. One way to accomplish this task is to paint the inside of the shroud as well as the platen with black paint. This will cause the hot energy to radiate much faster and the cooling system will be more effective. To supplement the black paint, wrapping the outside of the shroud will aide the heating and cooling process.

\subsection{Switch Controlled Venting System}

When the testing procedure is complete and the chamber has returned to nominal temperatures, the venting valve can be opened to bring the chamber back to atmospheric pressures. The current valve on the chamber is controlled by manually turning the venting valve to open and close it. Since everything internal to the chamber has continued to work properly, the only reason the side panels are not on the chamber, is to have access to that valve. By implementing a venting valve that can be controlled by a switch on the control panel, it will make the chamber much simpler for students to run.

\subsection{DAQ System}

Lauren Glenn put together a DAQ system as part of her thesis. The system is able to take outputs from thermocouples and feed them to the computer in the lab. The thermocouple wires from the HVEC vacuum chamber are inserted directly into an electronics board. This same layout can be applied directly to the blue chamber. Instead of connecting the double male thermocouple wire that connects the blue chamber to the thermocouple reader, a single male wire can be connected to the board, and thus the computer. This will allow more accurate data to be obtained and the tester will not be required to record measurements at every time interval. 


\subsection{Refine Thermal Desktop Model}

The model in Thermal Desktop does a good job of predicting the final temperature of the cylinder, but it can still become more accurate. The simulation does not quite track the data as it increases in temperature, so there is room for improvement there. This is likely the result of how the model had to be created. Experience in AutoCad modelling was very minimal, so the platen had to be modelled as seven separate blocks instead of one block with extrusions. Fixing the platen model should allow higher accuracy simulations. The heat strips in the simulation are blocks with very high specific heat and boundary nodes that allow the temperature of the block to be set. If there is a way to make the blocks heaters, this could improve accuracy as well. The simulation has not been run on cold cases, therefore its response to decreasing temperature is unknown. The cold cases would also require full thermal cycling to verify the simulation results. Finally, a heat map that includes all parts of the testing system, including the electrical wires, will provide more accurate results because it is likely that even the wires can affect the final outcome of the test.

\subsection{Platen Temperature Gradient}

In this thesis, the platen temperature was assumed to be constant across the whole surface to simplify the simulation model. This is not quite accurate as the platen should be hotter closer to the heat strips. Measuring the platen temperature at different points across the face will provide a deeper insight into how the chamber heats up and how the simulation should be altered. 


\subsection{Turbo Pump}

After using the turbo pump and turning it off, the mechanical pump is required to run until the user can be sure the turbo has stopped spinning. This can take anywhere from 15-20 minutes to complete. Currently, there is no way to tell what the RPMs of the turbo pump are, but a display could be installed to show how fast it is moving. This is another addition that would increase the safe and responsible use by students.

Additional safeguards can be installed to cut the power to the turbo pump should anything unexpected happen. This way, if there is a leak, for example, the turbo pump will automatically turn off if the pressure gets too high and is not being monitored by the user.

\section{7 $\quad$ Thermocouples}

The chamber controller is designed to display the temperature of the platen. It could be possible that another thermocouple could be attached and displayed by the controller. This would need further investigation to see if this is possible. Furthermore, the controller manual shows that there is a $0.1{ }^{\circ} \mathrm{C}$ error on what is displayed. There may be an additional error on the thermocouple wire itself as well, but that is still unknown.

There are smaller thermocouple wires that exist and can provide more accurate data for the user. The larger wires take longer to heat and cool and can alter the results of the test. 


\subsection{Chamber Shroud}

More investigation into the shroud temperature profile is required as well. The simulation produced temperature results for the shroud shown in Appendix E. The higher temperature tests caused the shroud to get hotter and radiate more heat to the cylinder. Whether there is conduction between the platen and the shroud could have a significant impact on testing. The view factor between the test article, the

platen, and the shroud can also be looked at in order to have a better understanding of the effect of the shroud.

\subsection{Test Setup}

For the higher temperature tests, the Plexiglas plate was not as effective for thermally isolating the test article. A test stand that is isolated from the platen wont allow conduction to take place and better simulate the space environment. Based on the dimensions of the test section, a test stand should be acquired for the chamber. 


\section{BIBLIOGRAPHY}

[1] C\&R Technologies. Users Manual Thermal Desktop: Version 6.0, 2017.

[2] David G. Gilmore. Spacecraft Thermal Control Hand Book, American Institute of Aeronautics and Astronautics, Inc., 2002.

[3] E. M. Sparrow, R. D. Cess. Radiation Heat Transfer, Augmented Edition, Hemisphere Publishing Corporation, 1970.

[4] Electronic Temperature Instruments. Emissivity Table [Online] Available: https://thermometer.co.uk/img/documents/emissivity_table.pdf, [Accessed 4 February 2018].

[5] Engineering Toolbox, (2003). Aluminum - Radiation Heat Emissivity. [Online] Available: https://www.engineeringtoolbox.com/radiation-heat-emissivityaluminum-d_433.html, [Accessed 4 February 2018].

[6] Engineers Edge. Thermal Properties of Metals, Conductivity, Thermal Expansion, Specific Heat. [Online] Available: https://www.engineersedge.com/properties_of_metals.htm, [Accessed 4 February 2018].

[7] GSFC-STD-7000A. GENERAL ENVIRONMENTAL VERIFICATION STANDARD (GEVS) For GSFC Flight Programs and Projects. NASA Goddard Space Flight Center,Greenbelt, Maryland, 2013.

[8] International Polymer Solutions. Thermal Properties of Acrylic PMMA [Online] Available: http://www.ipolymer.com/pdf/Acrylic.pdf, [Accessed 4 February 2018]. 
[9] J. Wert, D. Everett, J. Puschell. Space Mission Engineering: The New SMAD, Microcosm Inc., 2011.

[10] John H. Henninger, NASA Reference Publication 1121, (1984). Solar Absorptance and Thermal Emittance of Some Common Spacecraft Thermal-Control Coatings. [Online] Available: https://ntrs.nasa.gov/archive/nasa/casi.ntrs.nasa.gov/19840015630.pdf, [Accessed 4 February 2018].

[11] Lauren M. Glenn. Refurbished And 3D Modeled Thermal Vacuum Chamber, San Luis Obispo: California Polytechnic State University, 2017.

[12] Learn Engineering. Single Phase Induction Motor, How it works?, [Online] Available:https://www.youtube.com/watch?v=awrUxv7B-a8 , [Accessed 27 January 2018].

[13] Leybold Vacuum. Turbovac Operating Instructions, 2006.

[14] Leybold Vakuum. Turbotronik NT 20 Electronic Frequency Converter, 1997.

[15] M. Moran, H. Shapiro, D. Boettner, M. bailey. Fundamentals of Engineering Thermodynamics, John Wiley Sons, Inc., 2011.

[16] Vincent L. Piscine. The Space Environment and its Effects on Space Systems, American Institute of Aeronautics and Astronautics, Inc. , 2008.

[17] Watlow Winona. Series F4S/D User's Manual, 2011. 


\title{
APPENDICES
}

\author{
Appendix A \\ CHAMBER OPERATING PROCEDURE
}

Operation of this chamber is very straightforward. The steps have been outlined below.

\section{Mechanical Pump Operation}

1. Ensure the chamber is plugged into the outlet on the wall.

2. Flip the main power switch "ON"

3. With the door and venting valve closed, flip the mechanical pump switch up to turn it on

4. To turn it off, flip the mechanical switch down

5. Open the vent valve to return the chamber to atmospheric pressure

6. Turn off the chamber

\section{Turbo Pump Operation}

1. Follow steps 1-3 in Mechanical Pump Operation to turn on the mechanical pump.

2. After the chamber has reached 20 mTorr or lower, press the start button on the Turbotronik NT 20 control panel

3. To turn off the turbo, press the stop button 
4. Wait 15-20 minutes before turning off the mechanical pump and following steps 4-6 in the Mechanical Pump Operation

\section{Convectron Gauge Controller}

1. Ensure the chamber is plugged into the outlet on the wall.

2. Flip the main power switch "ON"

3. Press the "ON" button on the Granville-Phillips 307 Vacuum Gauge Controller

- This will immediately show the pressure for the chamber and roughing line

4. Press the "ON" button again to turn the controller off

\section{Ion Gauge Controller}

1. Follow steps 1-3 in the Convectron Gauge Controller proceudre

2. ONLY when the chamber convectron gauge readout shows all zeros after the turbo has been activated, press the "IG1" button to activate the ion gauge

- The ion gauge should light up

3. BEFORE turning off the turbo pump, press "IG1" again to turn off the ion gauge

4. Press the "ON" button again to turn the controller off 


\section{Appendix B}

\section{CHAMBER PROFILES}

The chamber arrived with profiles already programmed into the controller. These profiles were the first ones used to test the heating capabilities of the chamber. For the experimental testing, profiles were manually designed using the profiles in the chamber as reference.

The heating profiles for the experiments consisted of only three steps: Ramp Rate, Soak, and End. The following procedure requires on that the main power of the chamber be turned on. The control panel will take a second to turn on, and the chamber controller will show the "Main Page." Follow the steps below to create and run a profile. One important note: to go back to a previous prompt or page, hit the Left Arrow button.

\section{Creating a Profile}

1. Turn on the "MAIN POWER" switch

2. Use the Down Arrow button and scroll down to "Go To Profiles", then press the Right Arrow button

- This is the main profile page where profiles can be created, edited, or deleted.

3. Select the Right Arrow on "Create Profile"

4. A prompt will come up saying "Choose to Name", scroll down and press the Right Arrow on "Yes"

5. Use the Up and Down Arrows to adjust the characters and the Right and Left Arrows to switch between characters. 
- Keep pressing the Right Arrow when naming is complete until the next page comes up

6. This page is where the first step of the profile is chosen. Autostart has not been tested as the date and time in the chamber would need to be reprogrammed. Choose either "Ramp Rate" or "Ramp Time" for the first step and press the Right Arrow.

- Ramp Rate was used for all of the experiments in this thesis and no issues arose, so that would be the recommended option and the one used in this procedure

7. The next prompt asks whether the step should wait for a specific event or not, choose "Step does not wait" and press the Right Arrow button

8. Enter a Ramp Rate of $5{ }^{\circ} \mathrm{C} /$ minute and press the Right Arrow button

- $5{ }^{\circ} \mathrm{C} /$ minute was used for all of the experiments, a different ramp rate can be used if desired

- The chamber did not heat up at exactly $5{ }^{\circ} \mathrm{C} /$ minute, but that value made the heat strips operate at $100 \%$

9. Enter the set point that desired for the final PLATEN TEMPERATURE and press the Right Arrow button

10. Choose PID Set 1 and press the Right Arrow Button

11. A prompt will come up to "Choose Guar. Soak 1", select "Yes" and press the Right Arrow button

12. The next step can be established in the same manner following the prompts on screen. The experiments in this thesis used "Soak" as step number 2. 
13. When all desired steps have been input, select the last step as "End" and press the Right Arrow button and then select "All Off" and press the Right Arrow button again

14. Hit the Left Arrow Button and then make sure to "Save" the profile with the Up Arrow Button

- The Down Arrow button allows all changes to be cancelled and the previous profiles restored

The profile has now been created and can be run using the following procedure.

\section{Running a Profile}

1. Turn on the "MAIN POWER" switch

2. On the bottom left side of the controller, there is a green profile button, press that button

3. Press the Up Arrow button to select "Yes" to start a profile

4. Scroll down to the desired profile and press the Right Arrow button

5. Select the step in the profile at which the controller should begin (Usually step 1)

6. The selected profile is now running

- For HEATING profiles, flip the "Hot" baseplate switch ON (located underneath the controller)

- For COOLING profiles, flip the "Cold" baseplate switch ON (located underneath the controller)

7. The profile will run to its completion unless stopped manually 
- To stop a profile manually, press the green profile button again, select "Terminate", and hit the Right Arrow button

8. Flip the operational baseplate switch off when the profile is terminated 
Appendix C

\section{CHAMBER PRESSURES DURING TESTING}

The chamber pressure plots for each of the six tests as well as a table for the chamber pump down time are shown below for reference. All values in the plots are in $\mu$ Torr.

\section{C.1 Aluminum $40{ }^{\circ} \mathrm{C}$ Test}

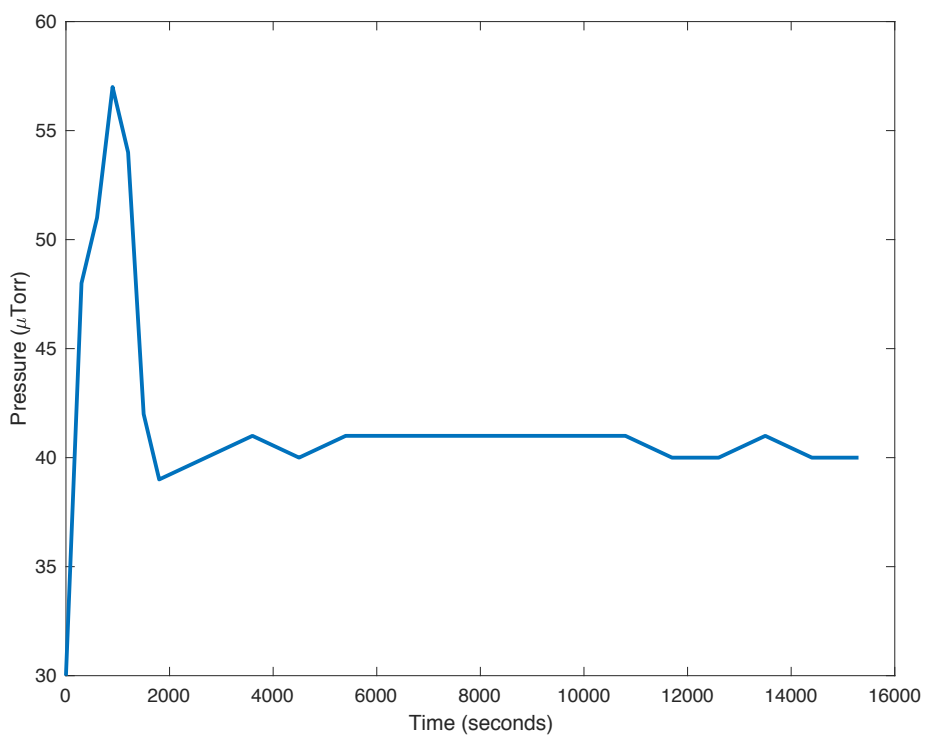

Figure C.1: Aluminum $40{ }^{\circ} \mathrm{C}$ Chamber Pressure 


\section{C.2 Brass $40{ }^{\circ} \mathrm{C}$ Test}

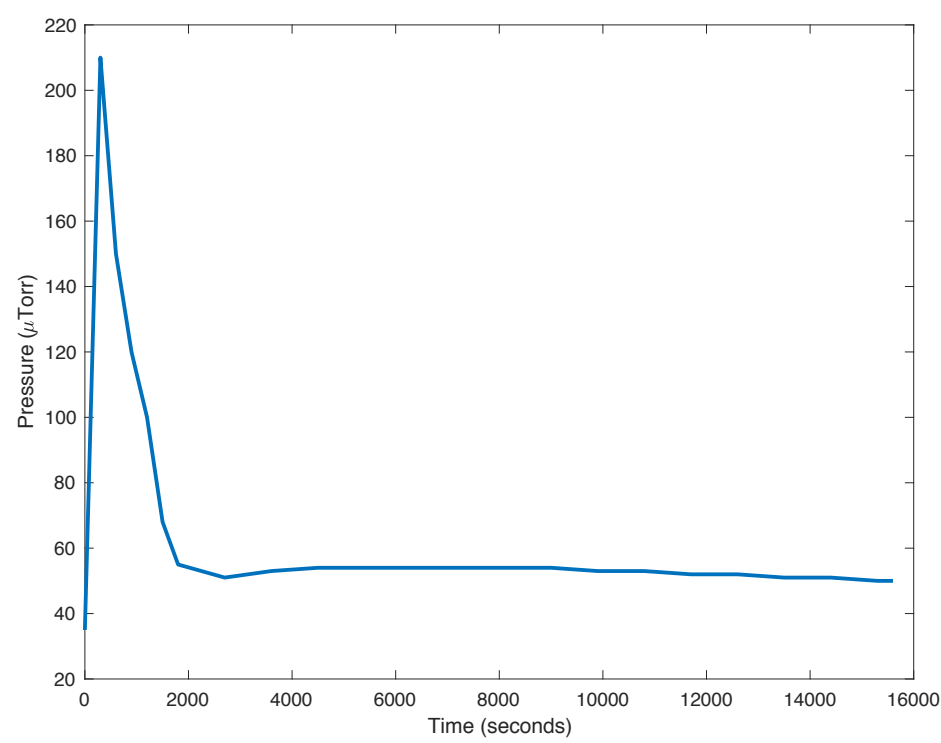

Figure C.2: Brass $40{ }^{\circ} \mathrm{C}$ Chamber Pressure

C.3 Aluminum $60{ }^{\circ} \mathrm{C}$ Test

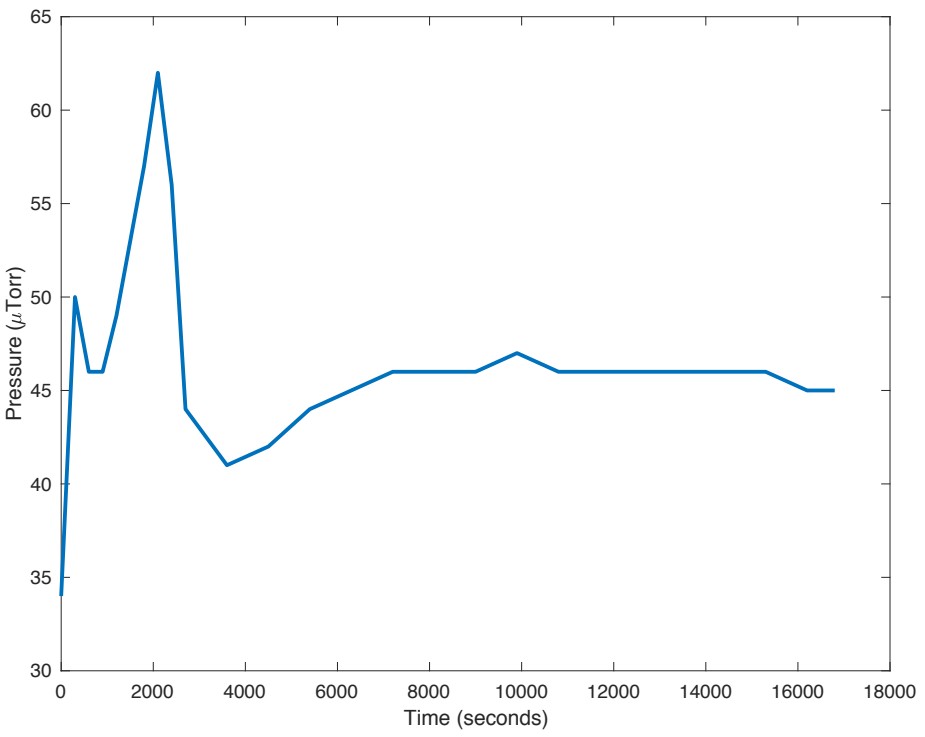

Figure C.3: Aluminum $60{ }^{\circ} \mathrm{C}$ Chamber Pressure 


\section{C.4 Brass $60{ }^{\circ} \mathrm{C}$ Test}

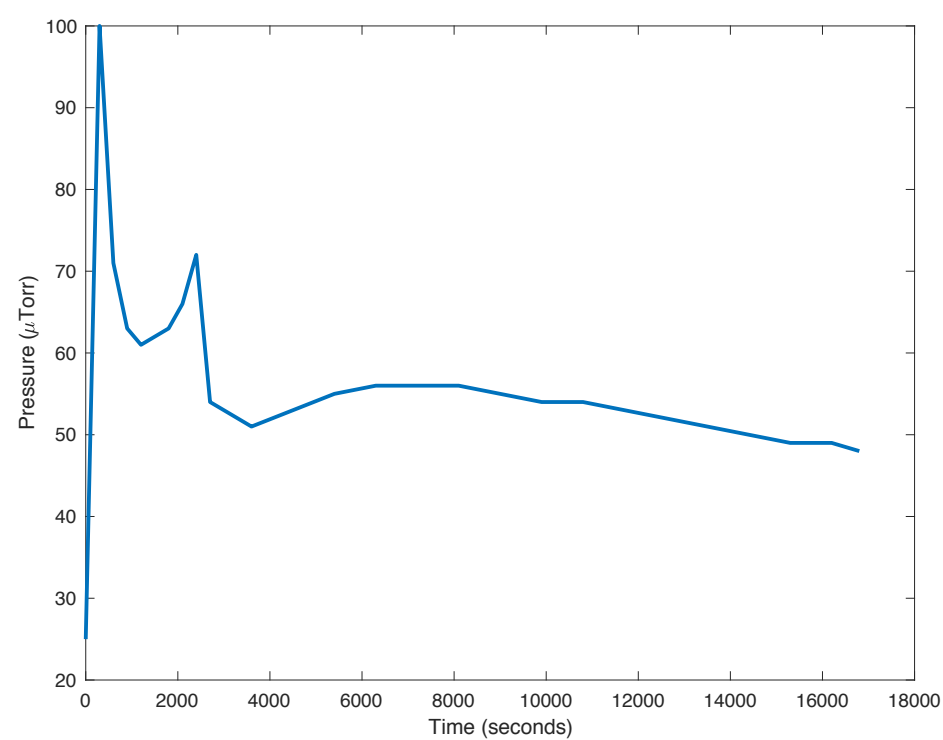

Figure C.4: Brass $60{ }^{\circ} \mathrm{C}$ Chamber Pressure

\section{C.5 Aluminum $80{ }^{\circ} \mathrm{C}$ Test}

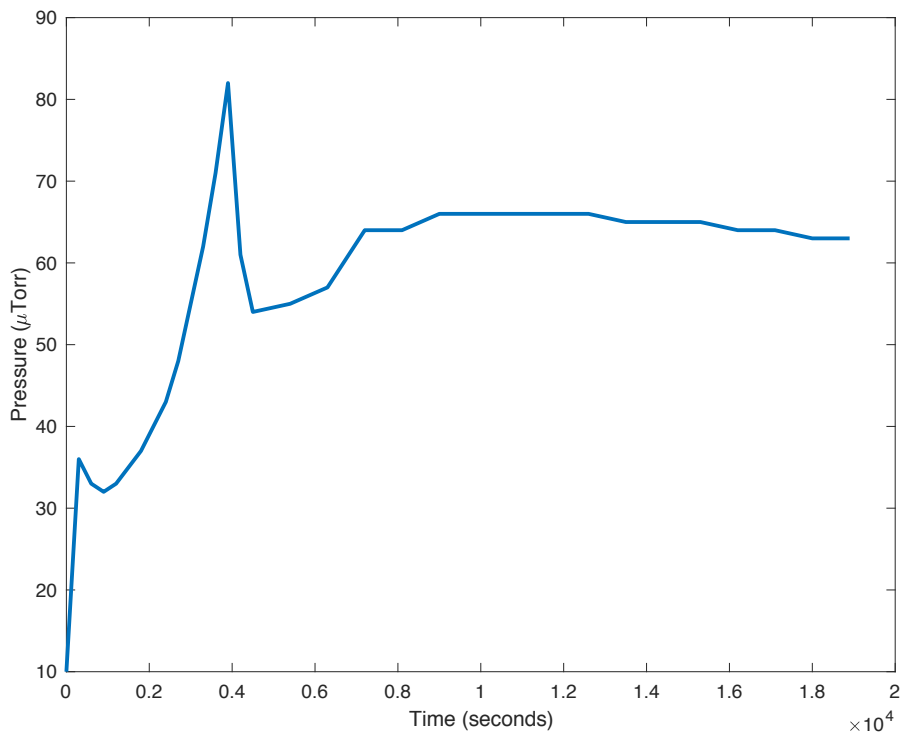

Figure C.5: Aluminum $80{ }^{\circ} \mathrm{C}$ Chamber Pressure 


\section{C.6 Brass $80{ }^{\circ} \mathrm{C}$ Test}

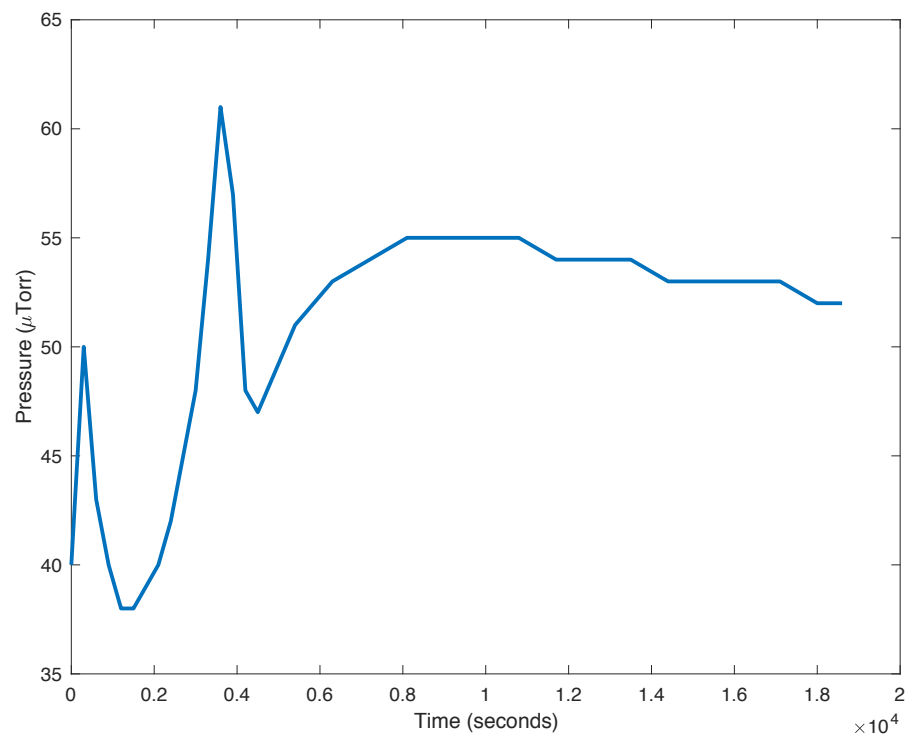

Figure C.6: Brass $80{ }^{\circ} \mathrm{C}$ Chamber Pressure

\section{C.7 Chamber Pump Down}

The table below shows the pressure of the chamber as it pumps down. The turbo pump was activated at the 4 hour mark. Pressure readings were recorded when possible so the tester should have an idea of what the order of magnitude of the pressure should be. The chamber has been seen reaching a pressure of $10 \mu$ Torr, however it did not accomplish that during this test. 
Table C.1: Chamber Pump Down Pressure vs. Time

\begin{tabular}{|c|c|}
\hline Time (hr:min) & Chamber Pressure (Torr) \\
\hline $0: 00$ & $7.6 \times 10^{2}$ \\
\hline $1: 00$ & $2.1 \times 10^{-2}$ \\
\hline $2: 00$ & $1.5 \times 10^{-2}$ \\
\hline $3: 00$ & $1.2 \times 10^{-2}$ \\
\hline $4: 00$ & $1.0 \times 10^{-2}$ \\
\hline $7: 00$ & $4.9 \times 10^{-5}$ \\
\hline $23: 00$ & $2.5 \times 10^{-5}$ \\
\hline $32: 00$ & $2.2 \times 10^{-5}$ \\
\hline
\end{tabular}




\section{Appendix D}

\section{CHAMBER TROUBLESHOOTING}

This appendix serves as a quick guide to fix any small issues that occur while working with the chamber.

In the event that the mechanical pump does not start, the first place that should be checked is the electrical panel. There is a small electrical safety switch that has to be engaged before the mechanical pump will start. When that switch is engaged, there is a noticeable pressure difference on the main power switch when turning on the chamber. Cody helped fix this issue the first time and it has not happened again during any of the testing that was completed.

If the profile on the controller is set to reach a steady state at or above the hot limit, the controller will turn off. The hot limit can be reprogrammed if a higher temperature is desired. The same is true if the cold limit is exceeded by a lower steady state temperature.

These were the only two issues that were discovered that can be fixed by the user. 
Appendix E

\section{CHAMBER SHROUD TEMPERATURE PROFILES}

The following plots display the temperature data for the shroud from the simulation only. No experimental data was collected.

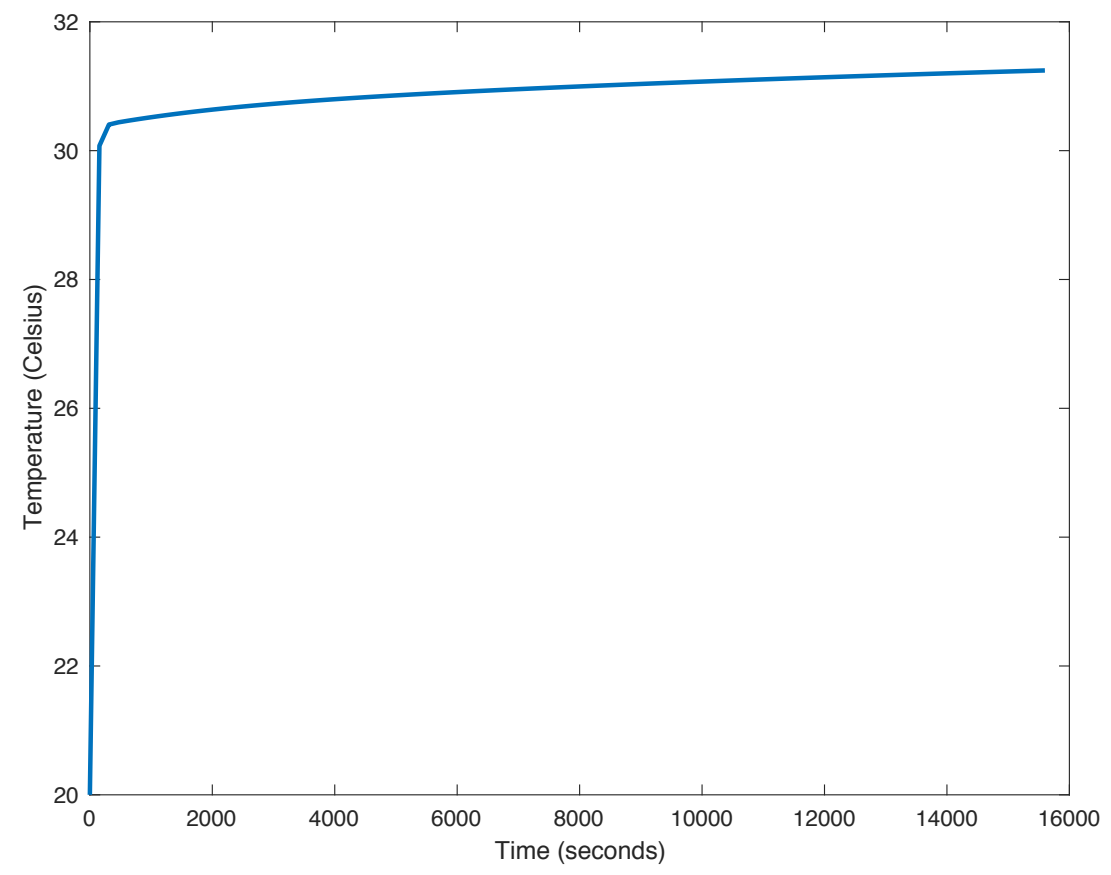

Figure E.1: Aluminum $40^{\circ}$ Simulation Shroud Temperature 


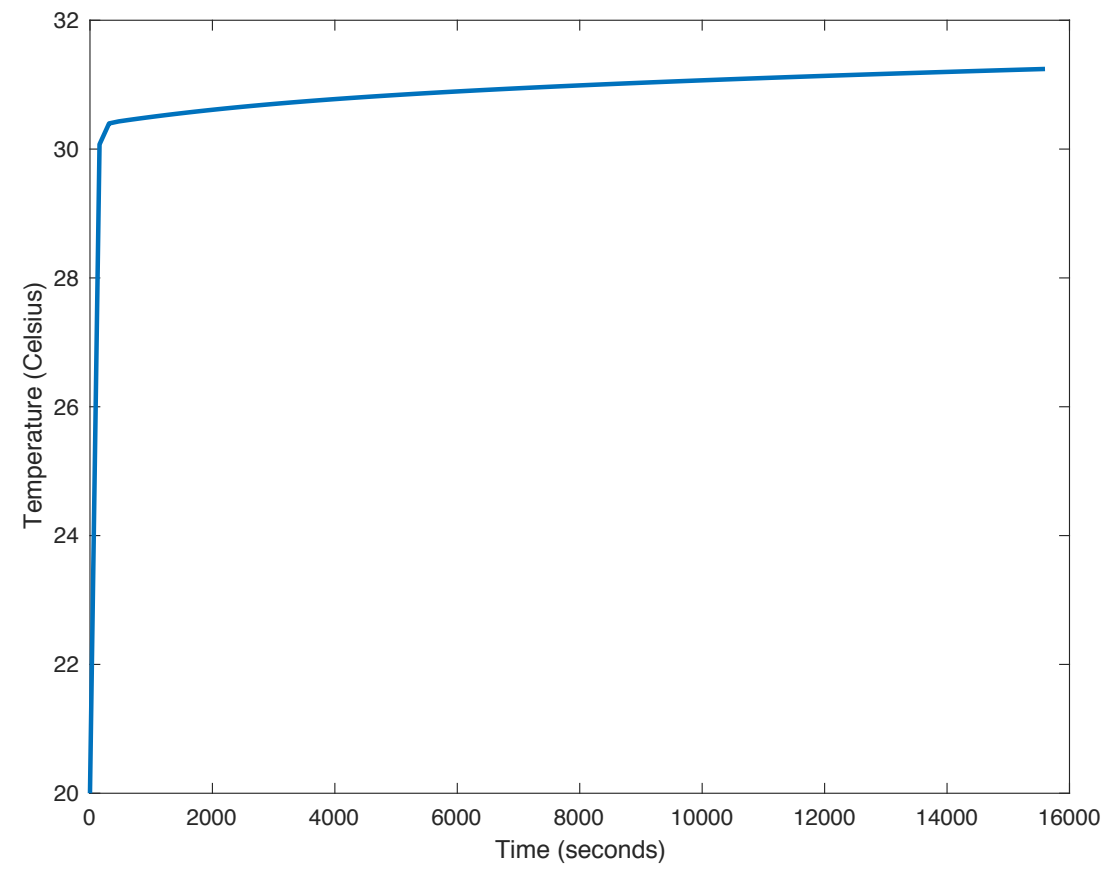

Figure E.2: Brass $40^{\circ}$ Simulation Shroud Temperature

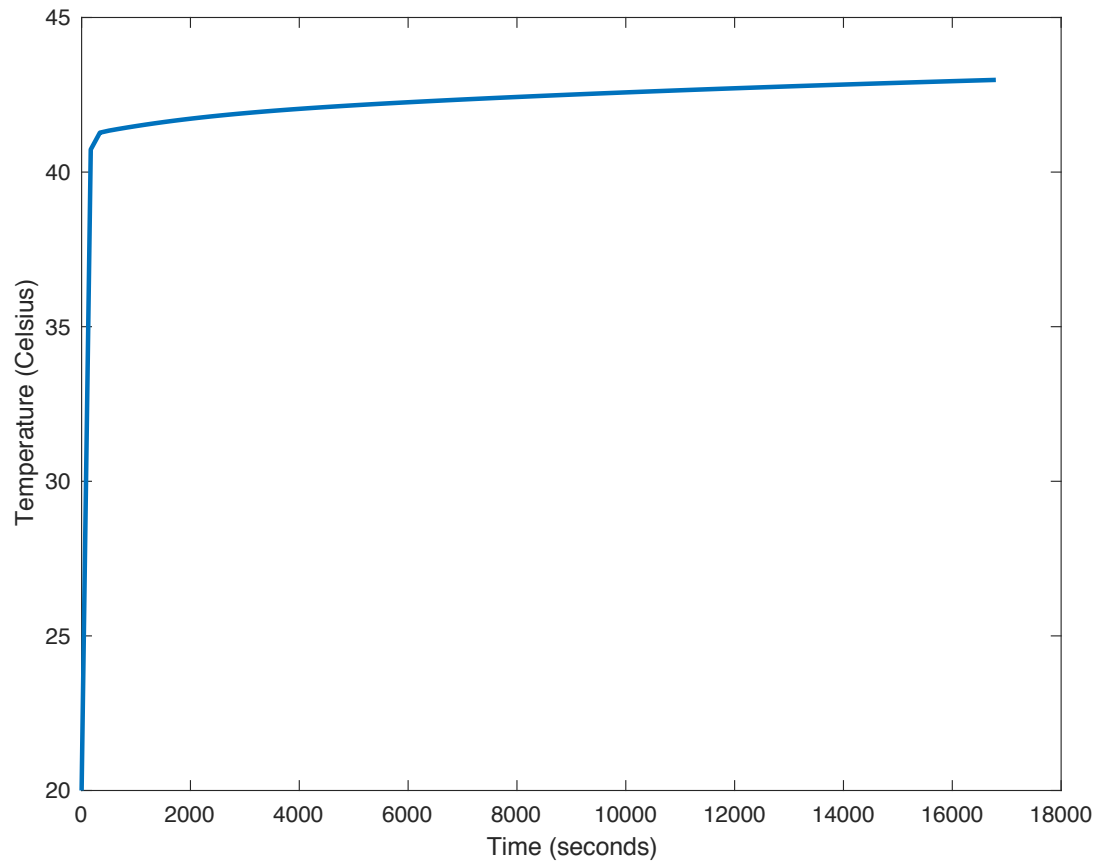

Figure E.3: Aluminum $60^{\circ}$ Simulation Shroud Temperature 


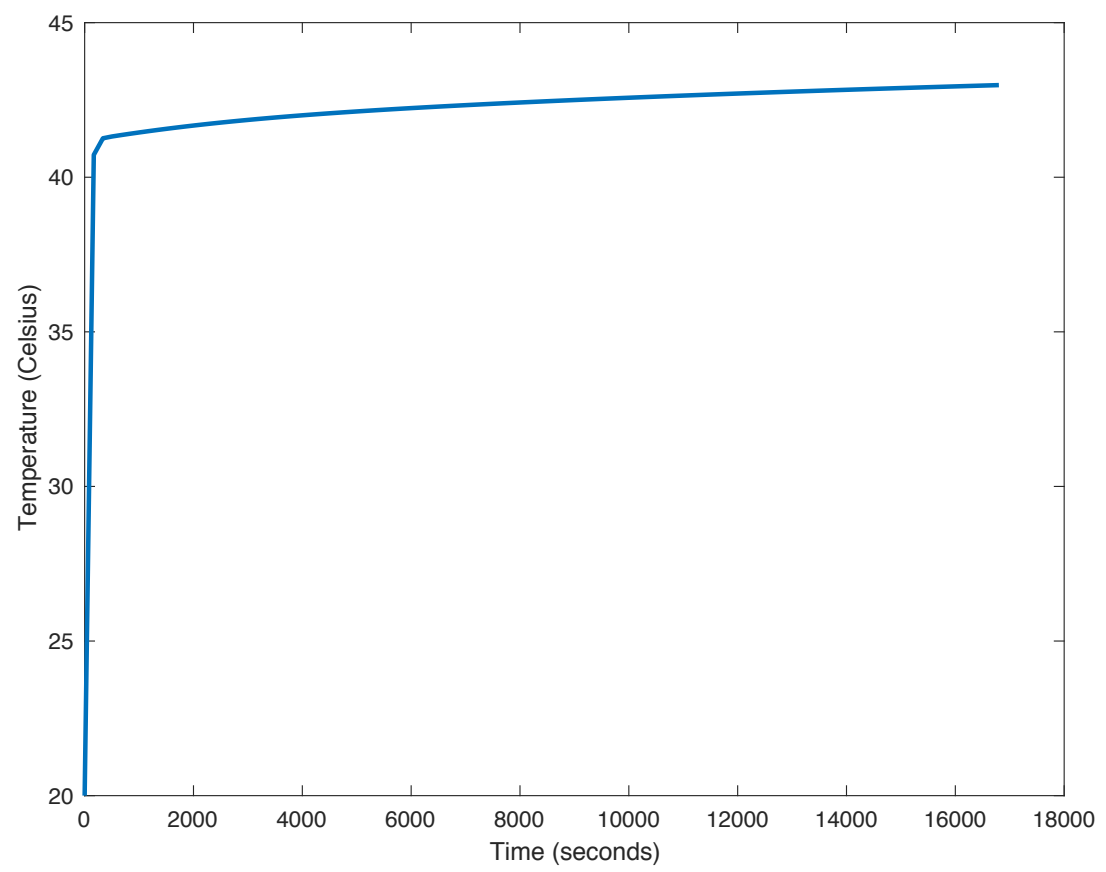

Figure E.4: Brass $60^{\circ}$ Simulation Shroud Temperature

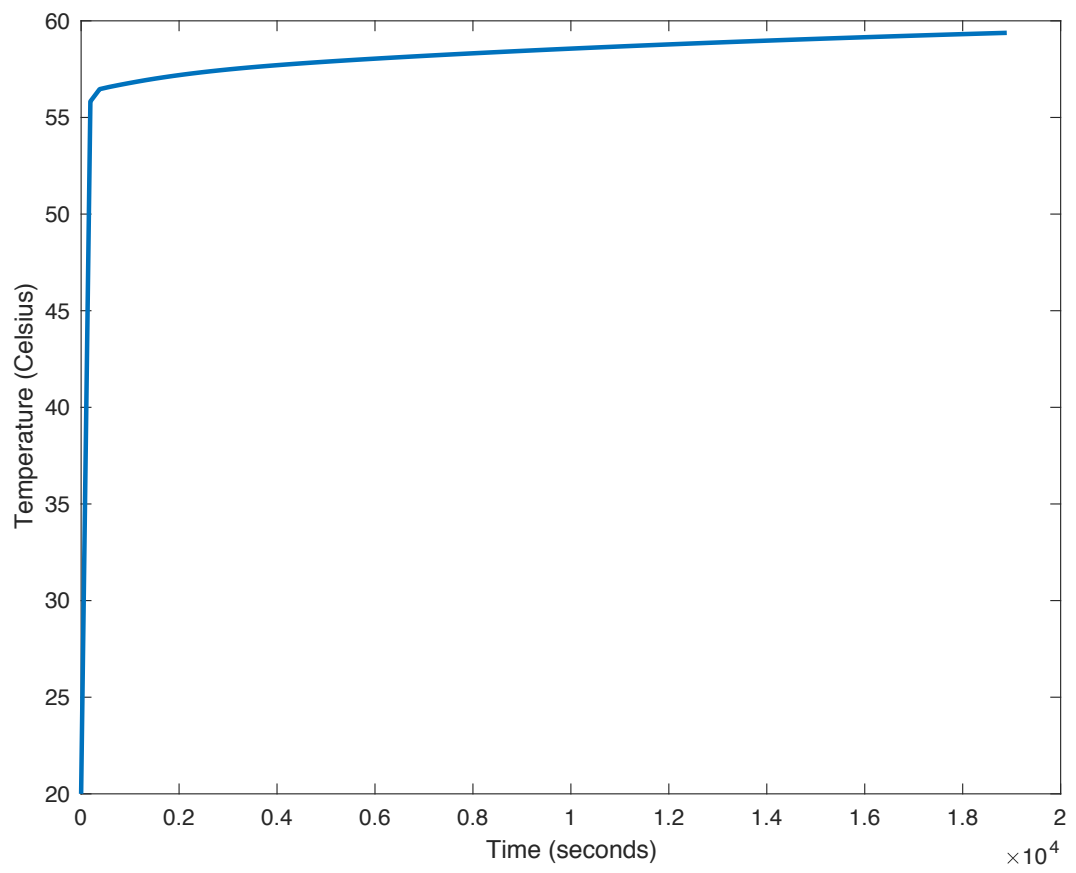

Figure E.5: Aluminum $80^{\circ}$ Simulation Shroud Temperature 


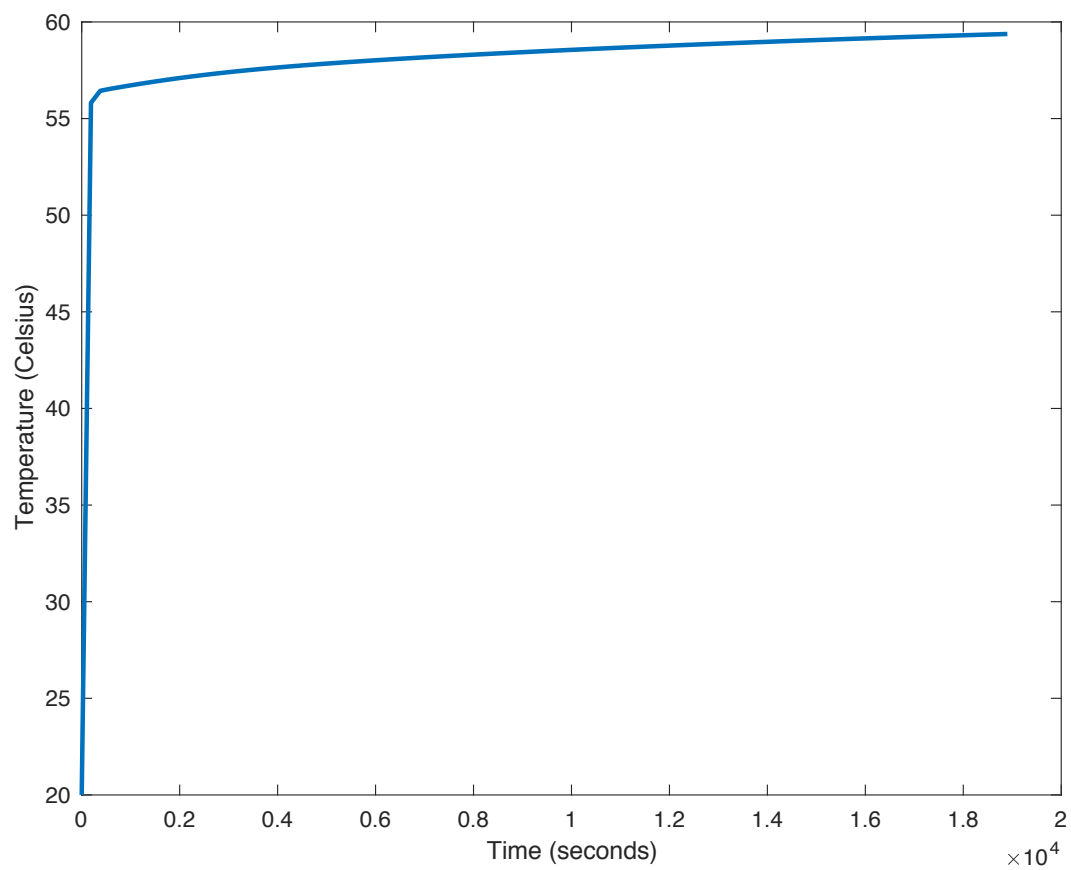

Figure E.6: Brass $80^{\circ}$ Simulation Shroud Temperature 
Appendix F

EXPERIMENTAL DATA

\section{Table of Contents}

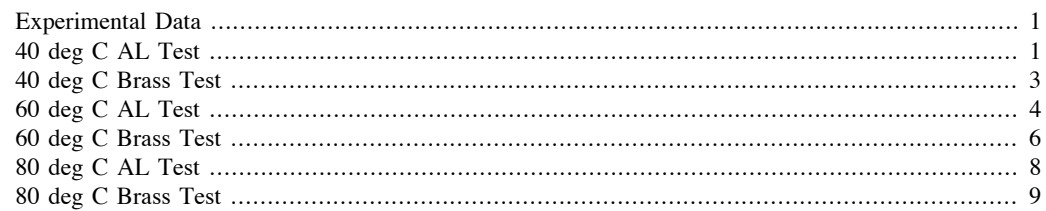

\section{Experimental Data}

\% The variables used in each test are identical.

$\%$

$\div t=$ Time of Measurement (listed in minutes and converted to seconds)

\% chpr = Chamber Pressure in microTorr

$\%$ chtemp = Chamber Temperature (read from thermocouple reader)

\% cyltemp $=$ Cylinder Temperature (read from thermocouple reader)

$\%$ plttemp $=$ Platen Temperature (Read from chamber control panel)

$\%$ err = variable used for error bar function

\% tsim = Time Output from the simulation (seconds)

\% cylsim = Simulation Cylinder Temperature (output in Kelvin, converted to

\% Celsius)

\section{$40 \operatorname{deg}$ C AL Test}

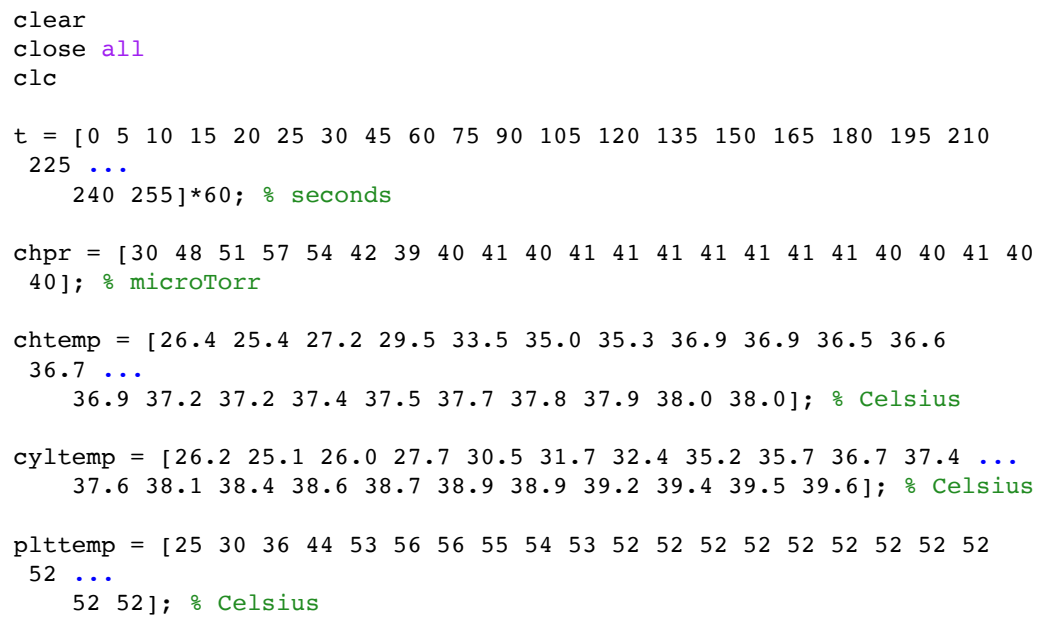




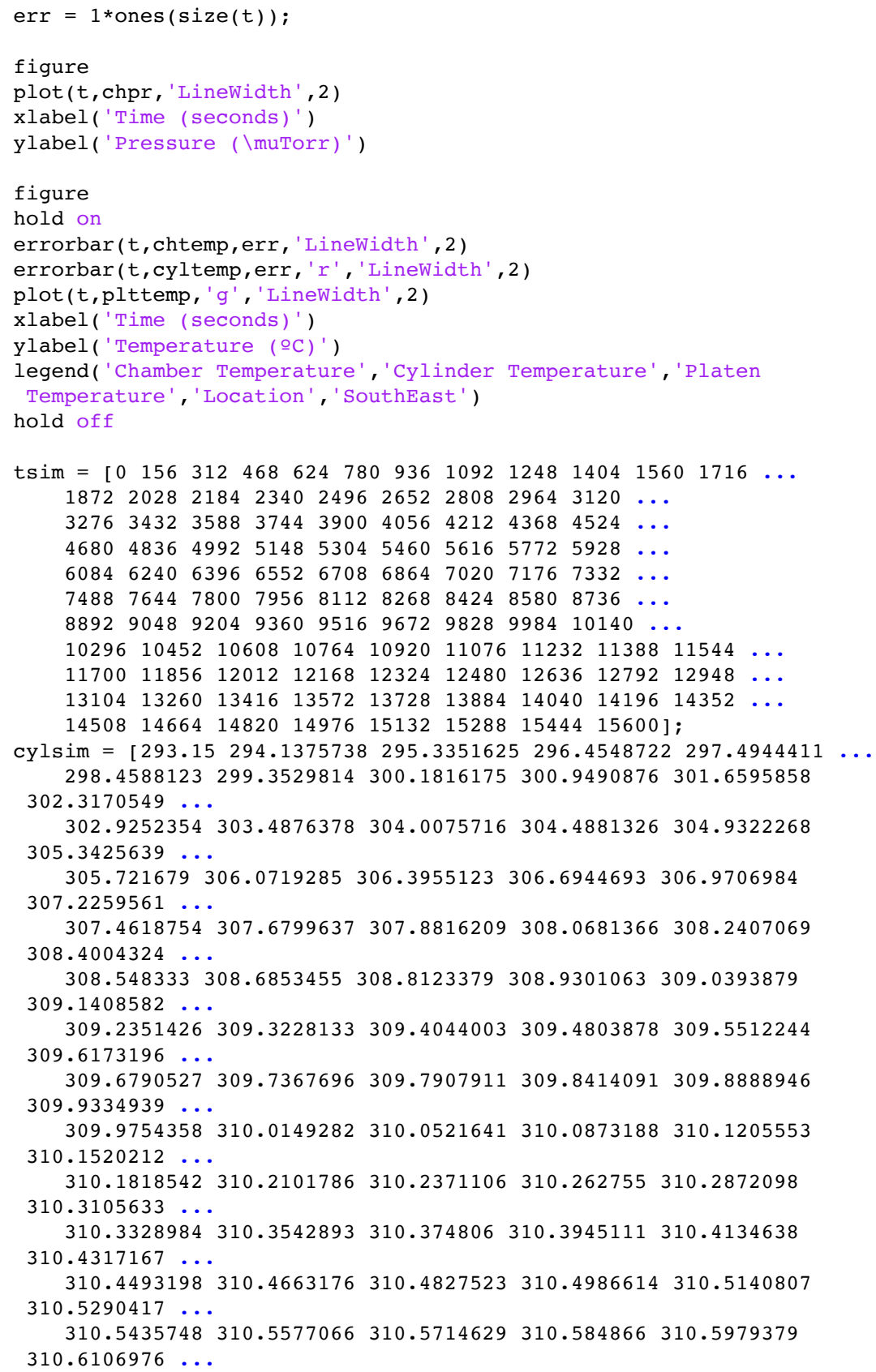


$310.6926303 \quad 310.7034374 \quad 310.7140526 \quad 310.7244841310 .7347406$ $310.7448291 \ldots$

$310.7547569 \quad 310.76453 \quad 310.774155 \quad 310.7836368 \quad 310.7929811$ $310.8021922 \ldots$

$310.8112751310 .8202336310 .8290718 \quad 310.8377931310 .8464012$ $310.854899]-273.15$;

figure

hold on

errorbar ( $t$, cyltemp, err, ' $r$ ', 'LineWidth ' ,2)

plot(tsim, cylsim, 'k' ' 'LineWidth' ,2)

xlabel ('Time (seconds)')

ylabel ('Temperature (이 ')

legend('Experimental Temperature','Simulation

Temperature', 'Location', 'SouthEast' )

hold off

\section{0 deg C Brass Test RERUN}

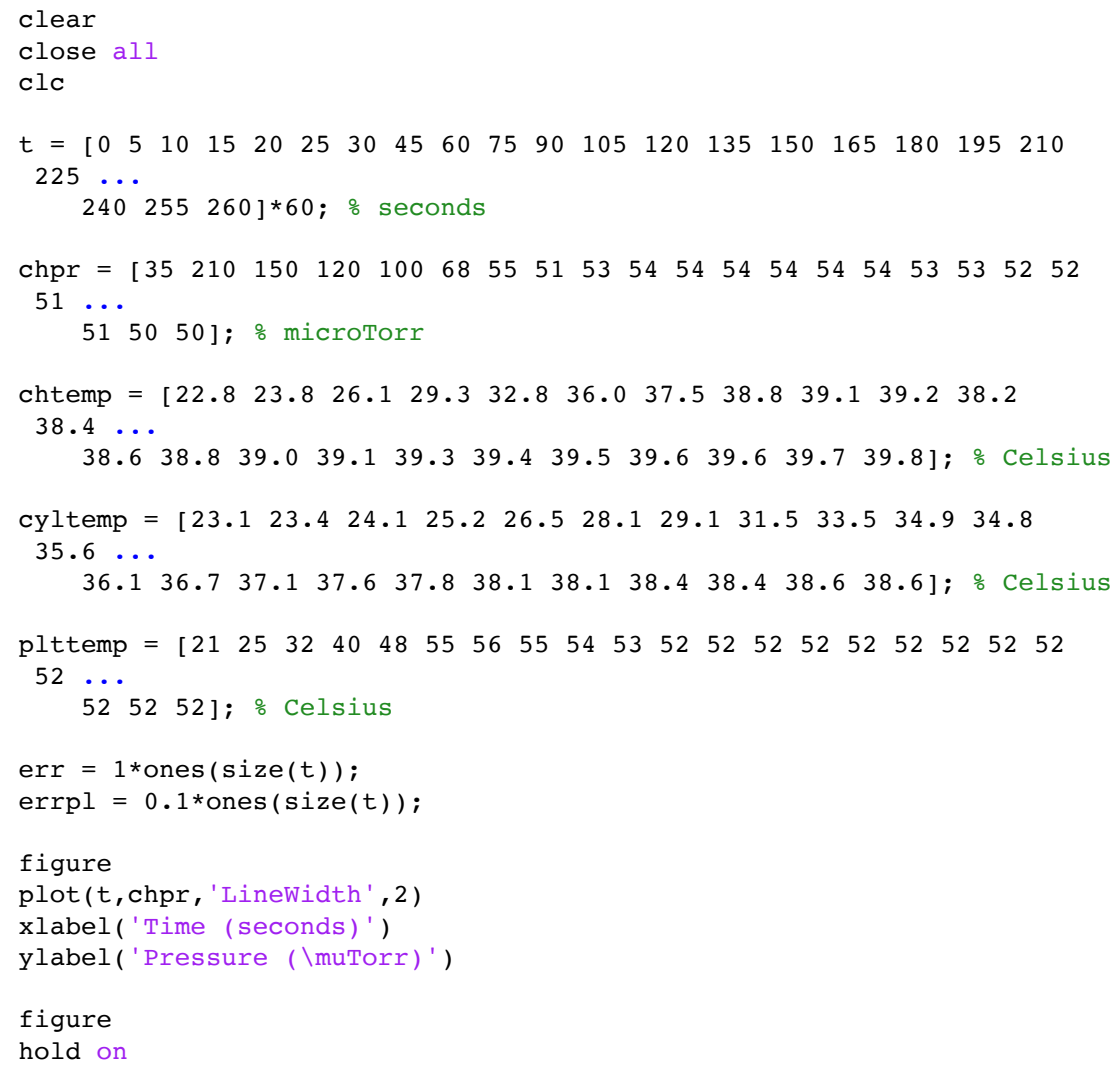




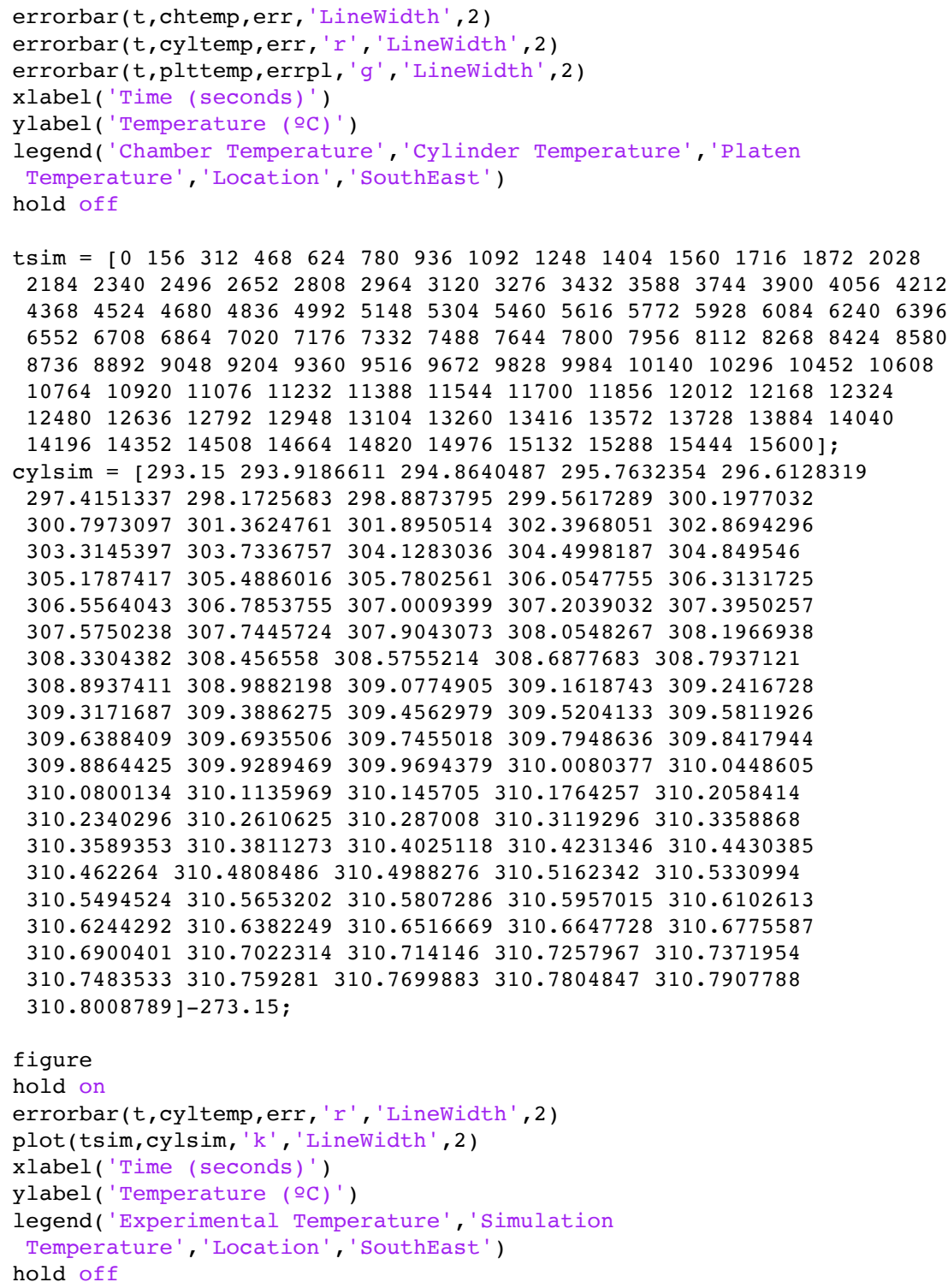

\section{0 deg C AL Test}

clear

close all 


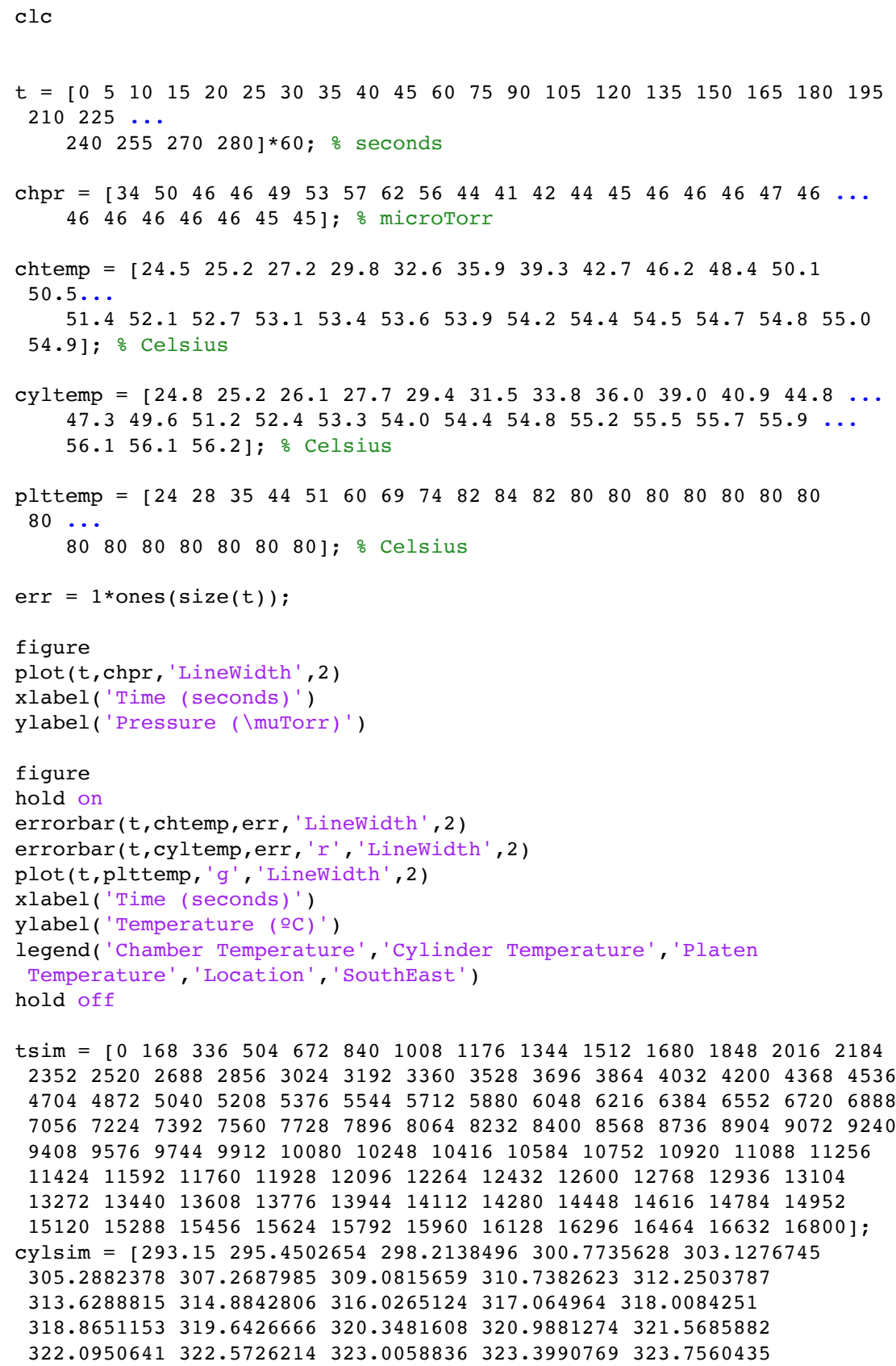


$324.0802845 \quad 324.3749727 \quad 324.6429926 \quad 324.886951325 .1092135$

$325.3119131325 .4969827 \quad 325.6661619 \quad 325.8210254 \quad 325.9629882$

$\begin{array}{lllll}326.0933301 & 326.2131992 & 326.3236339 & 326.4255642 & 326.5198312\end{array}$

$\begin{array}{llllll}326.6071872 & 326.6883125 & 326.7638151 & 326.8342448 & 326.9000923\end{array}$

$\begin{array}{llllll}326.9618018 & 327.0197691 & 327.0743526 & 327.1258715 & 327.1746152\end{array}$

$\begin{array}{llllll}327.2208408 & 327.2647818 & 327.3066453 & 327.3466199 & 327.3848723\end{array}$

$327.4215549 \quad 327.4568019 \quad 327.4907364 \quad 327.5234667 \quad 327.5550921$

$327.5856999 \quad 327.6153706 \quad 327.6441747 \quad 327.6721773 \quad 327.6994353$

$\begin{array}{lllllll}327.7260016 & 327.7519222 & 327.7772402 & 327.8019928 & 327.8262157\end{array}$

$\begin{array}{lllll}327.8499388 & 327.8731905 & 327.8959956 & 327.9183775 & 327.9403565\end{array}$

327.961952327 .9831806328 .0040584328 .0245995328 .0448169328 .064722

$328.0843261328 .1036386 \quad 328.1226694 \quad 328.1414261328 .1599173$

$328.1781494 \quad 328.1961299 \quad 328.2138644 \quad 328.2313592 \quad 328.2486192 \quad 328.26565$

$328.282456328 .2990422 \quad 328.3154123 \quad 328.3315709 \quad 328.3475215328 .363268$

$328.3788136328 .3941621328 .4093164]-273.15$;

figure

hold on

errorbar ( $t$, cyltemp, err, ' r' ' ' LineWidth ' , 2 )

plot(tsim, cylsim, 'k' , 'LineWidth ',2)

xlabel('Time (seconds)' )

ylabel ('Temperature ( $\mathrm{OC})^{\prime}$ )

legend('Experimental Temperature', 'Simulation

Temperature ', 'Location' , 'SouthEast' )

hold off

\section{0 deg C Brass Test}

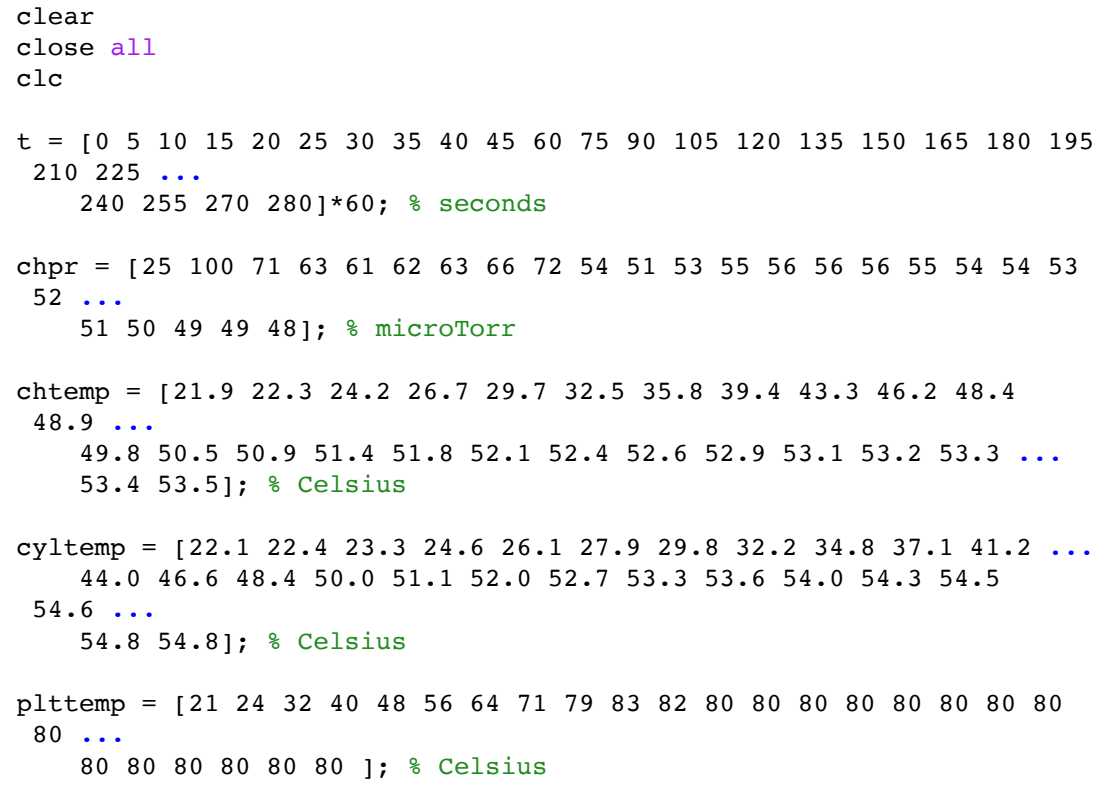




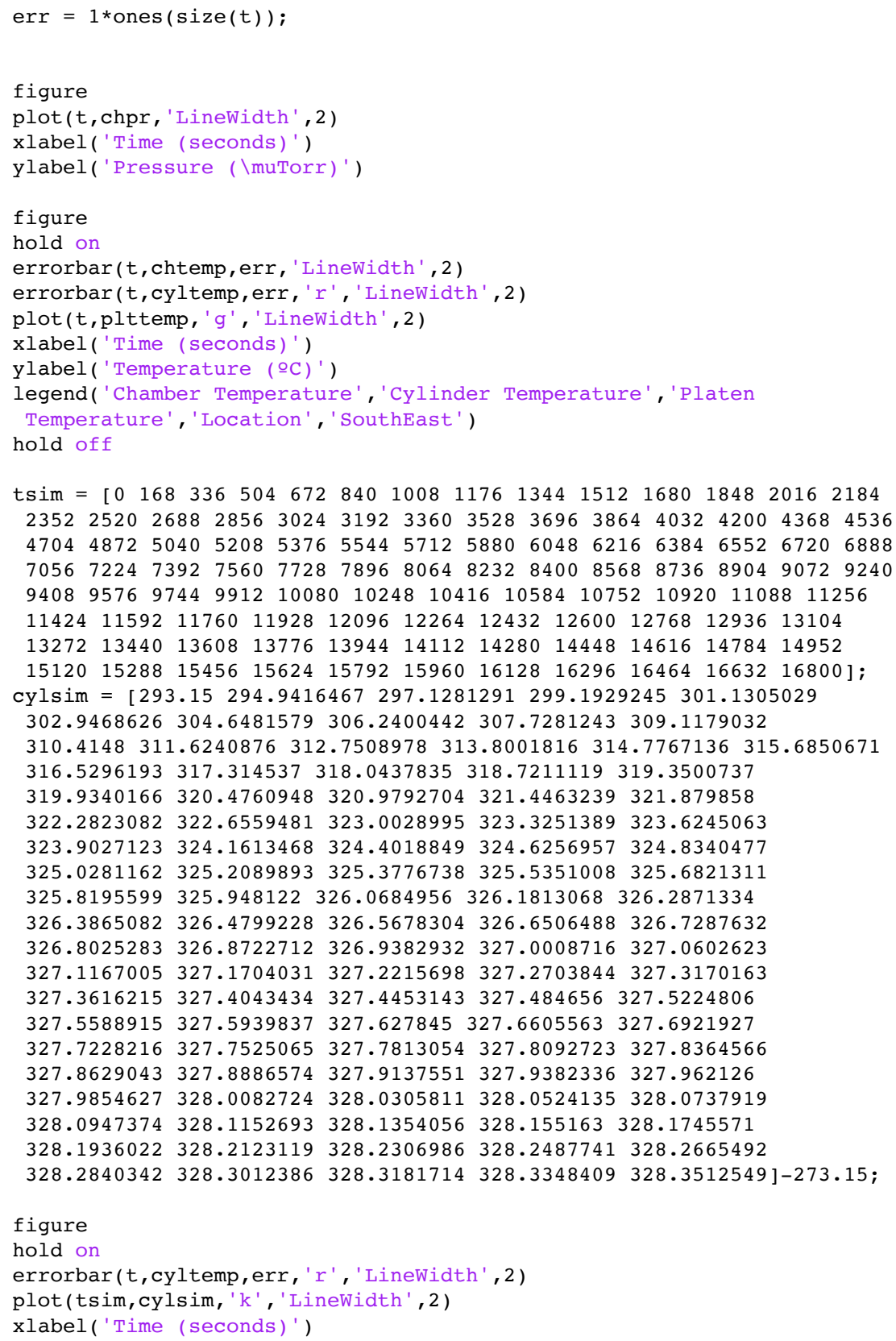


ylabel ('Temperature (이 ')

legend('Experimental Temperature', 'Simulation

Temperature', 'Location' , 'SouthEast' )

hold off

\section{0 deg C AL Test}

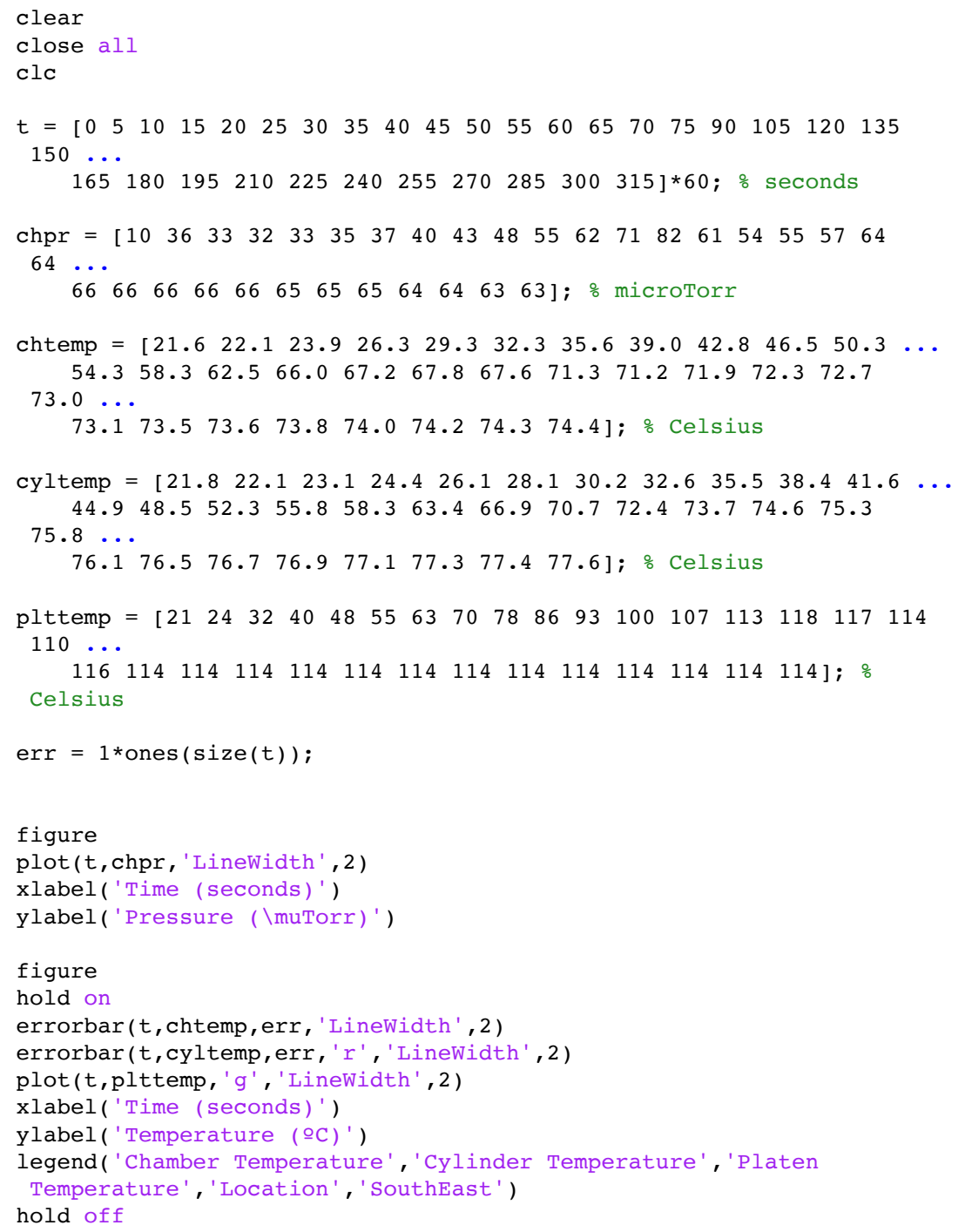




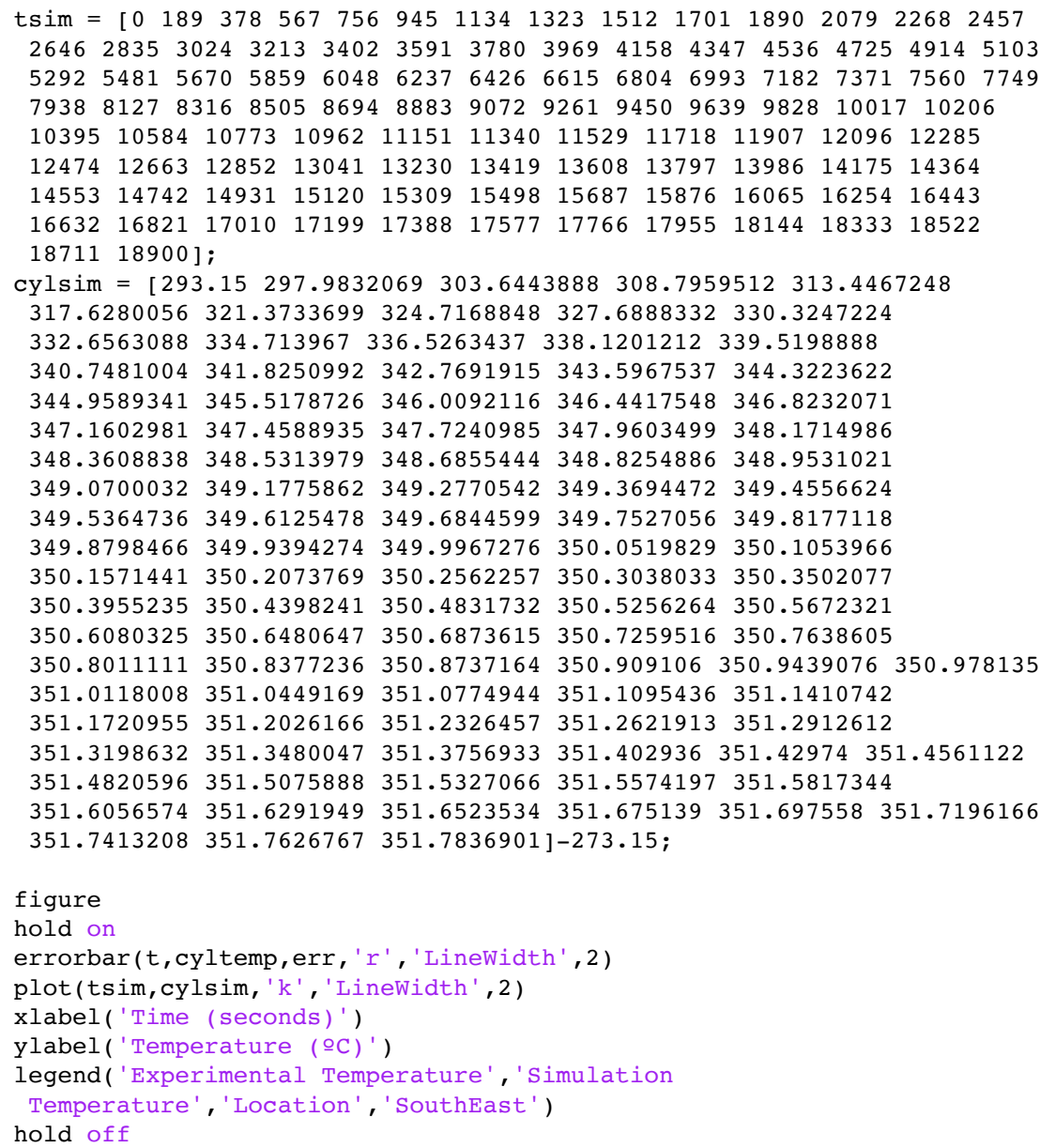

\section{$80 \mathrm{deg}$ C Brass Test}

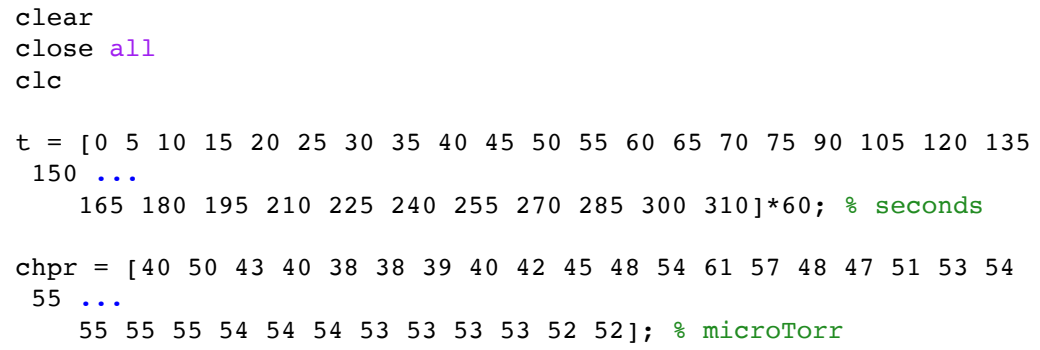




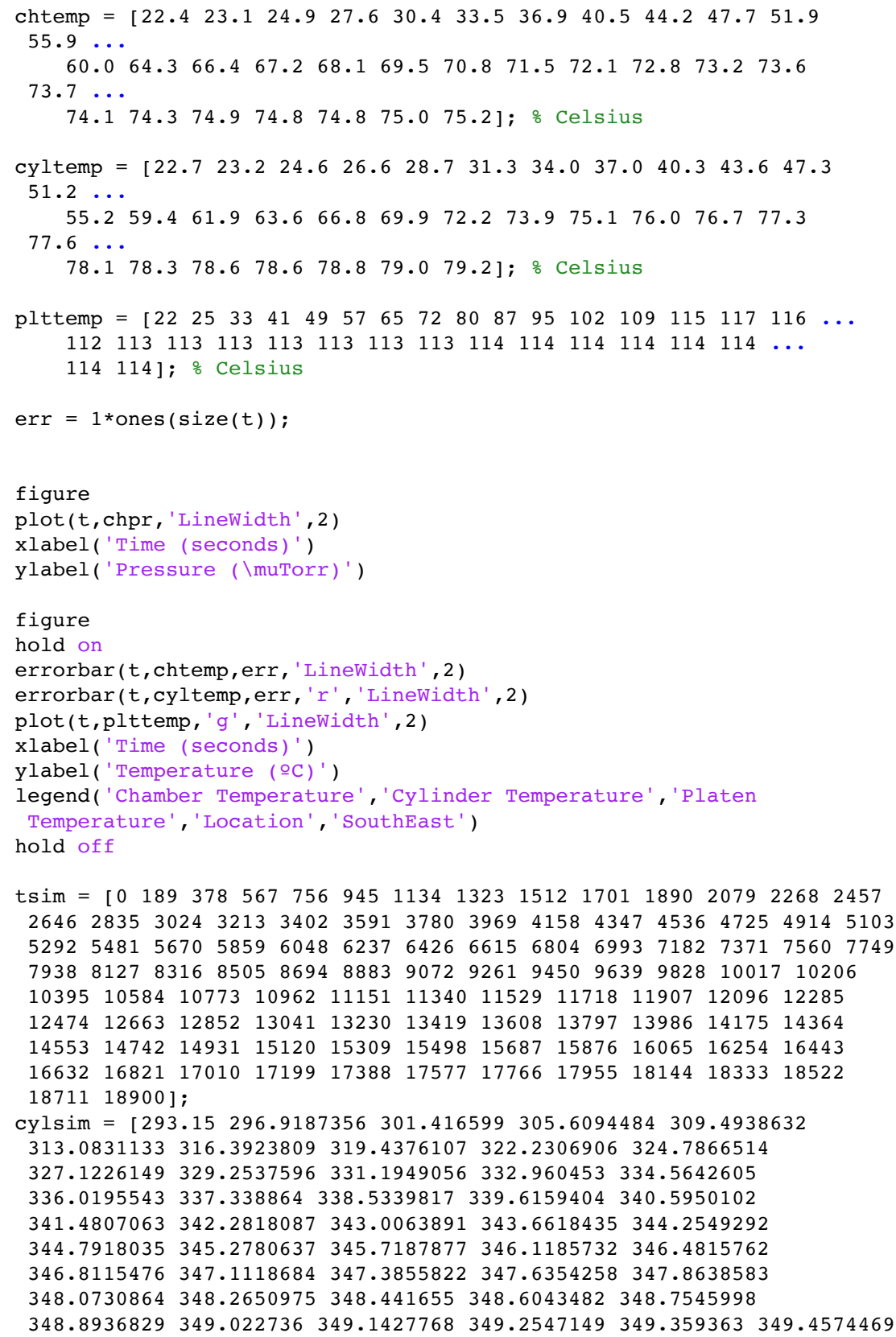


$349.5496146 \quad 349.6364449 \quad 349.7184543 \quad 349.7961038 \quad 349.8698051$ $349.9399253 \quad 350.0067925 \quad 350.0706991350 .1319064350 .1906477$ $350.2471311350 .3015428 \quad 350.354049 \quad 350.4047982 \quad 350.4539234$

$350.5015434 \quad 350.5477647 \quad 350.5926826 \quad 350.6363826 \quad 350.6789416$

$350.7204285 \quad 350.7609051350 .8004275 \quad 350.839046 \quad 350.876806 \quad 350.9137487$

$350.9499114350 .985328 \quad 351.0200292 \quad 351.0540433 \quad 351.087396 \quad 351.1201108$

$351.1522094 \quad 351.1837118 \quad 351.2146365 \quad 351.2450006 \quad 351.2748201$

$\begin{array}{llllll}351.3041099 & 351.332884 & 351.3611553 & 351.3889364 & 351.4162388\end{array}$

$351.4430736 \quad 351.4694514 \quad 351.4953821351 .5208755 \quad 351.5459407$

$351.5705866351 .5948216 \quad 351.6186542 \quad 351.6420921351 .6651432$

351.6878151351 .7101149351 .7320498 ]-273.15;

figure

hold on

errorbar( $t$, cyltemp, err, 'r' , 'LineWidth' ,2)

plot(tsim, cylsim, 'k' , 'LineWidth', 2 )

xlabel ('Time (seconds)' )

ylabel ('Temperature (으)' )

legend('Experimental Temperature', 'Simulation

Temperature ', 'Location ', 'SouthEast' )

hold off

Published with MATLAB® R2017b 